\title{
NURSING CARE OF THE CHRONICALLY CRITICALLY ILL: AN EXPLORATORY DESCRIPTIVE STUDY.
}

by

Anne Rosamond Butt

A thesis submitted to the Victoria University of Wellington in partial fulfillment of the requirements for the degree of Masters of Arts (Applied) in Nursing

Victoria University of Wellington

2010 


\begin{abstract}
Background

There is an emerging group of intensive care unit (ICU) patients known as the chronically critically ill (CCI). This patient group is steadily increasing worldwide (Nelson et al., 2004).No published literature was located that focused on the nursing experience of caring for CCI patients, however studies alluded to CCI patients as frustrating to look after.This is pertinent because these patients are costly to care for and considered burdensome to nurses and physicians. (Daly, Rudy, Thompson \& Happ, 1991). In a working environment where turnover and shortage of nursing staff is evident and predicted to worsen, this is cause for real concern about future resourcing for this patient group (Carasa \& Nespoli, 2002).
\end{abstract}

\title{
Research Aims
}

The aim of this study was to explore and describe nurses' experiences of caring for CCI patients. ICU nurses are the key providers of bedside care to all ICU patients. They have valuable contributions concerning the planning and implementation of patient-focused care, including that of long-stay and CCI patients.

\section{Method}

A qualitative approach was used with an exploratory descriptive design. Semistructured interviews were conducted which generated in-depth description of participant experiences.

\section{Findings}

Six key themes are identified:

1. Nursing autonomy and control

2. Work-related stress, compassion fatigue and staff allocation

3. The CCI patient in the ICU environment

4. Teamwork, nursing practice and continuity of care

5. The culture of ICU

6. Withdrawal of care and palliation. 


\section{Summary}

Six nurses from two tertiary level ICUs within New Zealand were interviewed using a semi-structured approach. Participants were encouraged to comment on several issues including access to training and resources, cultural issues within ICU and any suggestions for how CCI patient care might be improved.The interviews were transcribed to allow a thorough content analysis. These topics were explored and generated recommendations for changing practice.

\section{Keywords}

Critical care nursing

Chronic critical illness

Intensive care units

Exploratory descriptive 


\section{Acknowledgements}

I wish to thank several wonderful and supportive friends who have helped keep me focused on completing this thesis.

Firstly, my appreciation to the participants, who kindly volunteered their time and took part in the study. Their honesty and willingness to share personal experiences made the interview process much less intimidating than I had feared. My gratitude also to both research sites and those staff who helped in the recruitment process. The ICU Secretaries who spent hours retrieving information from the databases deserve a special mention for accommodating my requests.

My sincere gratitude to my supervisor Sara Quirke, who helped keep me on track and believed in the importance of this study, every step of the way. Also to the highly organised Abbey McDonald for ensuring every form, date and deadline was clear and manageable.

My thanks to Capital and Coast DHB and the intensive care unit nursing staff, whose continued support for this study was gratefully received.

Thanks to my friends Bex, Tiny, Celia and Debs for encouragement, patience and understanding. Also to my flatmate Kieryn who will finally be able to reclaim the dining room table, now that this thesis is complete. To Dan, I owe so much as you have believed in me and given me the confidence to keep going. A final thank you to my parents Lee and Geoff who spent many long phone calls encouraging me and simply listening. 


\section{Glossary of Terms}

\section{APACHE score}

APACHE stands for Acute Physiologic and Chronic Health Evaluation. The score is used as a method of assessing severity of illness in acutely ill patients in intensive care units ICUs. The score can be used to compare outcomes, evaluate new therapies and study the utilisation of ICUs. There are 3 components:

- An acute physiology score

- A chronic health score based on premorbid states

- A score based on the patient's age.

These are collected in the first 24 hours of ICU admission and should represent the worst physiological values (Bersten \& Soni, 2003). The original APACHE score was developed in 1981, then simplified in 1985 (APACHE II) and APACHE III in 1991. APACHE II has remained the most widely used severity of illness score (Bersten \& Soni, 2003).

\section{SAPS 2 score}

SAPS stands for Simplified Acute Physiology Score. SAPS 2 was designed to measure the severity of disease for patients admitted to intensive care units aged 15 or more. Unlike APACHE II, this system does not include a diagnostic category or chronic health status (Bersten \& Soni, 2003). 


\section{Table of Contents}

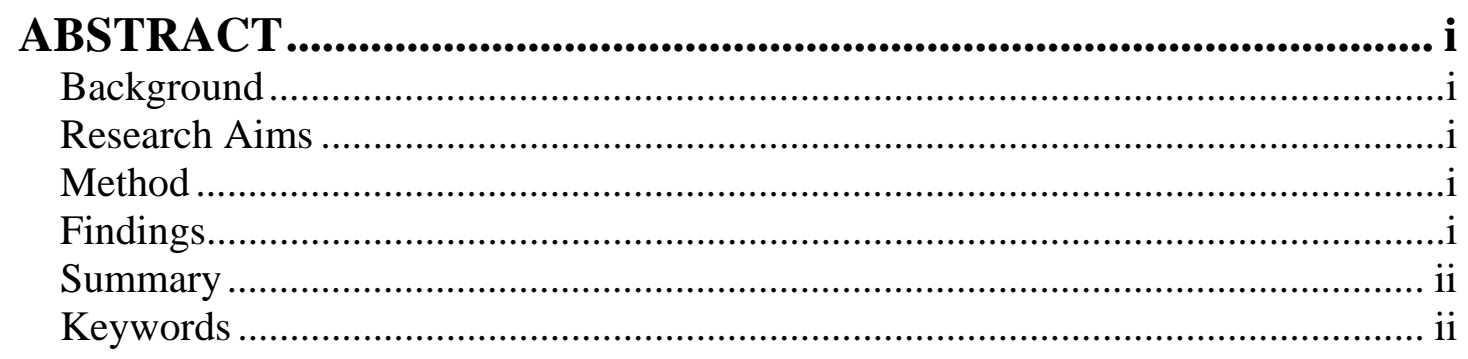

Acknowledgements ........................................................................ iii

Glossary of Terms .................................................................................. iv

CHAPTER ONE: INTRODUCTION AND POSITIONING OF THE STUDY

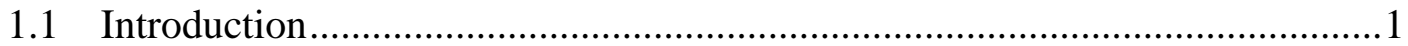

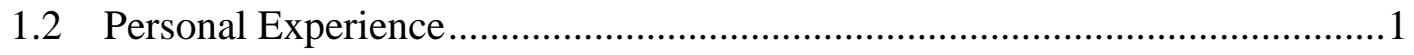

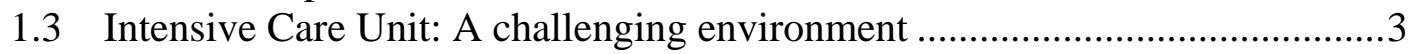

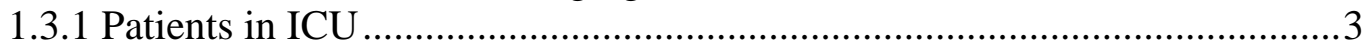

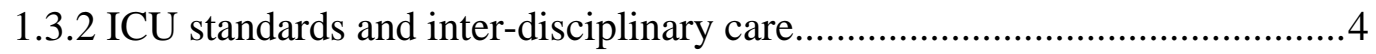

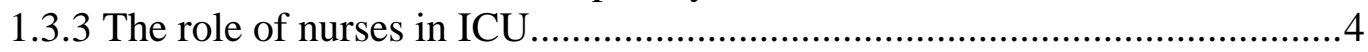

1.3.4 Staffing issues and work-related stress in ICU ........................................... 5

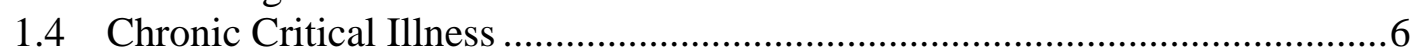

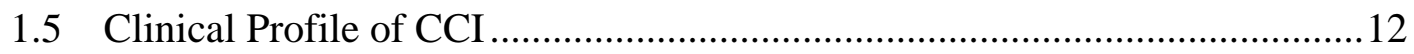

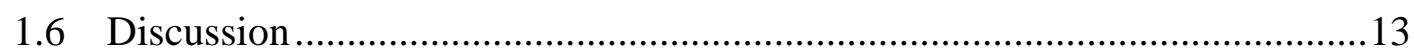

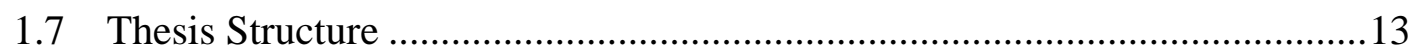

\section{CHAPTER TWO: LITERATURE REVIEW}

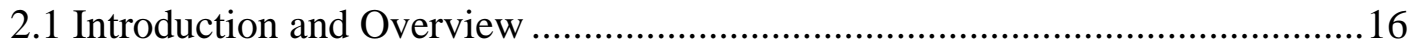

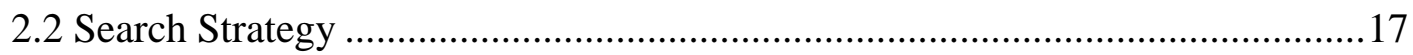

2.3 Nurses Experiences of Caring for CCI Patients...............................................19

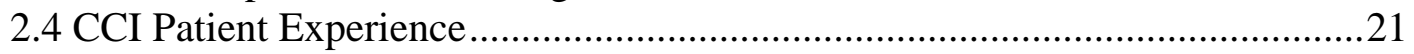

2.5 Costs, Outcomes and Quality of Life of CCI Patients ......................................23

2.6 Treatment Programmes for Chronically Critically Ill Patients ..........................26

2.7 ICU Nurses Autonomy and Control .............................................................28

2.8 Work-related Stress, Compassion Fatigue and Vicarious Traumatisation ........29

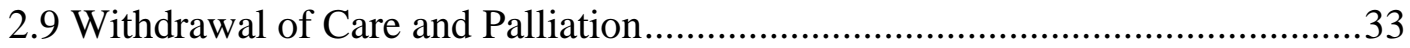

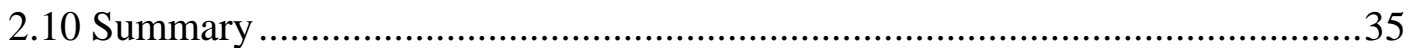

\section{CHAPTER THREE: METHODOLOGY AND STUDY DESIGN}

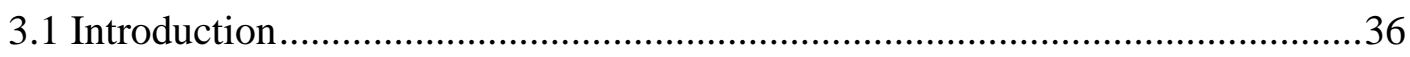

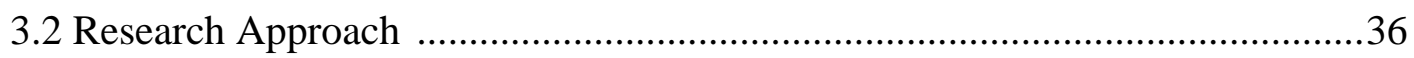

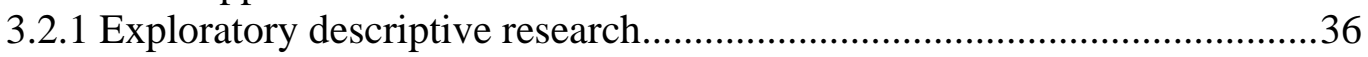

3.2.2 Justification for qualitative descriptive research methodology ..................37

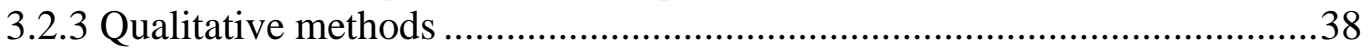

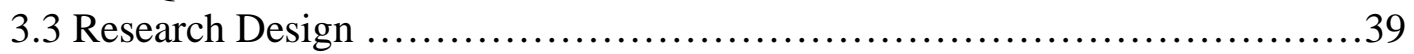


3.3.1 Benefits and risks associated with interview

3.3.2 Justification for semi-structured interview design......................42

3.3.3 Sampling ........................................................43

3.4 Participant Recruitment and Inclusion Criteria................................................4 44

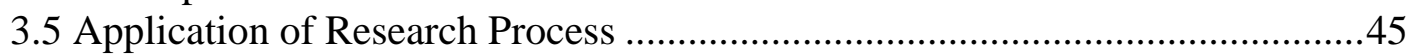

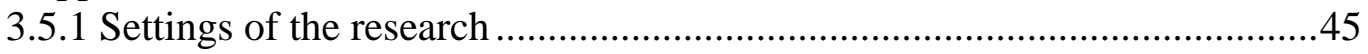

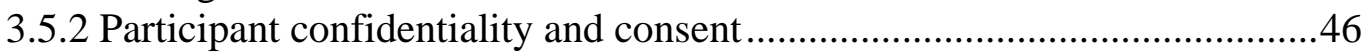

3.5.3 Semi-structured interviews: design and process .........................................4

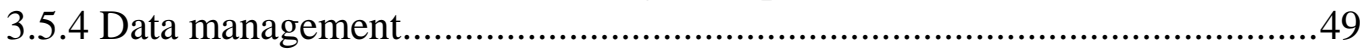

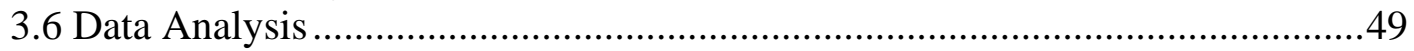

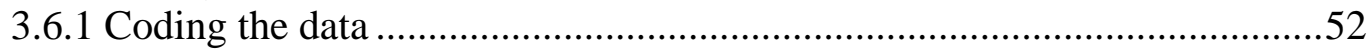

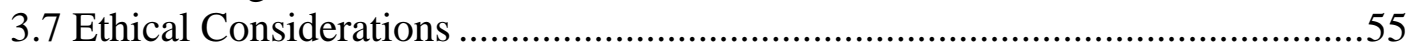

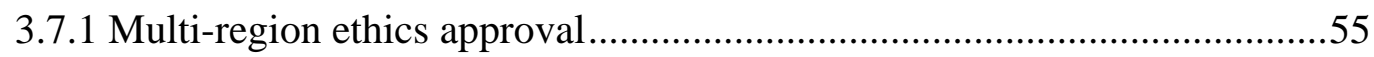

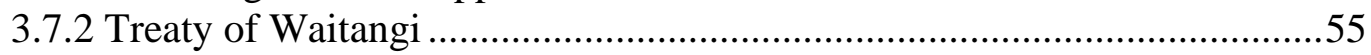

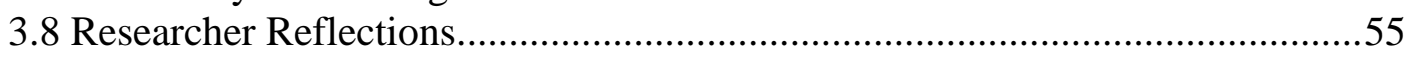

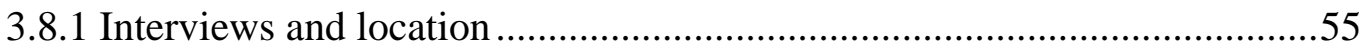

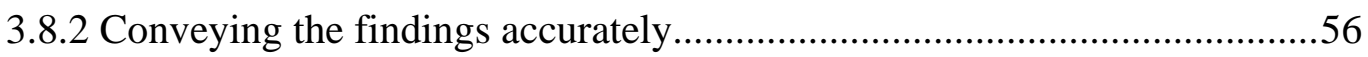

3.8.3 Ethical and emotional safety of participants ..............................................56

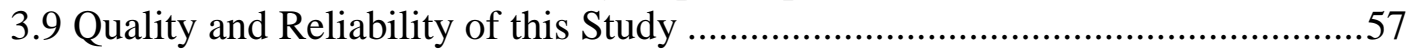

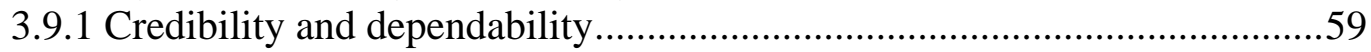

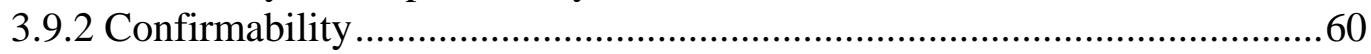

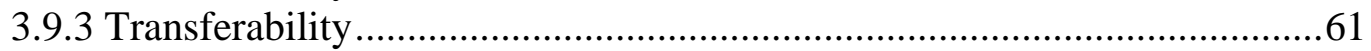

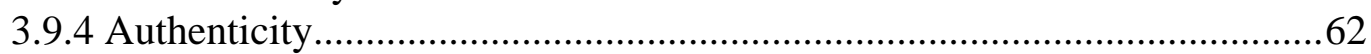

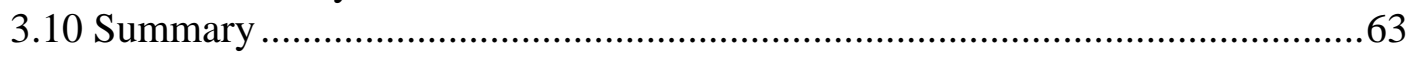

\section{CHAPTER FOUR: DATA FINDINGS AND ANALYSIS}

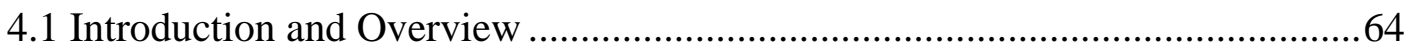

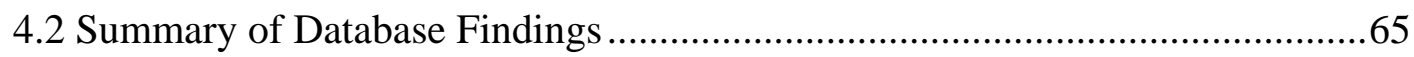

4.3 Participant Demographics and Recruitment ...................................................67

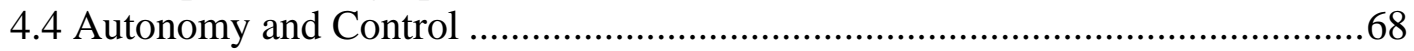

4.5 Work-related Stress, Compassion Fatigue and Staff Allocation ........................71

4.5.1 Work-related stress .............................................................................. 71

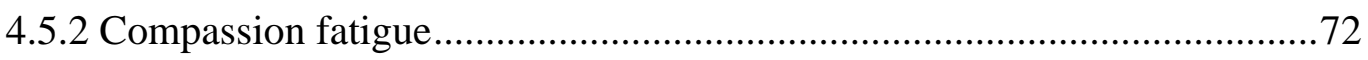

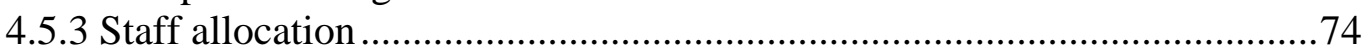

4.6 The CCI Patient in the ICU Environment....................................................... 76

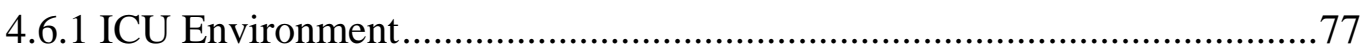

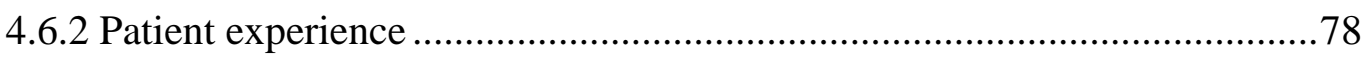

4.7 Teamwork, Nursing Practice and Continuity of Care.......................................81

4.7.1 Teamwork........................................................ 81

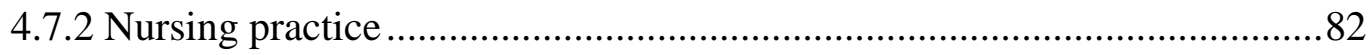

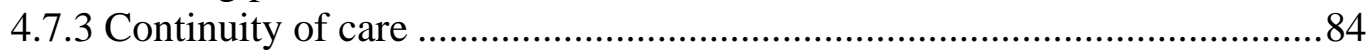

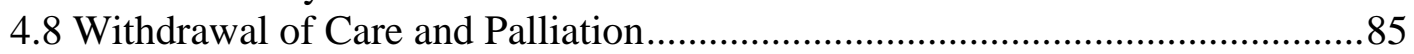

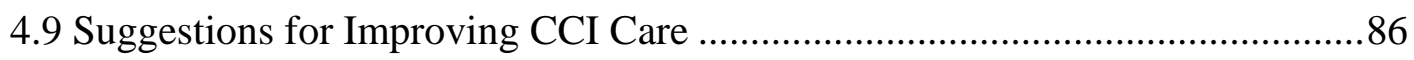

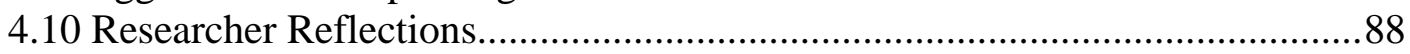

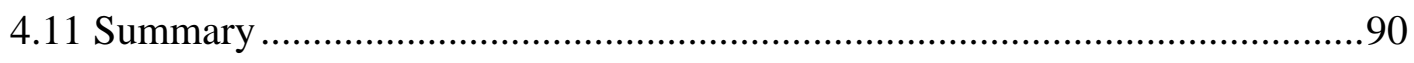

\section{CHAPTER FIVE: DISCUSSION AND THESIS CONCLUSION}

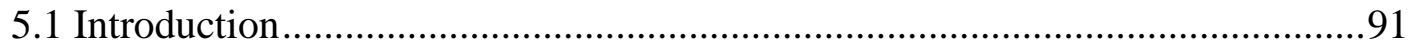

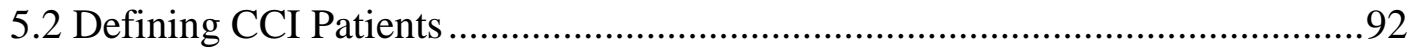

5.3 Exploration of Key Categories and Themes ..................................................992

5.4 Nurse Autonomy and Control ........................................................................ 94 
5.5 Work-related Stress and Compassion Fatigue ..............................................96

5.6 The CCI Patient in the ICU Environment.........................................................97

5.7 Teamwork, Nursing Practice and Continuity of Care......................................99

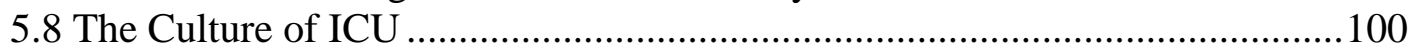

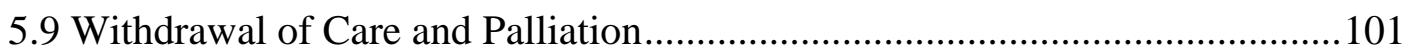

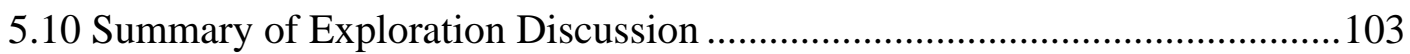

5.11 Implications for Improving Nursing Practice ............................................104

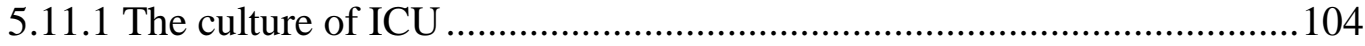

5.11.2 The CCI patient in the ICU environment...........................................104

5.11.3 Teamwork, nursing practice and continuity of care.............................105

5.11.4 Work-related stress, compassion fatigue and staff allocation.................107

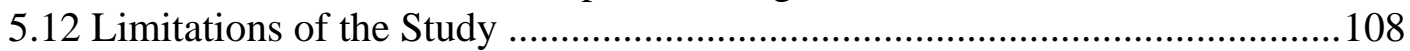

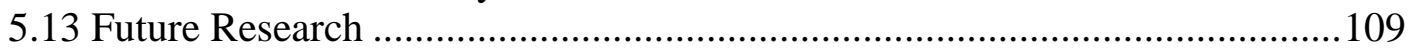

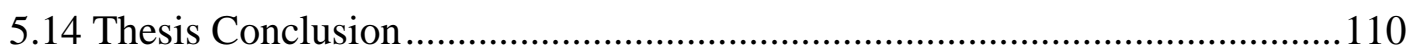

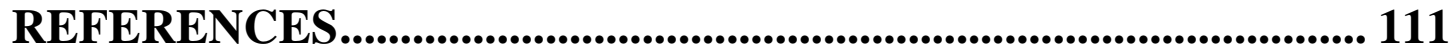

APPENDIX 1Flyer Advertising the Study.................................122

APPENDIX 2 Participant Information Sheet.................................123

APPENDIX 3 Research Synopsis.........................................124

APPENDIX 4 Ministry of Health Advisory Letter............................125

APPENDIX 5 Participant Consent Form.......................................126

APPENDIX 6Interview Questions...............................................127

APPENDIX 7Multi-region Ethics Approval Letter............................128 


\section{List of Tables}

Table 1 Summary of study critique and definitions of CCI......................8

Table 2 Search terms and number of hits.....................................18

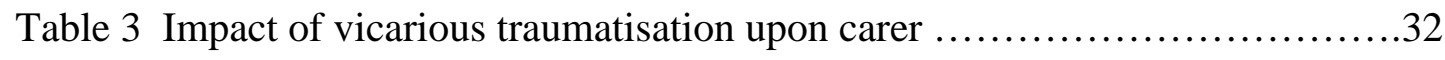

Table 4 Stages of data analysis based on Burnard (1991).......................51

Table 5 Details of CCI patients admitted to NID and SID during 2008............66

Table 6 Demographics of participants and exposure to CCI patients...............67

Table 7 Research aims and their associated themes............................91

Table 8 Types of frustration and negative association with CCI patients in relation to participant principles....................................93 


\section{List of Figures}

Figure 1 Burnard's (1991) analysis applied to this study...........................52

Figure 2 Summary of themes identified using Burnard's framework (1991).........54

Figure 3 Cycle linking participant lack of autonomy with compassion fatigue........95 


\section{CHAPTER ONE}

\section{INTRODUCTION AND POSITIONING OF THE STUDY}

\subsection{Introduction}

This chapter presents an overview of the aims and structure of this study. Personal and professional reasons for undertaking the research are provided, using the researcher's experience and observations of caring for chronically critically ill (CCI) patients.The integration of findings from the literature search into the design of the qualitative method is outlined, with discussion concerning the perceived benefits of this piece of work. The thesis structure is provided and the chapter concludes with a brief summary.

Although there has been an increase in the volume of research exploring the chronically critically ill patient within the intensive care unit (ICU), there has been none focused on the ICU nurses' experiences of caring for this patient group. When talking with colleagues and reading articles concerning CCI, there seems to be general acceptance that these patients are burdensome to clinical staff.No studies were located that explained why CCI patients were perceived in this way. Similarly, no studies articulated the actual experiences of ICU nurses caring for this patient group.In New Zealand there is an absence of research that focus on CCI patients and nursing care of this patient group. This paucity of clinical studies and overall perception of CCI patients as burdensome contributes to a clinical environment that negatively impacts on the desire and ability of ICU nurses to provide quality care to these patients.

\subsection{Personal Experience}

From my personal experience, the more I looked after CCI patients, the more I saw that their experience was strongly linked with the professionalism, skill and attitude of the nurse looking after them.When handing over the care of one CCI patient to another nurse I observed the negative impact this had on the patient. The nurse's lack of interest and casual remarks about not intending to 'do much' because they needed a 
quiet shift were heard by the patient. I wondered what is must feel like to be physically reliant on another person and have each day's experience rely upon the will, effort and professionalism of one nurse. On return to the same patient the next day the patient was sad and withdrawn, although happy to see me.On reflection, the nurse's conduct had a negative impact on the patient's experience. An underlying problem was that the nurse assumed caring for a long-stay patient would be easy. During conversation and informal observation I found that many nurses shared this opinion. In addition they viewed CCI patients as unexciting and unchallenging, which led to nonchalance and failing to meet the patient's physical, emotional and social needs.Furthermore, nursing care fluctuated dramatically depending on the level of interest and skill of the nurse.

When taking over the care of another CCI patient, the nurse explained how frustrating her day had been because the patient was in a bad mood. The patient was described as 'stroppy' and 'precious.' On assessment, the patient was frightened at having had the ventilator settings changed without any explanation. Compounding this fear was frustration at not being listened to and the nurse walking away when she couldn't understand his attempts at mouthing words. As I sat and talked with him, other staff commented on what I was doing, saying “oh you're good,” and “see you're having a quiet day there.” Although intended as light-hearted remarks, they revealed an underlying fact. As nurses we had lost the skill of compassionately caring for conscious patients, and replaced it with regimented technology-focused care. Nursing colleagues preferred to look after sedated, ventilated patients because they were 'easier to look after' rather than have their shift interfered with by the interjections and expressed needs of a conscious, talking patient. It was commonly perceived to be easier, and less taxing, to occupy a shift with assessment, planning and implementation of physical tasks, and pay little attention to the other aspects of holistic care: that of the patient's psychological and emotional needs.These aspects of care are of particular importance when patients survive the acute phase of their illness, but have a prolonged stay in ICU. These experiences led me to consider studying ICU nursing experiences of CCI patients for this thesis. In order to fully appreciate the ICU nurses' experiences consideration of their working environment was necessary. 


\subsection{Intensive Care Unit: A challenging environment}

This section provides a brief overview of the intensive care environment in relation to patient experience, the role of nurses, staffing issues, work-related stress, and interdisciplinary care. Discussing these topics helps provide context for understanding nursing care issues related to chronic critical illness. The implications of ICU as a challenging environment in which to look after patients are presented. This provides understanding of how the ICU environment might affect the experiences of nurses caring for CCI patients.

\subsubsection{Patients in ICU}

The patient population within ICU is constantly changing, with a worldwide increase in the number of people who live to old age (Dawson, 2006). This has led to an increased population of elderly patients within intensive care, who often have complex co-morbidities (Dawson, 2006). Patients are admitted to ICU with a plethora of medical conditions, such as septic shock, severe trauma, post-cardiac surgery, acute respiratory and renal failure, gastroenterological emergencies, acute neurological disorders, diabetic emergencies, infections and immune disorders, obstetric emergencies, environmental injuries, pharmacological and metabolic management, and haematological management (Bersten \& Soni, 2003).Depending on their diagnosis, ICU patient admissions vary in terms of length of stay and the types of experience they endure.

The experience of being a patient in ICU has been comprehensively studied in terms of physical and psychological needs, quality of life, the impact of technology and the ICU environment, the role of family and the development of 'ICU psychosis' (Granberg, Engberg \& Lunderg, 1996). It is internationally acknowledged that ICU is stressful for patients, whether it is due to a disease process or related to the physical environment (So \& Chan, 2003). Three of the most common stressors for patients in ICU are pain, sleep deprivation and fear or anxiety (DeKeyser, 2003). Additional stressors include: immobility, offensive smells, lights on all day and night, unfamiliar machinery and loud noises, invasive procedures, lack of privacy, separation from family, dependency and loss of control, impaired communication, loss of short-term memory, fear of death and uncomfortable tubes (Almerud, Alapack, Fridlund \& 
Ekebergh, 2007; Granja et al., 2005; Hafsteindottir, 1996; Hweidi, 2007; So \& Chan, 2004).

In order to effectively minimise patient exposure to these stressors, the ICU nurse needs to develop a holistic, integrated and comprehensive approach to care (Almerud et al., 2007); use more effective communication techniques (Hafsteindottir, 1996) and pain relieving treatment (Hweidi, 2007), provide a restful environment (Hweidi, 2007), focus on the patients' psychological needs by minimising stress and reestablishing self-control (So \& Chan, 2003), and act as a buffer against feelings of anxiety and isolation (DeKeyser, 2003).

\subsubsection{ICU standards and inter-disciplinary care}

Skilled communication and collaboration are essential for creating ICUs where interdisciplinary, patient-focused care can thrive (McCauley\& Irwin, 2006). The American Association of Critical Care Nurses (AACN) presented six standards for establishing healthy work environments within ICU (AACN, 2005). The standards include addressing skilled communication, true collaboration, effective decisionmaking, appropriate staffing, meaningful recognition, and authentic leadership (AACN, 2005). When these standards are met there are improved outcomes for patients and their family, improved job satisfaction and retention of nursing staff (McCauley \& Irwin, 2006).

Of these standards, skilled communication and true collaboration between the nurse and multi-disciplinary team professionals are integral to optimising patient and family satisfaction within the complexities of today's healthcare system (AACN, 2005). While inter-disciplinary teamwork has been associated with increased quality of health for patients, this collaboration and coordination of health professionals requires effective teamwork, organisational commitment and resourcing (Opie, 1997). Specifically, nurse-physician collaboration has resulted in improved outcomes for patients (McCauley \& Irwin, 2006).

\subsubsection{The role of nurses in ICU}

The role of the intensive care nurse is to provide specialist knowledge and skill when caring for critically unwell people, enhance the delivery of holistic, patient-centred 
approach in a high tech environment and provide the multidisciplinary team with a unique combination of knowledge and caring (The World Federation of Critical Care Nurses, 2005).Nurses work in critical care to provide expert level care to acutely unwell people and their family, develop knowledge and skills and master technology to enhance the caring aspects of their practice (Dawson, 2006; Wilkin \& Slevin, 2004). A clinically competent ICU nurse provides evidence-based care, which promotes patient autonomy, safety, equality and continuity of care (O'Sullivan, Preston \& Forti, 2000). Clinical skills that are inherent in an experienced ICU nurse include being able to recognise abnormal situations, encompassing diagnostic assessments, patient monitoring and management of complex equipment (Aari et al., 2008). The application of these skills is suitable for acutely unwell patients where the focus of the ICU nurse is to problem-solve severe or urgent problems.

\subsubsection{Staffing issues and work-related stress in ICU}

Research in the United States (US) and United Kingdom(UK) has demonstrated an alarming trend towards short staffing throughout hospitals and especially in ICUs (Letvak \& Buck, 2008). This is contributed to an ageing population of the nursing workforce, with predictions of worsening staff turnover and shortages over the next 15 years, as many nurses retire and leave the profession (Letvak \& Buck, 2008). In the US nursing shortfalls are predicted to reach 36\% by 2020 (Letvak \& Buck, 2008). Initiatives to improve staff retention range from reducing stress, improving the work environment, improving the nurses' ability to provide quality care, provide adequate staffing and assure their health and safety (Letvak, \& Buck, 2008).

Historically, intensive care units have struggled to retain their nursing staff, due to burnout and decreased job satisfaction (Davis et al., 2007). Nursing turnover and the associated costs are recognised as a chronic problem in the ICU nursing work force (Song et al., 1997). This phenomenon causes frustration and financial cost for clinical leaders who struggle to provide a professional, well-resourced and operational critical care service. Researchers have found no single factor or pattern underlying nurses' decision to leave ICU, yet there are several contributing factors linked with this trend: dissatisfaction with management, lack of support from management, a wish for increased autonomy and participation in decision-making (Ames et al., 1992). One US study found that management style, control over practice, group cohesion, 
autonomy, and job stress contribute to job satisfaction, intention to stay, and retention of nurses in ICU (Boyle, Bott, Hansen, Woods \& Taunton, 1999). It is important that ICU managers address retention and recruitment issues related to this group of highly trained nurses, because of the effects of staff shortage on patient safety and quality of care (Buerhaus, Donelan, Ulrich, Norman \& Dittus, 2005).

The ICU nurse's skills are effective when caring for acutely unwell patients, but the patient population group of CCI has unique health care needs that require intensive, well-organised and excellent nursing care (Carasa \& Nespoli, 2002). This excellence in nursing can be a driving force for innovative patient-centred practice, but if not resourced or staffed properly, could instead lead to work-related stress. In recent yearsICUs in England have incorporated clinical supervision into their workplace as a means to improve peer support and promote staff retention (Spencer, Kinnear \& Vieira, 2000; O’Riordan, 2002). Some ICUs used clinical supervision to encourage reflective dialogue, thereby developing professionalism and increasing quality of care(Lindahl \& Norberg, 2002; Price \& Chalker, 2000).Benefits of clinical supervision include stress reduction and empowering nurses to take control of their individual practice (Sexton-Bradshaw, 1999), peer support and networking (Cheater \& Hale, 2001)and support in managing professional and personally demanding complex nursing care (Lindahl \& Norberg, 2002).No literature was located concerning models of clinical supervision for ICUs in New Zealand.

Despite acknowledgement that ICU is a stressful working environment for nurses, and CCI patients are complex to care for, there has been no investigative study exploring ICU nurses' experiences of caring for these patients. In order to understand the impact of caring for CCI patients, it is necessary to have a clear definition of this patient group.

\subsection{Chronic Critical Illness}

The first documented use of the term chronic critical illness was by researchers Girard and Raffin (Girard \& Raffin, 1985). Their article discussed CCI as an emerging patient group arguing their prognosis as being poor (Girard \& Raffin, 1985). They examined why CCI patients die and suggested a management strategy for improving their prognosis. Prior to this, patients with a prolonged ICU admission were called 
'long-stay', 'long-term,' and 'very-long stay'. The two main criteria for defining CCI are length of stay and tracheostomy insertion. A summary of the definitions of chronic critical illness is presented in Table 1. 
Table 1: Summary of study critiqueand definitions of CCI

\begin{tabular}{|c|c|c|c|c|c|}
\hline $\begin{array}{c}\text { Author\& } \\
\text { Date }\end{array}$ & $\begin{array}{c}\text { Questions or outcome } \\
\text { variables }\end{array}$ & $\begin{array}{l}\text { Study } \\
\text { Design }\end{array}$ & Sample Profile & Outcomes & $\begin{array}{c}\text { Definition of } \\
\text { chronic critical } \\
\text { illness }\end{array}$ \\
\hline $\begin{array}{l}\text { Bashour et } \\
\text { al.,(2000). }\end{array}$ & $\begin{array}{l}\text { Determine whether hospital } \\
\text { discharge alone represents a } \\
\text { good outcome for patients who } \\
\text { had prolonged intensive care } \\
\text { after cardiac surgery. } \\
\text { Establish the proportion of ICU } \\
\text { resources used by this patient } \\
\text { group. } \\
\text { Identify pre-operative patient } \\
\text { characteristics that are } \\
\text { associated with prolonged ICU } \\
\text { stay. }\end{array}$ & $\begin{array}{l}\text { Inception } \\
\text { cohort study. }\end{array}$ & $\begin{array}{l}\text { Eligibility: Every } \\
\text { patient that } \\
\text { underwent } \\
\text { coronary artery } \\
\text { bypass graft } \\
\text { (CABG) and/or } \\
\text { valve surgery. } \\
142 \text { had a length of } \\
\text { stay }>10 \text { days. }\end{array}$ & $\begin{array}{l}\text { Prolonged ICU stay associated with } \\
\text { preoperative variables: elderly, combined } \\
\text { surgery (CABG and valve), re-operation, low } \\
\text { albumin, history of COPD, LVF, renal } \\
\text { dysfunction, and hematocrit. } \\
47 \text { died in hospital. } \\
\text { Median length of stay } 21 \text { days. } \\
\text { Many survivors of a prolonged ICU stay die } \\
\text { within first } 3 \text { months after hospital discharge. } \\
\text { Survivors had poor functional state. } \\
\text { The } 142 \text { patients used } 50 \% \text { of the total ICU } \\
\text { days and } 48 \% \text { of the total ICU direct costs for } \\
\text { 2'618 ICU patients. }\end{array}$ & $\begin{array}{l}\text { Patients with an } \\
\text { ICU length of } \\
\text { stay >10 days. }\end{array}$ \\
\hline $\begin{array}{l}\text { Carson \& } \\
\text { Bach (2002). }\end{array}$ & $\begin{array}{l}\text { To define CCI patients in terms } \\
\text { of demographics, diagnoses and } \\
\text { risk factors. } \\
\text { To review CCI outcomes } \\
\text { including: survival, functional } \\
\text { status, quality of life and costs of } \\
\text { care. }\end{array}$ & $\begin{array}{l}\text { Descriptive } \\
\text { study. }\end{array}$ & $\begin{array}{l}\text { CCI definitions } \\
\text { discussed: varies } \\
\text { from } 7-10 \text { days. }\end{array}$ & $\begin{array}{l}\text { Over half CCI patients are aged }>65 \text { years. } \\
\text { Patients with underlying co-morbidities who } \\
\text { develop an acute illness are at highest risk of } \\
\text { becoming CCI. } \\
\text { CCI have poor short and long-term survival. } \\
\text { Reported quality of life is generally good. } \\
\text { CCI consume a disproportionate amount of } \\
\text { ICU and hospital resources. } \\
\text { SCU have evolved to manage CCI at lower } \\
\text { costs than ICUs. }\end{array}$ & 7-10 days \\
\hline
\end{tabular}




\begin{tabular}{|c|c|c|c|c|c|}
\hline $\begin{array}{c}\text { Author \& } \\
\text { Date }\end{array}$ & $\begin{array}{c}\text { Questions or outcome } \\
\text { variables }\end{array}$ & $\begin{array}{l}\text { Study } \\
\text { Design }\end{array}$ & Sample Profile & Outcomes & $\begin{array}{c}\text { Definition of } \\
\text { chronic critical } \\
\text { illness }\end{array}$ \\
\hline $\begin{array}{l}\text { Daly et al., } \\
\text { (2005). }\end{array}$ & $\begin{array}{l}\text { Test the effect of a disease } \\
\text { management program on } \\
\text { hospital readmission patterns of } \\
\text { CCI patients during the first } 2 \\
\text { months after discharge. } \\
\text { Estimate cost-effectiveness of } \\
\text { the program. }\end{array}$ & $\begin{array}{l}\text { Randomised } \\
\text { Control Trial }\end{array}$ & $\begin{array}{l}334 \text { adults ( } 231 \\
\text { experimental; } \\
\text { control 103). } \\
\text { Enrolled into study } \\
\text { after } 72 \text { hours }\end{array}$ & $\begin{array}{l}\text { Significantly fewer mean days of re- } \\
\text { hospitalisation in the experimental group. } \\
\text { Financial costssaved were associated with } \\
\text { intervention. }\end{array}$ & $\begin{array}{l}>3 \text { days } \\
\text { mechanical } \\
\text { ventilation }\end{array}$ \\
\hline $\begin{array}{l}\text { Daly et al., } \\
\text { (1991). }\end{array}$ & $\begin{array}{l}\text { Compare the effects of the } \\
\text { Specialist Care Unit (SCU) with } \\
\text { the effects of ICU on nurse and } \\
\text { patient outcomes. }\end{array}$ & $\begin{array}{l}\text { Retrospective } \\
\text { and } \\
\text { Comparative } \\
\text { Analysis }\end{array}$ & $\begin{array}{l}24 \text { patients (10 } \\
\text { control; } 14 \\
\text { experimental). Age } \\
\text { range } 17-87 \text { years. } \\
\text { Eligibility criteria: } \\
\text { length of stay } 21 \\
\text { days or more. }\end{array}$ & $\begin{array}{l}\text { Most frequent reason for CCI patients' } \\
\text { prolonged stay: failure to wean from } \\
\text { mechanical ventilation. Mortality rate for ICU } \\
\text { is } 30 \% \text { and for SCU is } 33 \% \text {. Decreased costs } \\
\text { with SCU associated with less blood tests. }\end{array}$ & $\begin{array}{l}>7 \text { days } \\
\text { mechanical } \\
\text { ventilation }\end{array}$ \\
\hline $\begin{array}{l}\text { Estenssoro et } \\
\text { al., (2006). }\end{array}$ & $\begin{array}{l}\text { Describe the epidemiology, } \\
\text { clinical profiles, outcomes and } \\
\text { factors that might predict } \\
\text { progression of critically ill } \\
\text { patients to CCI. }\end{array}$ & $\begin{array}{l}\text { Prospective } \\
\text { Cohort Study }\end{array}$ & $\begin{array}{l}95 \text { patients fulfilled } \\
\text { inclusion criteria. }\end{array}$ & $\begin{array}{l}\text { Compared with other ICU patients the CCI } \\
\text { had higher APACHE scores, more multi } \\
\text { organ dysfunction (MODS), received more } \\
\text { interventions and had undergone emergency } \\
\text { surgery more frequently. CCI had higher } \\
\text { expected mortality rates. } \\
\text { ARDS, shock and MODs frequent on } \\
\text { admission in patients who became CCI. }\end{array}$ & $\begin{array}{l}\text { From time of } \\
\text { tracheostomy } \\
\text { insertion (for } \\
\text { ongoing } \\
\text { mechanical } \\
\text { ventilation). }\end{array}$ \\
\hline
\end{tabular}




\begin{tabular}{|c|c|c|c|c|c|}
\hline $\begin{array}{l}\text { Author \& } \\
\text { Date }\end{array}$ & $\begin{array}{l}\text { Questions or outcome } \\
\text { variables }\end{array}$ & $\begin{array}{l}\text { Study } \\
\text { Design }\end{array}$ & Sample Profile & Outcomes & $\begin{array}{c}\text { Definition of } \\
\text { chronic critical } \\
\text { illness }\end{array}$ \\
\hline $\begin{array}{l}\text { Heyland et } \\
\text { al., (1998). }\end{array}$ & $\begin{array}{l}\text { Compare the cost and } \\
\text { consequences of } 2 \text { policies: } \\
\text { withdrawing support from } \\
\text { patients with prolonged ICU } \\
\text { stay; continuing to care for } \\
\text { patients with prolonged ICU } \\
\text { stay. }\end{array}$ & $\begin{array}{l}\text { Economic } \\
\text { evaluation } \\
\text { using data } \\
\text { from a } \\
\text { prospective } \\
\text { cohort study. }\end{array}$ & $\begin{array}{l}61 \text { patients with } \\
\text { length of stay }>14 \\
\text { days. Patients } \\
\text { followed up until } \\
12 \text { months after } \\
\text { ICU admission to } \\
\text { assess quality of } \\
\text { life. }\end{array}$ & $\begin{array}{l}\text { At } 12 \text { months } 34 \text { had died. ( } 56 \%) \text {. } \\
\text { Quality of life did not differ between patients } \\
\text { with a short or a prolonged ICU. } \\
\text { The average ICU cost per day per patient was } \\
\text { similar for the two groups. }\end{array}$ & $\begin{array}{l}\text { Patients with an } \\
\text { ICU length of } \\
\text { stay }>14 \text { days }\end{array}$ \\
\hline $\begin{array}{l}\text { Nelson et al., } \\
\text { (2004). }\end{array}$ & $\begin{array}{l}\text { To assess patients' self-reported } \\
\text { burden of chronic critical illness. }\end{array}$ & $\begin{array}{l}\text { Prospective } \\
\text { Cohort Study }\end{array}$ & $\begin{array}{l}87 \text { patients eligible: } \\
50 \text { enrolled. } \\
\text { Eligibility criteria: } \\
\text { elective placement } \\
\text { of tracheostomy } \\
\text { tube. }\end{array}$ & $\begin{array}{l}\text { Half patients weaned from ventilator. More } \\
\text { than half of the cohort had died at } 3 \text { months } \\
\text { after discharge. Prevalence of symptoms: } \\
80 \% \text { unsatisfied thirst, } 90 \% \text { distressed due to } \\
\text { difficulty communicating, } 60 \% \text { psychological } \\
\text { symptoms and } 44 \% \text { reported pain as most } \\
\text { distressing symptom. }\end{array}$ & $\begin{array}{l}\text { From time of } \\
\text { tracheostomy } \\
\text { insertion. }\end{array}$ \\
\hline $\begin{array}{l}\text { Roulin \& } \\
\text { Spirig } \\
(2006) .\end{array}$ & $\begin{array}{l}\text { Define practice problems related } \\
\text { to caring for the chronically } \\
\text { critically ill. } \\
\text { Develop a care program based } \\
\text { on evidence. }\end{array}$ & $\begin{array}{l}\text { Action } \\
\text { Research }\end{array}$ & $\begin{array}{l}19 \text { health care } \\
\text { workers ( } 14 \text { nurses, } \\
2 \text { physiotherapists, } \\
3 \text { nurse assistants). }\end{array}$ & $\begin{array}{l}\text { Practice problems were identified as patient } \\
\text { characteristics and nursing/organizational } \\
\text { characteristics. } \\
\text { An evidence-based care program was } \\
\text { designed. The program needed to be } \\
\text { evaluated. }\end{array}$ & $>10$ days \\
\hline $\begin{array}{l}\text { Rudy et } \\
\text { al.,(1995). }\end{array}$ & $\begin{array}{l}\text { Compare the effects of a low } \\
\text { technology environment and a } \\
\text { nurse case management delivery } \\
\text { system with the traditional ICU: } \\
\text { patient outcomes, length of stay, } \\
\text { mortality, readmission, } \\
\text { satisfaction, complications and } \\
\text { costs. }\end{array}$ & $\begin{array}{l}\text { Comparative } \\
\text { Analysis. }\end{array}$ & $\begin{array}{l}220 \text { CCI patients } \\
\text { (145 SCU, } 75 \\
\text { ICU). Patients } \\
\text { were randomly } \\
\text { assigned to each } \\
\text { group. }\end{array}$ & $\begin{array}{l}\text { Significant cost savings in SCU ( } \$ 5000 \text { less } \\
\text { per patient in SCU compared with ICU). }\end{array}$ & $\begin{array}{l}\text { Patients with a } \\
\text { length of stay }>5 \\
\text { days. }\end{array}$ \\
\hline
\end{tabular}


Most studies use length of stay in ICU to define CCI, but this parameter varies from 3 days (Daly, Douglas, Kelley, O’Toole \& Montenegro, 2005) 7-10 days (Bashour et al., 2000; Carson \& Bach, 2002), 14 days (Heyland, Konopad, Noseworthy, Johnston \& Gafni, 1998), 21 days (Daly, Rudy, Thompson \& Happ, 1991) to 28 days (Hartl, Wolf, Schneider, Kuchenhoff \& Jauch, 2007). Two studies define the onset of CCI from the day of tracheostomy insertion (Nierman \& Mechanick, 1998; Nelson et al., 2004). The reason for inconsistencies in defining CCI are not clear, but it seems likely that sample sizes of studies might have been too small, if length of stay was as many as 28 or 30 days. For example, CCI is defined by Daly et al., (1991) as a length of stay $>21$ days, whereas Daly et al., (2005) use a length of stay $>3$ days. A much more significant sized sample could be used if only a few days were needed to make the CCI diagnosis.

The use of tracheostomy insertion to recognise CCI patients seems reasonable given the inference of prolonged ventilator weaning. However, the short timeframe required for tracheostomy (usually between 72 hours and 7 days) means the patient has not experienced the prolonged ICU stay that is synonymous with CCI. Tracheostomy insertion can identify a potential CCI patient, but is not a defining feature of CCI. The timeframe for tracheostomy insertion varies between ICUs and practice does not always match policy recommendations. For example, tracheostomy insertion may be advised at day 7 of admission, but in practice early tracheostomies may be performed in some patients, whilst others may be delayed until 8 or 9 days. Studies investigating the timing of tracheostomy insertion have conflicting findings in relation to mortality, ICU and hospital length of stay (Schauer, Engle, Maugher \& Cherry, 2009). There are no definitive guidelines so the timing of tracheostomy depends on physician judgment, clinical conditions and communication with family (Hsu et al., 2005). Using tracheostomy insertion to define or recognise CCI patients would be inconsistent and vary with each Consultant. It has therefore not been incorporated into the CCI definition used in this thesis.

As CCI patients are a recently named patient group, I did not expect to find resources or guidelines specifically designed to care for them. Therefore the terms 'long-stay' or 'long-term' were more appropriate terms to use with participants for this study. Furthermore I decided to begin each interviewwith a definition of CCI, to ensure clarity regarding the interview focus. 
For the purpose of this study CCI patients are defined as: ICU patients whose length of stay is 28 days or more, who have prolonged ventilator weaning due to respiratory failure, multi-organ dysfunction and general debilitation.In order to understand the complexity of these patients, their clinical profile is presented.

\subsection{Clinical Profile of CCI}

The difficulty associated with clearly defining chronic critical illness is further seen when describing the clinical profile and outcomes of this patient group. A cohort study in Argentina prospectively studied all ICU admissions over a three-year period, in order to identify predictive factors that might cause progression of critically ill patients to chronically critically ill (Estenssoro et al., 2006). CCI patients were defined as those having a tracheostomy inserted for mechanical ventilation. The researchers also looked at clinical outcomes and profiles of the CCI group and calculated severity of illness scores (Acute Physiologic and Chronic Health Evaluation [APACHE] II score). When comparing CCI patients with other ICU patients, CCI were sicker on admission, had more organ dysfunction, received more interventions, had undergone emergency surgery more frequently and had less underlying diseases (Estenssoro, 2006). Acute Respiratory Distress Syndrome (ARDS) and shock were significantly more prevalent in CCI patients. Recurrent complications during their ICU stay ranged from shock, unsuccessful ventilator weaning, failed extubations, atelectasis, stress-related gastrointestinal bleeding, malnutrition (due to intolerance of enteral nutrition, ileus and diarrhoea), and critical illness polyneuropathy. Very high infection rates were also found, which were linked to prolonged mechanical ventilation, ventilator acquired pneumonia (VAP) and ARDS (Estenssoro, 2006). Urinary tract and indwelling catheter infections was more than double the incidence in CCI patients than in the other ICU patients. There was no statistical difference in mortality rates between the two groups. Predictors of chronic critical illness were identified as the presence of ARDS, APACHE II and the absence of significant underlying diseases on admission to ICU (Estenssoro, 2006). No further studies into the clinical profile of CCI patients have been conducted. 
This study was useful as a benchmark for understanding the clinical profile of CCI patients. The researchers' compared their findings with those from a European cohort study. As the study was conducted in Argentina, the population group may have different characteristics to those from New Zealand. However, Estenssoro's (2006) findings add to our knowledge and understanding of CCI patients and may help inform the design of future local research. Furthermore, the complexity of this patient group is clearly demonstrated.

\subsection{Discussion}

Identifying the chronically critically ill as a group of ICU patients that have both prolonged medical problems and ICU length of stay has a direct effect on the nurses caring for them. Having established the nursing experiences of caring for this patient group as poorly documented and researched, the dominant focus of this study concerns discovering difficulties nurses experience when meeting CCI patient needs. A lesser focus is to discover the needs of CCI patients, as perceived by the ICU nursing participants. The absence of research and literature exploring nurses' experiences presented an opportunity for me to explore this area of interest by conducting a study in New Zealand. The study aims to contribute to our understanding of ICU nurses' experiences of caring for CCI patients. Exploring and describing nurses' experiences regarding their nursing care of chronically critically ill patients will achieve this. Underpinning the study is an implicit aim to address various counter-transferential responses of nurses who care for this patient group. The research question is: what are the experiences of ICU nurses caring for chronically critically ill patients? Secondly, what do nurses perceive CCI patient experiences to be?

\subsection{Thesis Structure}

The thesis centres on ICU nurses openly talking and discussing key aspects of their nursing practice, when looking after CCI patients. Participants were encouraged to comment on several issues, including access to training and resources, cultural issues within ICU, and suggestions for how CCI patient care might be improved.

The thesis is composed of six chapters. This first chapter introduces the concept of chronic critical illness within ICU and presents reasons for undertaking the study. The 
context and focus of the thesis are then articulated. Literature describing the ICU as a challenging environment for nurses to work in is discussed, with an introduction to chronic critical illness. The clinical profile of CCI patients is described to demonstrate the complexity of this patient group.

Chapter two begins with a search strategy, detailing how key articles were located and the databases and key words that were used. This follows with an in-depth critique of studies related to CCI patients, their associated treatment programmes and the impact of these patients upon ICU nursing practice. The literature critique reveals an absence of studies that focus on nursing CCI patients.

Chapter three describes the qualitative methodology used to answer the research question. The research aims, qualitative methods andjustification for the exploratory descriptive design are provided. Semi-structured interviews are presented as the most suitable method for data collection. Participant selection and the recruitment process are then described. The specific design of the interviews is presented before exploring the research process and discussion of quality and reliability issues. Finally ethical considerations are addressed.

Chapter four presents the findings. Content analysis was used to identify key categories and themes. Sections of participant transcripts are presented throughout this chapter to illustrate the discussion points and demonstrate authenticity.

Chapter five relates the findings to the known literature and discusses the implications of the results. As no similar research has previously been conducted, the nurses' experiences cannot be directly compared withthe experiences of other nurses caring for CCI patients. Instead, the key themes are presented in reference to existing literature and research. These themes include the nurses' need for control and autonomy, staff burnout, CCI patients not fitting the ICU mould, and nurses' distress in association with withdrawing care from patients. The implications for changing practice are then explored, and recommendations for improving care are provided.

Chapter six is the final chapter, which reflects upon the importance of this study, the research process and its limitations. The quality and reliability of the study 
arepresented in this chapter, with recommendations concerning the future direction of CCI care and support for nurses who look after this discreet patient group. 


\section{CHAPTER TWO}

\section{LITERATURE REVIEW}

\subsection{Introduction and Overview}

This chapter explores literature about nursing chronically critically ill (CCI) patients and identifies a gap in knowledge about intensive care nurses' experiences of caring for these patients.Over the past 10 years there has been an increase in the number of CCI patients. Studies have researched CCI treatment programmes, outcomes versus costs, and explored the outcomes and quality of life of the patient. None have primarily focused on the experiences of the nurses caring for the CCI patient. The reason for this apparent absence of research is unclear.The prevalence of CCI patients is estimated to be over 100,000 in the United States each year, and numbers are increasing (Nelson et al., 2004). This group of patients has complex medical and nursing needs and experience prolonged periods in intensive care units (ICU), where they are exposed to many physical and psychological stressors. Effects of these stressors upon the nurses caring for CCI patients are unknown. Given the stressful working environment of ICU, associated work-related stress and staffing issues, it is important to generate research exploring their experiences when caring for this patient group. Findings from this research will provide evidence-based understanding concerning the impact work-related stressors have upon nurses, the care they provide and how CCI patients are perceived.

There was considerable variability in the literature regarding the definition of CCI. Most studies used the length of stay in ICU to define CCI, but this parameter varied from $3-28$ days. Two studies chose to define the onset of CCI from the day of tracheostomy insertion. The importance of recognising a CCI patient is a crucial part of ICU's management and allocation of resources. Clarity of the definition of CCI, and prioritising which variables to use in order to make this definition remain elusive.

A lack of Australian and New Zealand publications concerning chronic critical illness in ICU patients was identified. Most of the research has been conducted in the United States and Canada.The types of research were mostly quantitative. Qualitative studies were 
descriptive using cohort and retrospective observational methods. These approaches are appropriate given the holistic nature of caring for this patient group.

Reported outcomes of CCI are variable. Studies from the 1980's found mortality rates were high (Goldstein et al., 1986; \& Wagner, 1989) whilst more recent studies conclude improved functional outcomes and quality of life (Montelucard et al., 2000; Teno et al,. 2000; Combes et al., 2003).

Given the increase in size of this patient group, and trend towards increasing lifeprolonging treatments within ICU, it is important to understand the experiences of nurses who care for CCI patients. CCI patients' recovery can be slow and difficult to see day to day which becomes a burden to medical and nursing staff, particularly in ICUs that have staff shortages (Daly et al., 1991). In a working environment with transient staffing levels, having an increase in nursing satisfaction is a compelling reason to explore the evidence surrounding nurses’ experiences of caring for these patients.

Theremainder of the chapter describes the search strategy, literature findings in regard to CCI patient outcomes and associated financial and staffing costs, and specialist programmes for this patient group.The final section reports on what is known about the experiences of ICU nurses who care for CCI patients. Findings of this literature review are used to inform the research design.

\subsection{Search Strategy}

The databases MEDLINE, CINAHL and PUBMED were searched using the keywords 'chronic critical illness', 'long-stay ICU patients', 'long-term ICU patients,' 'ICU nurses,' 'compassion fatigue,' 'secondary traumatic stress,' 'interdisciplinary care,' 'models of care,' withdrawal of care,' and 'nurse autonomy and control.'These key terms reflected the focus of the research enquiry and allowed for sufficient retrieval of relevant studies and discussion papers. The numbers of hits for each search term are presented in Table 2. The only limiter appliedwas restricting the dates from 2000 until 2009. This restriction was made so that retrieved articles would be relevant in terms of applicability to today's ICU climate. However this yielded a low volume of articles and therefore the timeframe was changed to 1980 until 2009. Hand searchingof reference lists of key articles was also 
conducted. COCHRANE and the Joanna Briggs Institute were searched but there were no systematic reviews relevant to this study. Finally Critical care organisations, including Intensive Care Services in New Zealand, New Zealand Nurses Organisation (NZNO), Society of Critical Care Medicine and American Association of Critical Care Nurses were explored using the internet to establish local and international opinion and guidelines. These websites lacked inclusion of CCI patients in their scopes of practice, and had little or no acknowledgement of long-stay patients within ICU.

Table 2 Search terms and number of hits

\begin{tabular}{|l|c|c|c|c|}
\hline \multicolumn{1}{|c|}{ Search Term } & Medline & PubMed & CINAHL & $\begin{array}{c}\text { Total number of } \\
\text { key articles used }\end{array}$ \\
\hline Chronic critical illness & 28 & 2246 & 17 & 14 \\
\hline Long-stay ICU patients & 5 & 35 & 431260 & 5 \\
\hline Long-term ICU patients & 5 & 868 & 1 & 6 \\
\hline ICU nurses & 165 & 1223 & 263 & 12 \\
\hline Critical care nurses & 13 & 6960 & 2902 & 9 \\
\hline Compassion fatigue & 64 & 160 & 116 & 5 \\
\hline Secondary traumatic stress & 38 & 646 & 49 & 7 \\
\hline Interdisciplinary care & 100 & 8967 & 159 & 4 \\
\hline Models of care & 491 & 74143 & 591 & 8 \\
\hline Withdrawal of care & 49 & 4710 & 38 & 6 \\
\hline Nurse autonomy and control & 5 & 651 & 9 & 4 \\
\hline
\end{tabular}

Combining some of these search terms identified key articles, for example, chronic critical illness and compassion fatigue. Abstracts were searched for relevance to chronic critical illness, critical care nursing and management of long-stay ICU patients. No Australian or New Zealand publications were located concerning chronic critical illness in ICU patients. Most of the research was conducted by nurses in the US and Canada, usingquantitative methodologiesthat focused on mortality and morbidity rates, quality of life and functional outcomes of very long-stay patients. No research studies were located that explored nurses' experiences of caring for this patient group. Many of the identified articles were quantitative in design, as they studied clinical profiles, financial outcomes and mortality/morbidity of CCI patients. The small amount of literature that helped explain CCI patient and ICU nurse experiences were descriptive qualitative studies using cohort 
and retrospective observational methods.Discussion papers were also located. The qualitative approaches used in these studies researching experiences are appropriate given the holistic nature of caring for this patient group.

The Critical Appraisal Tool (CAT) developed by Effective Practice, Informatics and Quality improvement (EPIQ) was used to identify key articles and rate the studies according to a hierarchy of evidence. Key articles were identified as those that focused on CCI patients and nursing care of this patient group. Each article was analysed for the relevance of the study topic to my research question, the types of method and study design, and quality and reliability of the research. The descriptive studies are described in the next section.

\subsection{Nurses Experiences of Caring for CCI Patients}

Several articles were found exploring the experiences of nurses in ICUs. These covered a range of topics: withdrawal of treatment in ICU (Halcomb, Daly, Jackson \& Davidson, 2004), developing closeness to relatives in ICU (Engstrom \& Soderberg, 2007), enteral nutrition (Persenius, Larsson \& Hall-Lord, 2006), coping strategies (Badger \& O’Connor, 2006), the experience of caring (Beeby, 2000), haemodynamic decision-making following cardiac surgery (Currey \& Botti, 2006), managing technology (Alasad, 2001) and medical futility (Heland, 2006). No research was located whose key objective focused on nurses' experiences of caring for CCI patients. Only one study describedcauses of frustration in ICU nurses caring for this patient group (Roulin \& Spirig, 2006). This description was a small part of a larger project and was not the main aim of the study (Roulin \& Spirig, 2006). A second study (Song et al., 1997) compared nurses’ job satisfaction, absenteeism and turnover between a traditional medical ICU and a Special Care Unit (SCU) for CCI patients.

In Switzerland a team of 19 health professionals developed a new programme of care for chronically critically ill patients in a traditional ICU. The aims of the program were to improve the nursing care of the CCI patients, to increase staff knowledge about these patients and to develop specific interventions, which would improve patient outcomes (Roulin \& Spirig, 2006). Their starting focus was to define more clearly difficulties perceived by staff, related to caring for this patient group (Roulin \& Spirig, 2006). 
Evidence about each perceived difficulty was identified as a combination of clinical experience, local context, knowledge derived from research, and patient preference (Roulin \& Spirig, 2006). The difficulties were categorised into two groups: problems due to patient characteristics and problems due to organisational and nursing characteristics.

Patient characteristics included: slow progress, physical problems (muscle wasting, immobility, impaired communication, slow ventilator weaning, sleep disturbances, poor wound healing, swallowing difficulties and diarrhoea) mental problems (memory loss, confusion, difficulty concentrating and depression), and frustrated families (Roulin \& Spirig, 2006).

Nursing and organisational characteristics were:

- Nurses feeling there is poor care continuity and coordination

- ICU focuses on fast-paced recovery rather than rehabilitation

- Poor knowledge about specific patient needs

- Loss of information over time

- Lack of competency in specific skills (tilt table, swallow tests)

(Roulin \& Spirig, 2006).

These factors led to feelings of frustration and burnout among caregivers (Roulin \& Spirig, 2006). In order to reduce their frustration and improve patient outcomes, the nurses believed they should know their CCI patients as individuals (history, expectations, worries and fears) and increase their knowledge about specific problems and care interventions (Roulin \& Spirig, 2006). Each of these perceived difficulties were addressed in the design and implementation of a patient-centred care program.

This study provides understanding concerning factors that led to nurses feeling frustrated with CCI patients. However, no data collection or analysis processesfor acquiring the nurses' experiences are provided. This makes determining the quality and reliability of these findings impossible.The most likely explanation for this omission is that the researcher's primary objective was to develop a care program, not explore the nurses' experiences. 
The problem of a high turnover of ICU personnel and the high costs associated with critical care treatment, were addressed in a study from the United States (Song et al., 1997). Nurse turnover in ICUs is high in the US which adds to overall ICU costs. In order to address this ongoing problem, a nurse-managed specialist care unit (SCU) was set up to care for CCI patients. The SCU combined two models of care (case management and shared governance) with a low technology environment. Their study concludes that when a case management model is combined with shared governance and minimal technology, the nurses have greater job satisfaction with an associated decrease in the rate of absenteeism (Song et al., 1997). Although the study did not explore the nurses' experiences, there is acknowledgement that the nurses' preferences and perceptions for the SCU practice model were closely related to job satisfaction and growth satisfaction (Song et al., 1997).

From these two studies there is little to inform the direction of enquiry of this thesis. The limited evidence (Roulin \& Spirig, 2006) concerning causes of nursing frustration gives valuable insight, but further research is needed to fully understand the nurses' experiences. There is no clear reason for the absence of research surrounding ICU nurses' experiences of caring for CCI patients. Nursescaring for CCI patients need to develop knowledge and understanding about patient symptoms and experiences, so that care can be managed effectively. The experiences of CCI patients are presented in the next section.

\subsection{Patient Experience}

One study (Nelson et al., 2004) focused on identifying symptoms experienced by CCI patients. The study was conducted in New York and set in a respiratory care unit (RCU) for treatment of CCI patients and used a prospective cohort design. Fifty CCI patients who underwent elective tracheostomy insertion were transferred from an adult intensive care to the RCU and were asked to describe their physical and psychological symptoms. Of the participants $75 \%$ reported experiencing $>10$ of the following symptoms during their ICU stay: weight loss, lack of energy and appetite, pain, dry mouth, drowsiness, shortness of breath when weaning and when fully ventilated, nausea, insomnia, thirst, difficulty communicating, nervousness, and feeling sad and worried (Nelson et al., 2004). Of these pain, psychosocial symptoms (feeling worried, sad or nervous) and severe stress due to difficulty with communication, were identified as the most distressing experiences for CCI 
patients (Nelson et al., 2004).Some aspects of this study cannot be applied to New Zealand hospital's management of CCI patients, as there are no such respiratory care units. However, the nature and type of physical and psychological symptoms experienced by the patients are universal, due to the trajectory of chronic critical illness. It is not unreasonable, therefore to imagine these CCI patients experiences of stress, pain and frustration, are likewise experienced by CCI patients within New Zealand.When I have cared for CCI patients, stress and frustration due to communication problems and uncertainty about the future have been common. Transferability of the study findings is not altogether achievable, given that it is conducted in a large US city, within a health care framework that is entirely different to that of New Zealand. Replicating the study within New Zealand hospitals would not be achievable as there are no specialist care centres to compare ICU practice of CCI patients with. However, the exploration and description of the CCI patient experience would be replicable, which adds to the generalisability and rigour of the study.The findings add to our understanding of the types of emotional and physical symptoms CCI patients may be experiencing. This in turn affects the nurses' experience, as they are required to manage their patient's symptoms.

Nelson et al., (2006) went on to study brain dysfunction (coma and delirium) in this patient group and concluded that severe, prolonged and permanent brain dysfunction is a prominent feature of chronic critical illness. The study had a sample of 203 CCI patients. The prevalence and duration of coma and delirium was measured during each patient's stay in the RCU. Mortality of these patients was then assessed at 3 and 6 months after discharge from the RCU. The study found the impact of brain dysfunction upon the patient and family was significant, especially given that before their critical illness most CCI patients lived and functioned independently in the community. The sample size of this study allows for greater generalisability of the findings. The study focuses on patient symptoms and level of brain dysfunction, which have measurable outcomes, thus making this study easy to replicate within New Zealand ICUs. The impact of CCI patients developing severe brain dysfunction upon the ICU nurse is not explored in the study (Nelson et al., 2006). 


\subsection{Costs, Outcomes and Quality of Life of CCI Patients}

The number of CCI patients is growing rapidly, as surgical and medical interventions become more advanced and patients survive their acute illness. This has a direct impact on ICU costs: figures varying between $\$ 22-\$ 64$ billion have been reportedly spent on CCI patients in ICU in the United States (Carson \& Bach, 2002). Research that explores the costs of CCI patients draw conflicting conclusions, particularly when questioning the controversial idea that CCI patients may not be cost-effective for hospitals to treat. Two studies from the 1980s are described as they provide historical context. The debate is thenexplored using five international studies. Rather than primarily focusing on the financial costs, the physical and emotional cost, or burden of caring for this group of patients needs exploration.

The issue of costs for managing CCI patients has been debated in terms of mortality. Wagner (1989) reported that $21 \%$ of total hospital resource consumption for long-term ICU patients occurs after their seventh day of mechanical ventilation; yet only $45-50 \%$ live to be discharged from hospital. Patients who survived these prolonged ICU admissions had a mortality rate of $49-85 \%$ within a year of hospital discharge (Goldstein, Campion, Thibault, Mulley \& Skinner, 1986). Given the high mortality rates and high costs, it was argued that resources might be more effectively used in other hospital services (Wagner, 1989). These studies by Wagner (1989) and Goldstein et al., (1986) are over 20 years old and conducted before the concept and identification of CCI patients, when the scope of invasive life-saving procedures was significantly more restrictive.Only one recent study supported these earlier findings (Bashour et al., 2000).

Bashour et al., (2000) researched long-term survival and functional capacity in cardiac surgery patients after a prolonged stay in ICU. The research design was a cohort study at a tertiary hospital, measuring the following primary outcomes: ICU length of stay, hospital mortality, post-surgery and post-discharge mortality and functional capacity, and relative resource utilisation (Bashour et al., 2000). The study found that many patients who survived ICU died soon after discharge from hospital, and many had a poor functional state (Bashour et al., 2000). The study questioned whether the small number of CCI patients consumed a disproportionate amount of ICU and hospital costs and resources (Bashour et al., 2000).More recent research contradicts these findings by clearly articulating an 
improved quality of life and functional patient outcomes (Heyland, et al., 1998; Combes et al., 2003; Montelucard et al., 2000; Teno et al., 2000;).

Heyland, Konopad, Noseworthy, Johnston \& Gafni (1998) conducted an economic evaluation in the US, on the costs and consequences of caring for patients in ICU with a prolonged stay (>14 days) from time of admission until 12 months afterwards. Their study aimed to compare the cost and consequences of a policy of continuing to care for patients with a prolonged stay in ICU with a proposed policy of withdrawing care. Sixty one patients met inclusion criteria for the study. At the time of discharge from ICU 42 (68.9\%) were alive, and at discharge from hospital 34 (55.7\%) were alive (Heyland et al., 1998). One year later and only 27 (44\%) were alive. Of these survivors most were living at home and able to perform their usual activities. The study concludes that patients with a prolonged stay in ICU had a reasonable quality of life and treating these patients in ICU was deemed a reasonable and efficient use of hospital resources (Heyland et al., 1998).

When focusing on the multiple physical and psychological symptoms experienced by CCI patients, it is easy to assume that their quality of life will be poor after discharge from ICU and from the hospital. Several studies were located that explored this theory. Combes et al., (2003) conducted a cohort study in France, of 347 patients who received mechanical ventilation for $>14$ days. The aim of the study was to determine the outcome and healthrelated quality of life of this patient group. Prolonged mechanical ventilation was linked with impaired health-related quality of life, especially concerning pain, energy, sleep, mobility, emotional reaction and pulmonary function, compared with other ICU patients (Combes et al., 2003). Out of their sample of 87 patients all but one patient lived at home, three years after discharge from ICU. From this they concluded that the considerable financial and personnel resources invested in the CCI patient were justifiable (Combes et al., 2003). Applying these findings to New Zealand ICUs may be limited, due to the different health care, funding and staffing infrastructures. However, the high rate of survival speaks for itself, disputing assumptions that CCI patients have a poor prognosis.

Another French study examined the outcomes, functional autonomy and quality of life of elderly patients (>70 years) with a long-stay (>30 days) in ICU (Montuclard et al., 2000). A prospective cohort study design was used with a sample of 75 patients aged 70 years or older. Three quality of life scoring systems were used to accurately capture the findings 
from telephone interviews and questionnaires. Independence with activities of daily living were found to be significantly decreased, except for feeding, and most patients remained independent with the possibility of being discharged home (Montuclard et al., 2000). From these results the researchers argued that prolonged ICU stays for elderly patients were justified. Their findings are in keeping with the work of Combes et al., (2003) which strengthens the generalisability of these study findings. Replication of the interviews using the 3 quality of life scales would be achievable in New Zealand hospitals, which adds to the generalisability of the interview results.

Teno et al., (2000) similarly looked at decision-making and outcomes in patients who spent more than 14 days in ICU. They conducted a prospective cohort study at five teaching hospitals in the US. Inclusion criteria were all ICU patients with an ICU length of stay of 14 days or longer, who were enrolled in the SUPPORT trial (Study to Understand Prognoses and Preferences for Risks and Outcomes of Treatments). Patients, their surrogate decision-makers and their physicians were interviewed about prognosis, communication and goals of medical care. The SUPPORT prognostic model was used to estimate a 6-month survival, and hospital costs were estimated on hospital data (Teno et al., 2000). Fifty five percent of patients had died by 6 months and an additional 19\% had substantial functional impairment (Teno et al., 2000). At six months after discharge from ICU $12 \%$ participants reported an excellent quality of life, $51 \%$ had a good or very good quality of life and 38\% reported poor quality of life. Although the mortality rate at 6 months was 55\%, 63\% of remaining patients experienced a very good or excellent quality of life. Nurses equipped with this knowledge could plan care using multidisciplinary involvement to facilitate CCI patients' rehabilitation. Changing the focus of nursing care from fixing acute problems, to promoting rehabilitation would change how CCI patients are perceived and cared for by nurses. Rehabilitation of patients with CCI would instead focus on preventing complications, maximising mobility and self-care, as well as providing psychological support (Thomas, Kreizman, Melchiorre \& Ragnarsson, 2002). Rehabilitation approaches have been implemented in the US where specialist care units (SCUs) have been designed to look after CCI patients. 


\subsection{Treatment Programmes for Chronically Critically Ill Patients}

In the US, Care programmes have challenged the previous notion that CCI patients could only be looked after in ICU, by demonstrating that nurse-led care units increased patient satisfaction, but at a lower cost than traditional ICUs (Rudy et al., 1995). These care programmes are nurse-managed SCUs, designed specifically to meet the needs of this CCI patients and increase autonomy and decision-making by the nurses working in the SCU (Song, Daly, Rudy, Douglas \& Dyer, 1997). The SCU environment has minimal technology and encourages autonomy for nursing staff and patient-centred decisionmaking (Song et al., 1997). These programmes have shown progress in daily care and nurses’ knowledge of their CCI patients (Roulin \& Spirig, 2006).

Rudy et al., (1995) led a 4-year clinical trial in the US, comparing CCI patient outcomes when looked after in either an ICU or a Specialist Care Unit (SCU). Two hundred and twenty CCI patients were randomly assigned to either the ICU or SCU. The researchers compared the following patient outcomes: length of stay, mortality, complications, satisfaction, and cost (Rudy et al., 1995). There was no statistically significant difference between the length of stay, mortality, complications, and patient and family satisfaction between the two units. The SCU readmission rate (8\%) was significantly lower than the ICUs (20\%). Charges and costs per patient were 6-7\% lower in the SCU, and actual cost savings were \$5000 less per patient, than patients in ICU (Rudy et al., 1995). The SCU's cost $\$ 19000$ less than the ICU to produce a survivor. The study concludes that nurse managers in a SCU setting can produce cost-efficient patient-outcomes equal to or better than those in ICU for CCI patients (Rudy et al., 1995). The study equates these conclusions with collaborative care delivered in an environment purposely planned to have less technology, be more open to visitors, have less ambient noise and distraction. The purpose-built environments therefore produced better patient-outcomes because the specific needs of CCI patients were met.

In summary, studies exploring these care management models have indicated that nurses were more satisfied working in the specialist care unit (SCU) than in ICU and absenteeism was reduced (Douglas et al., 1996; Song, Daly, Rudy, Douglas \& Dyer, 1997).Although this research was primarily focused on comparing the environments of the SCU with ICU, 
there is acknowledgement that nurses' job satisfaction and absenteeism were intrinsically linked to caring for CCI patients in a suitable environment.

In one New York hospital, CCI patients are moved from ICU into a Respiratory Care Unit (RCU), where their care is coordinated by a nurse practitioner (NP) working within a multi-disciplinary team. The criteria for transferring patients to the RCU are not stipulated in the article, but the patients are admitted from ICUs within Mount Sinai Hospital and from other affiliated facilities (Carasa\& Polycarpe, 2004). The RCU aims to wean these patients from mechanical ventilation whilst providing quality care for all associated comorbidities. Emerging data from the RCU shows a decrease in the average length of stay of patients, from 33.3 days in 1995, to 25 days in 2001 (Carasa \& Polycarpe, 2004). The authors assert the reason for this improvement is due to the role of the NPs and collaboration between them, the nurses, therapists and consultant physician (Carasa\& Polycarpe, 2004).

In a Swiss hospital, rather than design specialist units, a nurse-led care program was implemented which identified key areas that needed to be developed to better look after CCI patients (Roulin \& Spirig, 2006). These were communication tools to help patients express their needs and desires; patient diaries to help patients know what happened during their ICU illness and reduce psychological morbidity following critical illness (Griffiths \& Jones, 2001), specialised patient history to inform the nurse about the patient as a person, not just a clinical entity; and weekly nursing rounds to improve care continuity, outcomes and coordination and increase staff professionalism (Halm et al., 2003). The impact of the programme has not been formally evaluated, but anecdotal evidence indicates improvements in daily care for not only CCI, but also all ICU patients (Roulin \& Spirig, 2006).

In New Zealand there are no care programmes, specialist care units or respiratory care units purposefully designed for CCI patients, but there are two specialist health units for specific patient groups. These include CAVIT Acquired Brain Injury (ABI) and Burwood. CAVIT ABI is a contracted provider for the Accident Compensation Corporation (ACC) and the Ministry of Health for active brain injury rehabilitation. Programmes involve a specialist team setting goals with the patient and family and coordinated by a key-worker 
and rehabilitation physician (http://www.cavit.co.nz/cavit/rehabilitation/intensive_rehabilit ation.html).

Burwood is a centre of excellence in Christchurch specialising in rehabilitation and elective orthopaedic surgery. They offer specialist facilities including a brain injury rehabilitation service, spinal unit and pain management. Patients spend between a few weeks to 18 months in the unit, re-learning essential functions, such as breathing and mobilising.

The admission criteria for both these facilities exclude CCI patients due to their health status. Although there are no purpose-built units to look after CCI patients in New Zealand, there are several tertiary level ICUs that care for them. The nurses who work in these ICUs manage as best they can to meet the unique needs of CCI patients, but their experiences of doing so have not been explored.

In order to gain an accurate understanding of the ICU nurses' experience of caring for CCI patients, it is necessary to explore three topics that are influential in how CCI patients are perceived. Firstly, inherent in ICU nurses' practice is autonomy and wanting to be in control. Second, the impact of work-related stress and compassion fatigue upon ICU nurses is pivotal in how nurses cope with stressful situations. This leads to discussion linking vicarious traumatisation with potential effects on nursing experiences. Thirdly is withdrawal-of-care and palliation and how they share some similarities in practice and nursing management with CCI patients.

\subsection{ICU Nurses Autonomy and Control}

Autonomy is commonly associated with a nurse's ability to make decisions based on professional judgment, and then act on these decisions within their scope of practice (Wilkinson, 1997). Autonomy is generally considered a positive and desirable component within nursing (Ballou, 1998) and has been linked with increases in job satisfaction and well-being (McCloskey, 1990). Nurses who work autonomously carry out their duties in a self-determined manner with control over work activities (Varjus, Suominen \& LeinoKilpi, 2003).A lack of autonomy among nurses has been identified as a significant cause of job dissatisfaction and as a reason for leaving a job (Blegen et al., 1993). Restricted 
involvement in decision-making for patient careis a common example of nurses lacking autonomy (McGrath, Reid \& Boore, 2003). Often this is due to inadequate working relationships between the doctor and nurse. As a close doctor-nurse relationship is essential in intensive care, there is risk that poor inter-professional working relationships develop, unless a more effective way of team decision-making could be developed (Coombs \& Ersser, 2003).

In a study by Hurst and Koplin-Baucum (2005), nurses reported a need to control certain aspects of the ICU patient. Nurses associated being in control of a shift with the successful completion of tasks that led to feelings of happiness and accomplishment (Hurst \&KoplinBaucum, 2005).In a multi-centred study in Sweden and England, nurses were interviewed and found to have conflict between patient interests and those of other people, such as physicians, relatives and other patients (Elander, Dreschler \& Persson (1993) These were identified as ethical problems and were complicated by competing loyalties and role conflicts (Elander et al., 1993).

Nurse autonomy was researched in relation to interdisciplinary teamwork, nurse outcomes and nurse assessed quality of care, in a multi-centre study in England (Rafferty, Ball \& Aiken, 2001). Postal questionnaires surveyed 10022 staff nurses in 32 hospitals. Nursing autonomy was positively correlated with improved perceptions of the quality of care delivered and higher levels of job satisfaction (Rafferty et al., 2001). A strong association was made between autonomy and teamwork, suggesting a synergistic working relationship (Rafferty et al., 2001).

\subsection{Work-related Stress, Compassion Fatigue and Vicarious Traumatisation}

It is widely acknowledged that nurses experience work-related stress, otherwise known as compassion fatigue, compassion stress, emotional contagion or the cost of caring (Sinclair \& Hamill, 2007). Commonly identified causes of stress are workload, patient care, interpersonal relationships with colleagues, knowledge of nursing and nursing skills, types of nursing and bureaucratic-political constraints (Bailey, 1985). Nurses have been found to alleviate work-related stress by avoidance strategies (McGrath et al., 2003). Work-related stress involves a gradual wearing down of an individual over time, whereas compassion 
fatigue has an acute onset (Sabo, 2006). The presence of work-related stress increases the likelihood of developing compassion fatigue (Sabo, 2006).

Caring for patients with chronic illnesses, who may never fully recover has been recognised as extremely challenging for care providers, yet the continuation of individualised treatment is critical to the patient's health (Figley, 1998). As the longevity of ICU patients increases, so has the likelihood for nurses to have increased and prolonged exposure to suffering and/or dying patients (Meadors \& Lamson, 2008). The terms compassion fatigue and secondary traumatic stress have been used to describe the effects of prolonged exposure to trauma (Figley, 1998). Compassion fatigue is an occupational risk to all professionals who provide direct or indirect care patient care (Figley, 1995). Long-term effects of compassion fatigue upon nurses include suppressing emotions, reluctance to acknowledge they are experiencing trauma and distancing themselves from patients (Badger, 2001). Nurses often move from one traumatic event to another without taking time to assess their responses and thereby unwittingly increase chances of having a delayed response to traumatic situations (Badger, 2001). In distancing themselves from patients, nurses might believe they are protecting themselves from emotional injury, yet they avoid all but the most essential personal exchanges, thus diminishing the value of the nurse and compromising the welfare of the patient (Badger, 2001).

The implications of compassion fatigue on nurses caring for CCI patients are significant. If the nurse is unaware of his/her internal coping strategies when working with CCI patients, the quality of care they provide may be compromised. Linked with nurses' coping strategies istransference. This term refers to an unconscious transferring of experiences from one interpersonal situation to another (Jones, 2004). The nurse reassigns feelings, thoughts and attitudes from an original situation to the present, thus influencing the development of relationships with others (Jones, 2004). Positive transference can show in feelings and actions of love, altruism and admiration, whereas negative transference can lead to negative feelings of mistrust, hostility and hatred (Coren, 2001). For example, if a nurse endures a traumatising experience with one CCI patient, the negative feelings from this experience could be transferred onto subsequent CCI patients. It is therefore important that nurses recognise both positive and negative feelings that may influence their working relationships (Jones, 2004). Five strategies have been suggested to help lessen the harmful 
effects of traumatic stress: self-care techniques, informal support, formal psychotherapy, education and maintenance of realistic goals (Badger, 2001).

In addition to this, there is the concept of vicarious traumatisation: the process through which a carer's inner experience is negatively transformed through empathic engagement with patient's traumatic experience (Pearlman \& Saakvitne, 1995a). Although this might be considered a tenuous link, there are some interesting parallels with nursing CCI patients that warrant discussion. As Sinclair \& Hamill (2007) observe, trauma not only affects the person who is present, but also those with whom they discuss their experience. To illustrate, an ICU patient might be traumatised as a result of prolonged mechanical ventilation and shares this impact with the ICU nurses, which could lead to a risk of vicarious traumatisation in this population of nurses. The impact of vicarious traumatisation results in profound changes in the carer's frame of reference, self-capacities, ego resources, psychological needs and cognitive schemas, and imagery, as summarised in Table 3 (Pearlman \& Saakvitne, 1995a). 
Table 3 Impact of vicarious traumatisation upon carer (Pearlman \& Saakvitne, 1995a).

\begin{tabular}{|c|c|c|}
\hline $\begin{array}{l}\text { Area of change } \\
\text { affected }\end{array}$ & Components of change & Changes in self \\
\hline Frame of reference & $\begin{array}{l}\text { Disruption in one's sense of: } \\
\text { Identity } \\
\text { Worldview } \\
\text { Spirituality }\end{array}$ & $\begin{array}{l}\text { Feeling disconnected } \\
\text { Feeling confused and sorrowful } \\
\text { as worldview has been } \\
\text { challenged } \\
\text { Experience despair, confusion } \\
\text { and helplessness. }\end{array}$ \\
\hline Self-capacities & $\begin{array}{l}\text { Intolerance } \\
\text { Inability to control negative } \\
\text { emotions }\end{array}$ & $\begin{array}{l}\text { Loss of self-esteem, anxiety, } \\
\text { critical of self, loneliness }\end{array}$ \\
\hline Ego Resources & $\begin{array}{l}\text { Disruption in personal growth } \\
\text { and awareness of personal } \\
\text { needs }\end{array}$ & $\begin{array}{l}\text { Overworking, poor decision- } \\
\text { making, insensitive to own } \\
\text { needs }\end{array}$ \\
\hline $\begin{array}{l}\text { Psychological needs } \\
\text { and cognitive } \\
\text { schemas }\end{array}$ & $\begin{array}{l}\text { Disruption to: } \\
\text { Safety } \\
\text { Trust } \\
\text { Self-esteem } \\
\text { Intimacy } \\
\text { Control }\end{array}$ & $\begin{array}{l}\text { Increased fearfulness, not } \\
\text { trusting own instincts } \\
\text { Feels less independent, doubts } \\
\text { own feelings } \\
\text { Lower self esteem, devalues } \\
\text { other's interests } \\
\text { Blocking of one's innermost } \\
\text { feelings, loss of pleasure with } \\
\text { hobbies } \\
\text { Decreased sense of control in } \\
\text { their lives }\end{array}$ \\
\hline Imagery & $\begin{array}{l}\text { Activation of a personally } \\
\text { traumatic memory }\end{array}$ & $\begin{array}{l}\text { Images evoked can stay with } \\
\text { person after contact with } \\
\text { patient }\end{array}$ \\
\hline
\end{tabular}


Vicarious traumatisation affects therapists or carers in different ways. Although this topic is relatively new to research, emerging data shows that therapists may experience general feelings of sadness, despair or lacking energy (Sinclair \& Hamill, 2007), decreased ability to live fully, love, work, play and create (Pearlman \& Saakvitne, 1995b) and increased use of alcohol and drugs, detachment, loss of empathy, avoidance and guilt (Young, 2003). As many of the effects of vicarious traumatisation are cumulative, there are significant implications for how this might affect the workforce within ICUs caring for CCI patients.

\subsection{Withdrawal of Care and Palliation}

Three articles relevant to withdrawal of care in ICU were explored to draw parallels with management of CCI patients. Firstly, a study by Beckstrand, Callister \& Kirchhoff (2006) established critical care nurses ideas for improving end-of-life care. Critical care nurses felt that ensuring patient's dignity and comfort, making environmental changes, managing patient's discomfort and promoting family presence, all improved end-of-life care in ICUs (Beckstrand, Callister \& Kirchhoff, 2006).

A study describing nine nurses' experiences of caring for dying patients in an ICU (Fridh, Forsberg \& Bergbom, 2009), revealed several similar experiences to those of the participants in Beckstrand et al.,'s (2006) research. The physical environment of ICU can have a major impact on the nurses' ability to provide dignified care for patients and their families, particularly if there is a lack of private rooms and restrictions tovisiting family members (Fridh et al., 2009). Other key findings included prioritising patient's comfort and dignity, caring for family and caring for unaccompanied patients (Fridh et al., 2009).

A recent study in a New Zealand ICU compared belief and practice between doctors and nurses concerning withdrawal of active treatment (Psirides \& Sturland, 2009). Questionnaires and auditing of medical notes were used to determine that a wide disparity in belief and practice, with variable documentation regarding end-of-life decision-making (Psirides \& Sturland, 2009). The study concludes with 
recommendation for a standardised approach to improve communication between medical and nursing staff (Psirides \& Sturland, 2009).

Two articles were located specific to palliative care opportunities for the CCI patient. The first is a case study by Koesel (2008), who argues that due to the significant psychological and physical symptom burden as well as distress associated with prolonged impaired communication, there is an opportunity for palliative care involvement with CCI care. As symptom management and communication are primary focuses of palliative care providers, these are transferable to CCI patient management and can be used to ensure ongoing clarification of goals and communication surrounding the patient's wishes and needs (Koesel, 2008). Koesel (2008) uses the one-year survival as the outcome marker to strengthen her case, reminding readers that as little as $10 \%$ of CCI patients are home with an independent functional status after 1 year. With this is mind, there is an increasing burden upon health professionals, families, and society to provide ongoing care for these complex patients (Koesel, 2008). Koesel (2008) asserts the need to ensure optimal communication among clinicians, patients, and families to establish long-term goals and maximize CCI patients' quality of life. The author is careful to focus on symptom burden rather than care of dying patients, which is an important distinction, lending support to the argument that there is scope for palliative care involvement within the management of CCI patients care.

A further study by Nelson (2002) discusses the prognostic uncertainty of knowing only in retrospect that a patient was actively dying while life-prolonging interventions were aggressively pursued. Rather than inflict this paradigm upon CCI patients, Nelson (2002) argues that a more appropriate model of care is required, with aggressive management of communication and comfort needs of patients and family. The discussion then explores symptom experience, assessment and management before articulating how to set patient goals with consideration to patient-centred decision-making. The article concludes with a more positive view of outcomes of CCI patients, stating that palliation need not be associated solely with the end of life, but can assist with active efforts aimed at achieving favourable outcomes, such as to liberate patients from mechanical ventilation. 
From these two perspectives, the integration of palliative and critical care seems reasonable for CCI patients.

\subsection{Summary}

This chapter has described and critiqued literature concerning the CCI patient, their clinical profile and experiences, financial and staffing costs, quality of life and treatment programmes related to this patient group. It was difficult to extract a clear definition of chronic critical illness from the literature. When identifying CCI patients the length of ICU stay varied considerably between studies (three, five, ten, fourteen or twenty eight days). Some used tracheostomy insertion to define the onset of CCI. This indicates a lack of clarity regarding who exactly this patient group encompasses.

CCI patients are increasing in number and this trend is set to continue. This has a direct impact on ICU costs both in terms of actual expenditure and burden of care to nurses and physicians. (Daly, Rudy, Thompson \& Happ, 1991). These patients have been presented as a complex patient group. In a working environment where turnover and shortage of nursing staff is evident and predicted to worsen, there is cause for real concern about future resourcing for this patient group.There is sparse evidence describing the experiences of ICU nurses caring for CCI patients and no research studies were located. Given the complexity of this patient group, it is interesting that no previous studies have sought to explore the experiences of CCI patient healthcare providers. The absence of research focusing on nurses' experiences of caring for CCI patients has been identified as a gap in the literature. It is the intention of this study to explore this previously un-researched topic. It is timely to be carrying out this research given the emerging numbers in this patient group and the trend towards worsening ICU staffing retention and recruitment. Chapter Three describes the qualitative methodology used in this study to answer the research question. 


\section{CHAPTER THREE}

\section{METHODOLOGY AND STUDY DESIGN}

\subsection{Introduction}

This chapter begins with presentation of the research aims. A brief explanation of theories supporting the research approach is provided, describing the reasons for using an exploratory descriptive research design to study the research topic and aims. An overview of the methodological approach is presented with rationale for using semi-structured interviews as the data collection method. This leads to the process of how the semi-structured interviews were developed in order to gain as much insight into the participants' experiences, and thereby answer the research question. The participants are then described, with reference to inclusion and exclusion criteria of the study, representativeness and the sampling process. The research process section then explores the settings of the study and the participant recruitment process. A brief introduction to the data analysis approach is outlined, before exploring the quality and reliability of the study. This section finishes with an explanation of the ethical considerations that were required for completion of the research and establishes the quality and reliability of the study.

\subsection{Research Approach}

\subsubsection{Exploratory descriptive research}

Qualitative research has several general characteristics, including having a holistic approach, being flexible and capable of adjustment during data collection and the requirement for the researcher to become intensely involved and become the research instrument (Polit \& Beck, 2004). Qualitative research methodologies can be broadly categorised into either critical or interpretive. Critical methodologies have social change as their primary agenda, whereas interpretive methodologies seek to raise awareness of topical issues through exploration and description (Roberts \& Taylor, 2002). Descriptive research has historically been classified under the interpretive category, and used as a starting point for studies, such as grounded theory inquiry. Description in social sciences and nursing research, has been relatively 
unacknowledged as a distinct method of equal standing, compared with other qualitative methods, such as grounded theory, phenomenology and ethnography (Sandelowski, 2000). A qualitative descriptive study is the methodology of choice when descriptions of an experience or phenomena are desired (Sandelowski, 2000). Qualitative descriptive studies provide a comprehensive summary of an experience, in everyday terms, thus describing what has been found and exploring what is already there (Sandelowski, 2000).

\subsubsection{Justification for qualitative descriptive research methodology}

When reviewing the literature to prepare for the design of this study, it became apparent that a variety of methods had been used when researching CCI patients. As several studies were focused on clinical outcomes, the quantitative approaches of cohort studies were appropriately used. My interest, however, concerned the nurses' experiences, rather than measurable outcomes. The research topic was inappropriate for a quantitative methodological approach for several reasons: the findings of the research would not be quantifiable with numbers and pre-selected variables using statistical analysis (Gillis \& Jackson, 2002), quantitative description limits what can be learned about the meanings each participant gives to events (Sandelowski, 2000), quantitative description is less interpretive than qualitative description (Sandelowski, 2000) and there is less room for the unanticipated discussion (Becker, 1996).Unanticipated discussion is when the participant talks freely about topics important to themselves, that are not in keeping with the research topic (Becker, 1996).

This led me to pursue a qualitative design as this approach emphasises the accurate portrayal of the experience of each participant being studied (Gillis \& Jackson, 2002) and ascertains a straight description of the events of the phenomenon. Descriptive studies typically describe what is (Gillis \& Jackson, 2002). The what is factor concerning this study is uncovering what is the experience of ICU nurses' looking after CCI patients? Using this qualitative approach will allow the collection of as much data as possible, thus capturing all elements of the nurses' experiences, and providing an accurate description of the experience of nursing CCI patients (Sandelowski, 2000). 
According to the hierarchy of evidence descriptive studies are positioned on the lowest rung of the ladder, and are therefore considered by many as the crudest form of enquiry (Thorne, Kirkham \& MacDonald, 1997).However, as Sandelowski (2000) argues, descriptive studies yield valuable information for practice, and are capable of producing a complete and valued end-product in themselves.As there is so little knowledge surrounding this research topic, using a descriptive methodology will provide a useful starting point on which to base other higher quality research studies.

\subsubsection{Qualitative methods}

Choosing a method that is congruent with the exploratory descriptive methodology is important. In order to generate knowledge under the descriptive theoretical framework, a method should be used that fits in with the type of knowledge sought (Roberts \& Taylor, 2002). The three main qualitative methods are: participant observation, focus groups and interview. These are briefly described and their suitability to this study explained.

Participant observation requires the researcher to become involved in the action within a setting, whilst observing the details within it (Roberts \& Taylor, 2002). This method requires the researcher to spend time settling into the environment before the study begins, so that the participants get used to having the researcher present. This method was considered for this study, as this method would explore not only the actions and behaviour of the nurse, but also the setting and the impact this has on the participant. It was felt that participant observation would take a considerable amount of time to set up and implement, especially as it is acknowledged that it takes time for people to get used to having the researcher present. Also, this method would not delve deeply into the experiences and feelings of the nurse, rather it would pay attention to the observed practices, which would not be helpful for answering the research question.

Group processes,namely focus groups, are group interviews that aim to understand the social dynamic and interaction between participants, through the collection of observational and verbal data (Redmond \& Curtis, 2009). At first the idea of using focus groups to generate thoughts and share knowledge about caring for CCI, seemed ideal. Logistically group interviews appeared easier to arrange than individual 
interviews. Concerning data collection there was potential for dynamic group discussion thatmight generate ideas and honest debate. However, after reading literature surrounding qualitative methods, significant limitations to this method became apparent: participant recruitment is often complex to organise and less depth and detail about issues and the participant is provided (Redmond \& Curtis, 2009). There were several factors that would have made it difficult for me to arrange group interviews. These include identifying suitable participants, coordinating the hire of an interview venue with negotiating an agreed time and date that suited each participant In light of shift patterns and short-staffing, the successful organising of group interviews within the time restrictions of this thesis was not achievable.

Another concern was that despite the focus group providing a wide range of experience, it might fail to delve deeply into the individual's experience, given the public nature of the focus group (DiCicco-Bloom \& Crabtree, 2006). This issue was important, because while some participants might feel supported or empowered during a group interview, others may not want to share sensitive information in a group, because of risk to their emotional safety (Whiting, 2008).

\subsection{Research Design}

This study has used an exploratory descriptive methodology, with semi-structured interviews as the method for data collection. In additionintensive care unit (ICU) databases at the North Island ICU (NID) and South Island (SID) were accessed to ascertain the incidence and types of patient who are chronically critically ill(CCI). This data has been presented in tables and provides background context to the study. Data detailing participant demographics and exposure to CCI patients was acquired during the interviews, to provide background and context to their experiences. The study was advertised to prospective participants using flyers, which were displayed in their ICU.

The overarching aim of the research is to explore and describe ICU nurses' experiences of looking after CCI patients. Having established both CCI patients as a complex group and that nurses' experiences of caring for them is poorly researched, the dominant focus of this study concerns discovering difficulties nurses experience 
when meeting CCI patient needs. A lesser focus is to discover ICU nurses' perceptions of CCI patient needs. The research aims were to:

1. Identify the influencing factors that affect the nurses' experience of caring for chronically critically ill patients.

2. Ascertain the availability and use of resources that ICU nurses' access when planning and implementing care to CCI patients.

3. Explore ICU nurses' perceptions of CCI patient experience.

4. Explore topics of interest that are brought up by the participant in relation to CCI care.

5. Generate ideas for how nursing care of CCI patients might be improved.

It was important to gain as much detail concerning the nurses' experience as possible, and encourage the disclosure of difficult concepts.

The focus group method seemedunlikely to provide sufficiently detailed data, which led me to consider face-to-face interviews. Interviews can be structured, unstructured or semi-structured and involve the researcher asking the participant purposeful questions, with a view to investigate a research problem (Roberts \& Taylor, 2002). The structured interview follows a list of set questions using a strict format, and is more usual in quantitative research. I did not want to constrain the participants' answers or miss out on spontaneous discussion so this method was not chosen for the study. Semi-structured and unstructured interviews are useful in qualitative research as they encourage in depth exploration of a topic. Unstructured interviews are most widely used in ethnographic studies, and in conjunction with the collection of observational data over time (DiCicco-Bloom \& Crabtree, 2006). Semi-structured indepth interviews are the most common interviewing technique used in qualitative research, and are usually organised around a set of open-ended questions, with free dialogue directing some of the discussion (DiCicco-Bloom \& Crabtree, 2006). Interviews typically progress according to the developing stages of rapport: apprehension, exploration, co-operation, participation and conclusion. Developing rapport with the participant is essential in interview as it creates a trusting, respectful relationship, where the participant feels comfortable sharing information and personal experiences (DiCicco-Bloom \& Crabtree, 2006). 
There are many types of question that can be used during interviews, including closed, open-ended, presence-absence, rank-ordering and index development (Gillis \& Jackson, 2002). Open-ended questions are preferred if the researcher does not wish to impose responses on the participant, but wishes to encourage the participant to reflect on and identify their true feelings (Warren \& Karner, 2005). This type of question is therefore ideal for semi-structured interviews in which the researcher seeks to encourage dialogue. 'Prompt' questions are also invaluable during the interview as they help the interviewer gain more information if the participant does not provide detailed answers, and ensures key issues are addressed (Whiting, 2008). Closed questions are useful at gaining factual and demographic data, which allows comparability of responses thus facilitating analysis (Gillis \& Jackson, 2002).

\subsubsection{Benefits and risks associated with interview}

Interviews encourage individuals to think and talk about their needs, wants, expectations, and understandings at both conscious and unconscious levels (Nunkoosing, 2005). This is important for descriptive studies that seek to unpack the whole story surrounding an event or phenomenon.

Interviews can be quick to organise. Appointments are easier to negotiate with each participant, as the researcher deals solely with each individual, rather than large groups of people. Interviews also allow questions to be adapted, so that ineffective questions can be avoided and new ones added (DiCicco-Bloom \& Crabtree, 2006). Overall, interviews generate good quality data, since the interviewer can clarify questions and answers to promote more accurate results (Harwood \& Hutchison, 2009). Finally, interviews allow the interviewer to delve deeply into social and personal matters and provide the participants with a platform to elaborate and digress, which can be productive as they explore the participant's interest and knowledge (DiCicco-Bloom \& Crabtree, 2006).

In-person interviews generate verbal and non-verbal communication, which can potentially bias the experience of both the participant and interviewer (Harwood \& Hutchison, 2009). With regard to how this affects the validity of the data findings, the interviewer needs to be explicit with descriptions of their own characteristics, since their actions and words affect the participant's responses (Harwood \& 
Hutchison, 2009). This means that any bias, leading questions or manipulating prompts need to be articulated in the report. Field-notes can be a useful way for researcher's to reflect upon any communication bias (Whiting, 2008). Less structured interviews require an element of expertise from the interviewer, in the handling of open-ended and probe questions. Novice interviewers often find it difficult to know how far to probe during interview, which may lead to potential information not being shared by the participant (Whiting, 2008). When using prompt questions, caution should be given to inadvertently leading the participant. The interviewer should be aware that their expectations could affect the participant’s reply (Whiting, 2008).

\subsubsection{Justification for semi-structured interview design}

In a study exploring ICU nurses' experiences, semi-structured interviews were used effectively to obtain information relevant to the study (Price, 2004). This led me to explore the benefits of semi-structured interview strategies. The rationale for choosing semi-structured interviews for this study centres on the current absence of knowledge and understanding of nurses' experiences of caring for CCI patients. Using a semi-structured format with open dialogue would allow for a range of questions to be asked covering all the necessary topics, thereby addressing the aims and objectives of this study.

The next decision was whether to conduct the interviews in person, via telephone or video-link. This decision was predominantly dictated by the size and scope of this thesis project. The expense and logistics of videoconferencing produced many reasons why this method was not chosen. Face-to-face interview was felt to be the most suited method as this was affordable, logistically easy to organise, would make the best use of time and allow rapport to develop quickly with participants. Although rapport can be gained through telephone interviews, I felt that visible social and nonverbal cues, gestures and facial expressions, would be missed if a face-to-face interview were not carried out (Pitts \& Miller-Day, 2007). Although these cues and gestures are not critically appraised in this research, they contribute to the overall feeling and attitude of the participants and add meaning to their answers.

As part of the interview design the location of each interview was considered as an important aspect. ICUs are typically busy, noisy places where constant alarms and 
interruptions might impede the flow and concentration that would be required in order to get the most from each interview. It is recommended to conduct interviews in a quiet, private room that is comfortable (Burns \& Grove, 2005). A low stimulus environment would encourage the participants to concentrate on the discussion topics and fully engage with informative answers (Burns \& Grove, 2005).

\subsubsection{Sampling}

Sampling refers to the process of selecting participants from a population for inclusion in a study (Hammersley \& Mairs, 2004). Qualitative approaches typically use purposive sampling (Patton, 1990). The ultimate goal of purposive sampling is to gain participants deemed information-rich for the purposes of the study, rather than produce findings that are generalisable to a population (Sandelowski, 2000). Qualities of suitable participants for interview include being knowledgeable about the topic, able to reflect and provide experiential information and be willing to talk (Morse, 1991). Purposive sampling identifies potential participants and provides them the opportunity to voluntarily choose to participate in the study. The sampling process for the study was purposive as a specific nursing group (ICU) was identified.

In qualitative research, the sampling process is largely determined by the type of methodology and the topic under investigation (Higginbottom, 2004). The target population for this study is defined as 'ICU nurses that look after CCI patients.' The accessible population in this group refers to those ICU nurses who the researcher can feasibly access (Gillis \& Jackson, 2002). In this case, the accessible sample refers to all ICU nurses from the two tertiary level ICUs in New Zealand. This sample group was ideal for the study as it presented access to ICU nurses who would have a raft of experience caring for CCI patients.

The interest of this research lies in understanding the meaning of the participants' experience, rather than trying to generalise the results to a larger population. The results of this study cannot be generalised to the target population (Creswell, 1998), however, the sample was large enough to generate a sufficient volume of detailed information that allowed meaningful analysis and discussion of the results. The sample size was appropriate for the scope of the 90-point thesis, for which this research was conducted. 


\subsection{Participant Recruitment and Inclusion Criteria}

To be included in the study participants must have worked as a registered nurse in ICU for at least 1 year and have cared for a CCI patient within this period.

The recruitment process for willing volunteers to participate in this study, started after access had been gained to NID and SID through the Directors of Nursing (DoN). Several strategies were employed to recruit participants including a flyer (Appendix 1) advertising the study. Secondly the unit leaders promoted the study in the ICU newsletter and at the Unit staff meetings. The flyers specified contact e-mail and phone details. This generated one volunteer from NID and none from SID. The clinical nurse leaders (CNL) of both ICUs were asked to e-mail a list of staff with $>1$ years ICU experience. Both CNLs declined this request preferring instead to encourage participation from staff by displaying the flyer and advertising it in the ICU newsletter. The Associate Charge Nurse Managers (ACNMs) and clinical nurse educator (CNE) at NIDdisplayed the flyer alongside an envelope containing participant information (Appendix 2) and research synopsis (Appendix 3). This also generated no volunteers.

Anotherrecruitment strategy was to meet with staff and explain the study. I spent two full days at each ICU. I introduced myself and presented the study to staff in person during morning tea and handover. This provided a good environment to initiate conversations and generate interest in the study.

To be included in the study participants must have worked as a registered nurse in ICU for at least 1 year and have cared for a CCI patient within this period. The inclusion criterion was based on my assumption that a year would have allowed each nurse sufficient time to care for a CCI patient. When recruiting at NID one nursehad worked there for less than 6 months but had cared for CCI patients. I reasoned the most important factor for participant inclusion was the experience of caring for CCI patients. I therefore enrolled this nurse in the study. I then wrote to the Ministry of Health who advised that the participant's results could be included in the thesis, at the discretion of the researcher (Appendix 4). However, due to time constraints for 
completing the thesis, re-submission of the multi-region ethics application was not achieved. The data pertaining to participant N1 has therefore not been included.

In order to capture the spoken words of participants, I had arranged to use audio-tapes and transcription. The use of these data collection and reporting methods were explained to each participant as part of the recruitment process and when obtaining consent for interview.

\subsection{Application of Research Process}

\subsubsection{Settings of the research}

The research was conducted in ICUs at two tertiary hospitals (one North Island, one South Island). In order to maintain confidentiality, the North Island ICU was coded 'NID' and the South Island ICU as 'SID'.These sites were selected from a total of five tertiary level hospitals in New Zealand.Verbal consent from the Director of Nursing and CNL from each hospital was gained, which allowed access to the ICU databases and the ICU nurses.

NID and SID were chosen for a number of reasons: both are large units and provide tertiary level care. ICUs in regional hospitals are unlikely to care for many CCI patients, as patients that need prolonged ventilation would be transferred within a short period of time to a tertiary hospital (http://executive.govt.nz/9699/minister/english/hsp/framework.htm, accessed $25^{\text {th }}$ June 2009). The selected tertiary hospitals have a large number of nursing staff with a range of skill and experience, which increased the likelihood of finding suitable participants for the study. I felt that conducting the research in the ICU where I work might risk exposing participants to bias and confidentiality issues. As noted by McEvoy (2001), work colleagues might be willing to participate, but the interviews might not reflect a genuine situation. Choosing ICUs where my opinions about caring for CCI patients were not known would also eliminate bias.

No participants from SID responded to the flyer advertisement; one participant volunteered from NID. The reason for this poor response is unclear.All other participants were recruited after meeting them at shift handover and morning tea, where I was able to briefly outline the aims of and importance of my research. 
During this recruitment process I was concerned that my eagerness to find willing volunteers might risk me sharing my own views and assumptions about CCI patients. This could potentiality influence the participants and affect their answers during the interviews. I discussed this potential problem with my Supervisor and we agreed that after introducing myself, I would use the research synopsis to outline the key aspects and importance of the study. This proved to be the most successful means of recruiting participants and worked well in maintaining objectivity. I did not feel at any of these meetings that I imposed my views on the nurses.

The interview settings varied at each site. NID and SID gave assurance that a suitably quiet room would be provided where the interviews could proceed without distraction or interruption.Interviews at SID were carried out in a quiet seminar room, adjacent to the clinical work areas. By contrast, the interviews at NID were conducted at the bed spaces. Attempts were made to find a quiet interview room, but these had to be frequently vacated to allow family meetings.

\subsubsection{Participant confidentiality and consent}

Confidentiality of the participants was achieved by coding the data so that the participants were not identifiable. Participants from the North Island ICU were coded N1, N2 and N3; and participants from the South Island were coded S1, S2 and S3. It was important to ensure that participants could not be identified through their answers, so all identifying features of each participant were removed to maintain confidentiality.In the transcripts participants were referred to using their code.Access to the audiotapes and transcriptions were limited to my University supervisor and me to maintain privacy and confidentiality of participant answers.

At the beginning of each interview, participants were given a detailed synopsis of the study, an information sheetoutlining the research topicand a consent form to sign (Appendix 5). Permission to audiotape the interview was obtained, explaining that the tape recording could be stopped at any time and the participant could withdraw from the study at any time. It was explained that as primary investigator, I would transcribe the tapes and that no other persons would listen to them. Consent for a follow-up telephone interview, in the event that clarification of answers was required was also obtained. 


\subsubsection{Semi-structured interviews: design and process}

The semi-structured interviews used questions that answered the research question by addressing the aims. The questions were informed by findings from the literature review and from expert opinion concerning research methods. The interview questions (Appendix 6) comprised a mixture of open and closed questions, which allowed guidance through key topics, yet encouraged spontaneous exploration of topics that arose during the interviews. During the opening few moments of each interview it was important to find an effective way to ease the participants into talking. An effective method was to ask a series of closed questions concerning their level of experience, how many years they had worked in ICU and the number of CCI patients they had looked after in the previous 12 months. This technique was useful in learning background information about the participant and getting them used to sharing details about themselves. A short definition of chronically critically ill patients was provided before proceeding with the interview questions. Providing a definition at the onset of the interview helped focus each participant on the types of patient who fitted this description, and reassured them of the purpose and direction of my inquiry.

Interviewing each participant face-to-face had additional advantages. I was able to visit the physical ICU environment and gain first-hand insight into some of the practical issues that were discussed in the interviews. When participants referred to physical attributes of the ICU I was able to confirm straight away what they were saying (Whiting, 2008). The power differential between the participant and myself was most evident at the start of each interview, before a trusting rapport had developed. Mid-way into the interviews the participants became familiar and more confident with the subject matter and a trusting relationship was established. In my opinion this led to honest examples of practice and personal experiences being shared, from which exploratory discussions developed. The audiotape was unobtrusive and did not cause stress to any of the participants, and avoided unnecessary interruptions of having to stop and write notes. Interviews lasted between 30 to 50 minutes.

Each interview had a core set of questions that covered the main topics identified in the literature review. The interviews explored each participants’ experience of: 
- looking after CCI patients

- familiarity with evidence-based recommendations

- teaching and resources they have accessed

- their focus of care

- how they felt they could improve their care to CCI patients.

The majority of questions were deliberately open, to reduce apprehension and encourage the participant to share as much of their personal experience as possible. I found the most effective way to encourage dialogue, was to ask one of the following two open-ended questions:

- Can you tell me about your experience of caring for CCI patients?

- Think about the last CCI patient you looked after and describe to me this experience: what went well, what didn't go well or caused frustration?

In answering these, participants focused on topics that were meaningful to them. Sometimes several topics were covered in their first answer. When asked how participants felt when allocated a CCI patient, the speed of answer was consistently fast, with repetition of the answer to emphasize the response. Often participants seemed more at ease talking about patient experiences than their own. Re-directive statements were successfully used to return the focus onto the nurse. For example, when asked to describe important nursing aspects of caring for CCI patients, participants would instead talk about patient issues. Prompts required during interviews included emotional aspects of nursing CCI patients.

When changing topics, it was useful to remind participants of an interesting issue they had mentioned earlier, and use the identified issue to proceed with interviewing. This helped participants feel listened toas the next question focused on a topic they had themselves raised. This gave the interviews a spontaneous and fluid direction that was unique to each participant. Usually after participants had answered longer open questions, a shorter-answered question was offered, so changing the topic and helping participants re-focus. Closed questions sought to establish whether there were care plans and training resources for the nurses to use when looking after CCI patients and 
how nursing care differed between CCI and other ICU patients. Participants were then asked to explain their answer more fully.

Each interview uncovered topics of interest that were particularly meaningful to the individual participant. These differed from person to person, and varied from explaining personal dislikes, to suggesting solutions for improving patient care. No matter how different these topics were, the level of passion and importance placed on these issues was consistently high. Once the participant identified such an issue it was difficult to move them forwards from this point, and frequently this topic would be returned to throughout the remainder of the interview.

Each interview closed with an invitation to the participant to share any further thoughts concerning CCI patients they felt were important. This drew each interview to a natural conclusion, at which point the tape recorder was stopped. Participants were thanked for participating in the study and asked if they wanted a copy of the findings on completion of the thesis.

\subsubsection{Data management}

Two recording devices were used to prevent potential loss of data. The audio-tapes were coded, so that the original name and identifying features of each participant were removed, thereby protecting the identity of all involved. Storage of the audiotapes, transcriptions and database information were in a lockable filing cabinet in the Research nurses' office. Access to the data was limited to the primary researcher and University Supervisor. The audiotapes were wiped once the thematic analysis was complete and all printed material needing to be discarded was shredded on site after the data analysis chapter had been written.

\subsection{Data Analysis}

Sandelowski \& Barroso (2003) classified five typologies of qualitative findings as: no finding reports, topical survey, thematic survey, conceptual description and interpretive explanation. Neither no finding reports or topical survey are considered true types of qualitative finding as the data is simply reproduced with minimal interpretation, or presented as lists of identified variables (Sandelowski \& Barroso, 2003). For this reason they are not considered appropriate methods for analysing this 
study's data. Thematic survey moves away from merely listing topics toward describing themes and offering more penetrating descriptions (Sandelowski \& Barroso, 2003). The goal is to provide knowledge and understanding of the phenomenon under study (Downe-Wamboldt, 1992). For this reason thematic survey is the most suited method for analysing the findings of this study.

There are three approaches to thematic survey (content analysis): conventional, directed and summative. In conventional content analysis, categories are derived from data during data analysis, thus presenting the researcher with a richer understanding of the phenomenon (Hsieh \& Shannon, 2005). This approach is appropriate when existing knowledge, literature and theory surrounding a phenomenon is limited (Hsieh \& Shannon, 2005). The benefits of this approach are that preconceived categories are avoided and instead new insights are allowed to emerge directly from the study participants (Kondracki \& Wellman, 2002). Directed content analysis uses a more structured process than the conventional method, by incorporating existing research, concepts and variables into the initial coding of each category (Potter \& LevineDonnerstein, 1999). This approach is useful at either supporting or extending existing theory (Hsieh \& Shannon, 2005). The summative approach is typically used to analyse particular words in relation to particular content. All content analysis approaches require a coding system to locate patterns within the data (Morgan, 1993).

A conventional content approach has been used in this study to identify implicit and explicit themes identified in the interviews and present gaps in the participant's knowledge. The conventional approach is best suited for this study, as it will help draw out new knowledge and understanding surrounding a previously un-researched population. Burnard's (1991) framework for data analysis has been used to produce a detailed and systematic recording of themes and issues addressed in the interviews. This framework uses 14 stages to comprehensively analyse the content of the interviews. The framework has been adapted and summarised inTable 4. 
Table 4Stages of data analysis based on Burnard (1991).

\begin{tabular}{|c|c|}
\hline Stage 1 & Write notes after each interview. \\
\hline Stage 2 & $\begin{array}{l}\text { Read the transcripts and become immersed in the data. Make notes } \\
\text { throughout the reading and generate general themes. Become more } \\
\text { aware of the participant's frame of reference. }\end{array}$ \\
\hline Stage3 & $\begin{array}{l}\text { Re-read the transcripts and identify specific headings and categories to } \\
\text { describe all aspects of content, excluding 'dross.' This is the Open } \\
\text { Coding stage and generates categories. }\end{array}$ \\
\hline Stage 4 & $\begin{array}{l}\text { Organise the categories into precise groups. Similar categories are } \\
\text { grouped together into broader categories. }\end{array}$ \\
\hline Stage 5 & $\begin{array}{l}\text { The new list of categories is revised, removing repetitious headings, to } \\
\text { produce a final list. }\end{array}$ \\
\hline Stage 6 & $\begin{array}{l}\text { Two colleagues are invited to validate the categories in the final list. The } \\
\text { categories are discussed and adjustments made as necessary. }\end{array}$ \\
\hline Stage 7 & $\begin{array}{l}\text { Re-read transcripts alongside the agreed list of categories. Establish the } \\
\text { extent to which the categories cover all aspects of the interviews. }\end{array}$ \\
\hline Stage 8 & $\begin{array}{l}\text { Coding is used to link data with category headings. Colours are used to } \\
\text { distinguish each piece of the transcript allocated to a category and sub- } \\
\text { heading. }\end{array}$ \\
\hline Stage 9 & $\begin{array}{l}\text { Multiple photocopies of the transcripts are made. The coded sections of } \\
\text { the interviews are cut out, then all items of each colour code are } \\
\text { collected together. The context of the interview is maintained by } \\
\text { keeping a copy of the complete transcript as reference. }\end{array}$ \\
\hline Stage 10 & $\begin{array}{l}\text { The cut out sections are pasted onto sheets with headings and sub } \\
\text { headings. }\end{array}$ \\
\hline Stage 11 & $\begin{array}{l}\text { Participants are asked to validate the appropriateness of the category } \\
\text { system and adjustments are made. This is to validate the findings. }\end{array}$ \\
\hline Stage 12 & $\begin{array}{l}\text { All data is collected for direct reference before writing up the findings. } \\
\text { Any data that is unclear is referred back to the transcript for clarification. }\end{array}$ \\
\hline Stage 13 & $\begin{array}{l}\text { The process of writing the findings begins, section by section. In order to } \\
\text { stay close to the original meanings and contexts, the writing is done with } \\
\text { access to the original transcripts or recordings. }\end{array}$ \\
\hline Stage 14 & The research findings are linked with the literature. \\
\hline
\end{tabular}

As there are several stages using Burnard's model (1991), it was easier to group some of these together. The main bulk of categories were identified during stages $1-3$, as these were the obvious topics that were discussed. During stages 4-8 similar headed categories were condensed into precise groups. For example, referrals to physiotherapy and swallow assessments were grouped under the sub-heading multidisciplinary team and continuity of care. The final stages 9-14 generated the final list of themes. 


\subsubsection{Coding the data}

This section used Burnard's (1991) 14 stages of analysis to accurately record and describe the themes that emerged during the interviews. The data analysis process is summarised in Figure 1.

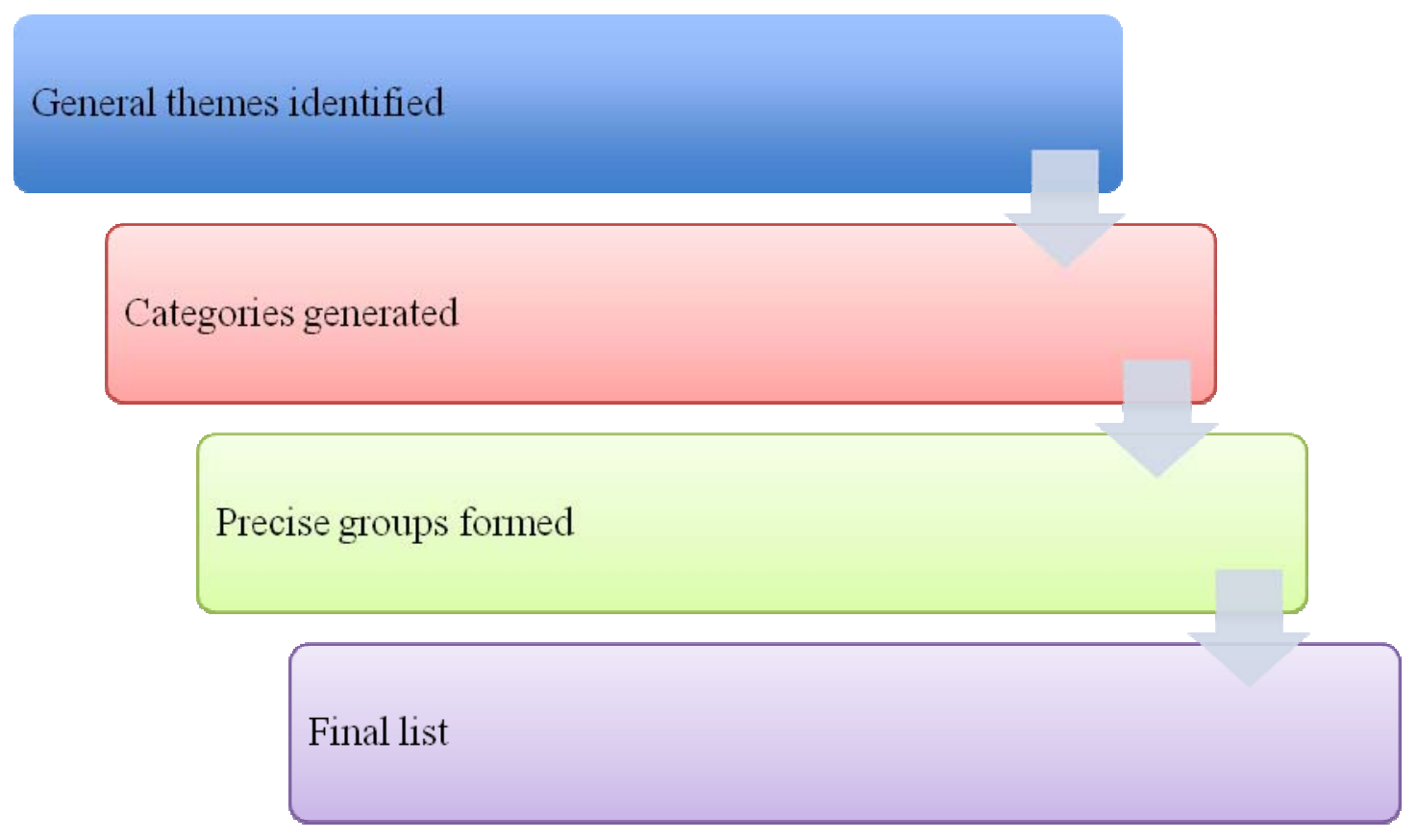

\section{Figure 1: Burnard's (1991) analysis applied to this study}

Using Burnard's (1991) model establishes broad themes, then condenses these into categories and as the researcher becomes immersed in the data, precise groups are generated before a final list of specific themes is established. The research aims were revisited prior to data analysis, which helped keep the study focused on answering the research questions. Brief notes were made after each interview, detailing impressions and obvious themes. The transcripts were read several times, which generated a list of general themes that were broad enough terms to encompass several categories within each theme (Figure 2). The categories were then grouped together under higher-order headings so that similar terms were grouped into one broader category (Figure 2). During this stage some less obvious categories began to emerge as I became more familiar with the data. Precise groups were elicited from the general themes and categories using colour-coding, for exampleCCI experience was highlighted pink. Any sections of transcript that matched either the ICU environment 
or patient experience subheadings were highlighted in pink, then cut out and taped to amatching coloured card according to their category. Care was taken to capture the true meaning of participant's answers, by including conversation before and after the comment of interest. This avoided cutting out strings of words devoid of context that could risk altering the meaning of what was said (Burnard, 1991).

In order to appreciate the context of pieces of conversation, a complete copy of each transcript was re-read alongside the precise group of categories. This generated a final list of themes that accurately reflected factors that affected the nurses' experience (Figure 2).As an example of how the coding system was refined, the general theme ICU environment, resources and staff support generated two specific categories. These were nursing allocation and work-related stress and compassion fatigue. In order to capture the true intention of the data nursing allocation was refined to staff allocation and peer support. Work-related stress and compassion fatigue were strongly associated with nursing autonomy so this group was re-named as the precise group autonomy and control. Autonomy and control was included as a final theme as this aspect of nursing was not only a precise theme in it's own right, but also an inherent component of why staff allocation and peer support impacted on the ICU nurses experience of caring for CCI patients. The final list was discussed with my University Supervisor and adjustments were made to some of the broader terms, to help capture the true intention of the data. The analysis findings are summarised in Figure 2. 
-Nursing, medical and interdisciplinary management of CCI patients

- ICU environment, resources and staff support

- CCI patient and their family in ICU

-Withdrawal of care and palliation

- Teamwork, allocation and continuity of care

themes

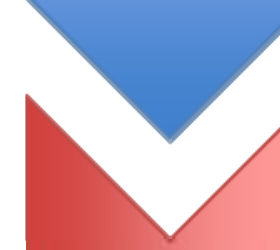

- Culture of ICU and staf

- Nursing allocation

- The ICU environment

- Medical and nursing practice

Categories $•$ Work-related stress and compassion fatigue

-Withdrawal of care and palliation

-Multi-disciplinary team and continuity of care

- Communication between nurse, patient and doctors

-Staffing, allocation and peer support

-ICU environment, resources and training

- Autonomy and control

-Withdrawal of care and palliation

groups

- Autonomy and control

-Work-related stress, compassion fatigue and staff allocation

- The CCI patient in the ICU environment

- Team work, nursing practice and continuity of care

Final list $\quad$ The culture of ICU

-Withdrawal of care and palliation

Figure 2 Summary of themes identified using Burnard's framework (1991). 


\subsection{Ethical Considerations}

\subsubsection{Multi-region ethics approval}

The study required a multi region expedited ethics application from the Ministry of Health, for permission to conduct interviews with hospital staff, and obtain data from the ICU databases (Appendix 7). A locality clearance was required from NID as this was Hospital policy. SID had no policy requiring locality assessment from researchers requesting site access.

It is the researcher's obligation to minimise risk or potential harm to participants. I had taken into consideration that if a participant became upset or need emotional support, I would stop the interview and make sure they were provided with adequate support. If any participant divulged sensitive information revealing a professional misconduct, I would have been professionally obliged to relay this information to the team leader of ICU. Neither of these situations occurred.

\subsubsection{Treaty of Waitangi}

It was essential that this research support the principles of the Treaty of Waitangi (Ministry of Health, 2002). The intention was to produce a body of work that benefits the physical, cultural and psychosocial needs of Pakeha and Maori. At the time of writing this thesis there was no data quantifying the incidence of Maori CCI compared with Pakeha CCI. This research will provide new data exploring the incidence and types of patients that become chronically critically ill in ICU.

\subsection{Researcher Reflections}

It is important to reflect on the methodology and research processes. The way in which the semi-structured interviews developed and were conducted, and the role of myself as interviewer are discussed in this section.

\subsubsection{Interviews and location}

Initially I was very concerned with the interview itself. In particular, the choice and use of questions,how to encourage honest answers, and concern that I did not manipulate the interviews through accidental use of strategic words and interjection. After the first interview I was both surprised and relieved at how well it had gone. 
The participant enjoyed talking and had covered all the topics I had wanted to address. She had raised some interesting topics that were important to her CCI experience. In subsequent interviews I was required to prompt participants more, which once led me to talking more than the participant. From this I learnt that waiting for an answer is important, rather than trying to fill every silent gap with a comment or observation. I felt I was respectful in the way I conducted the interviews and used language that was easy to understand. A mistake I initially made when asking a question, was to turn the question into 2 or 3 questions, by offering the participant several options. For example, “describe to me the last CCI patient you looked after" then had "what was good about it, what was bad? How did it make you feel? ” added. Although the participants were able to answer this question, on reflection, I should have kept it simple and focused.

Travelling to the two different locations had unexpected influences on participant recruitment. Whilst SID impressed their willingness to embrace nursing research and had enthusiastic volunteer participants, NID were more reserved and apprehensive. Both ICUs felt responsible for providing volunteers, especially because I was physically present with the sole reason of wanting to interview nurses. This worked well to some extent, as I was successful in interviewing three participants at both hospitals.

\subsubsection{Conveying the findings accurately}

My second concern was how I would respectfully and honestly convey a true depiction of the interview content. I felt that participants had divulged honest and sincere experiences, and I needed to decide which of these mattered. I explored qualitative studies and found that in other nursing descriptive studies, Burnard's (1991) 14 stage approach to data analysis had effectively identified themes, yet had remained true to the original interview content. I read through the 14 stages and felt that this approach would allow an accurate representation and analysis of the transcripts (Burnard, 1991).

\subsubsection{Ethical and emotional safety of participants}

During the coding process, sections of conversation were located that contained identifiable features of the ICUs, participant and hospital. Although these portions of 
interview were interesting, this data was removed from data analysis to maintain participant confidentiality.

Given the honesty with which participants had answered questions and shared personal experiences, when I reported the findings it was important for me to protect their emotional safety. The participants had provided me with rich description detailing a number of topics that exposed negative perceptions and practice. There was risk that the data could be presented in a judgmental manner, thereby detracting from the valuable provision of honest experiences. For this reason I have been careful to present the participants' answers word-for-word. When speculating the reasons for some of the findings I have referenced quotes, so that the reader can follow the analysis process.

Identifying gaps in knowledge and practice was not specifically investigated during any of the interviews. Rather it was an overall picture that emerged while analysing the transcripts. I had intended to ask participants about their familiarity with research-based recommendations that they applied in their practice. However, their lack of familiarity with the term chronically critically ill prevented me from exploring this topic too deeply. Pressing participants for knowledge they did not seem to have would have been unproductive and caused undue stress. I did not want to risk deterring an enthusiastic participant from sharing their experiences, for fear they might get an answer wrong. In isolation these gaps in knowledge and practice may seem innocuous, but when they are brought together and viewed as a bigger picture, there is compelling evidence that not much is really known or understood by the participants about caring for CCI patients.

\subsection{Quality and Reliability of this Study}

Quality issues surrounding qualitative research have followed an historically contentious debate concerning the terms validity and reliability. There have been ongoing arguments concerning the appropriateness of using the quantitative terms validity and reliability to qualitative studies, due to fundamental differences between these two research approaches. Some argue that these terms do not fit into an interpretive approach that values insight and creativity (Denzin \& Lincoln, 2000) so instead the terms truthfulness and consistency are used (Appleton, 1995). An 
important criteria for qualitative research is that it is both descriptively sound and explicit, as well as interpretively rich and innovative (Polit \& Beck, 2004).Guba and Lincoln (1994) established five criteria for promoting trustworthiness in qualitative research: credibility, dependability, confirmability, transferability and authenticity.

Credibility refers to confidence in the truthfulness of the data and in the interpretations of the results (Polit \& Beck, 2004). Inclusion of verbatim quotes from the participants in the findings aids the accurate portrayal of their experiences, as it allows the reader to determine the accuracy of the researcher's interpretation.

Dependability refers to the reliability of data over time (Polit \& Beck, 2004). In order for research to demonstrate reliability, the method and study design must be able to be replicated to produce the same results. This can be difficult to achieve in qualitative studies as the data collection considers the time, place, environment and local situation surrounding each interview (Polit \& Beck, 2004).

Confirmability explores the accuracy, relevance and meaning of the data. In order for a qualitative study to demonstrate confirmability, the findings need to clearly establish a true representation of the information that participants provided (Polit \& Beck, 2004). The researcher's conclusions and interpretations of the data should be clearly articulated, and reflect the participant's voice and conditions of the inquiry (Polit \& Beck, 2004). The researcher's biases and motivations should not be evident in any way in the interpretation of the findings. It is important that the researcher clearly states any bias, assumption or intention that might impact upon the confirmability of the study. Any bias should be kept separate from the participants' experience. Using reflective journals can add to the confirmability of research by allowing the researcher to freely express impressions, thoughts and observations during data collection. These reflections can capture important contributing factors to how the data might be interpreted (Roberts \& Taylor, 2002).

Transferability focuses on the generalisation of the study and looks at the extent to which the data and findings are relevant to other contexts (Guba \& Lincoln, 1994). In qualitative descriptive studies, the intention is not to produce findings that are generalisable, rather the findings will be applied only to a specific population 
(Higginbottom, 2004). The sample is chosen to provide information-rich data, thus allowing smaller numbers of participants to be involved (Higginbottom, 2004). The lack of generalisability in qualitative studies has fuelled criticism of its usefulness and value (Mays \& Pope, 2000). In defence of this criticism, Sandelowski (1997) asserts that generalisation in qualitative research needs to be understood in broader ways: providing detailed knowledge, promoting a creative understanding of cultural aspects, and providing the means to extend work beyond the limitations of any one project.

Authenticity refers to the extent to which the researcher has demonstrated a true and fair range of different realities, through the conveyance of the participants' lived experience (Polit \& Beck, 2004). Qualitative research should convey the real feelings, mood and experiences of the participants, thereby helping the reader better understand their lived experience in order for authenticity to be achieved (Polit \& Beck, 2004).

In order for qualitative research to achieve quality and reliability, the data analysis process needs to be clearly articulated. This allows the reader to follow each step of the researcher's analytic process (Polit \& Beck, 2004), rather than be left to guess how the findings or discussion were reached. Guba and Lincoln's five criteria have been used as headings, to establish the integrity of this study (Guba \& Lincoln, 1994).

\subsubsection{Credibility and dependability}

This study was carried out in an honest manner. The data was audio-taped with permission of each participant. During transcription, it was sometimes difficult to capture the spoken word because of accents and mistaking words for others. I was required to make a judgment call on minor words, but was able to re-play the audiotape until I was confident I had obtained as much detail from the tape recording as possible. I found it useful to re-play the entire audiotape of each interview while reading the transcription, which ensured detailed accuracy of each transcript during interpretation (DiCicco-Bloom \& Crabtree, 2006).

This study demonstrates dependability in the fact that it could be replicated by any researcher who wished to explore nurses' experiences of caring for CCI patients. The participant group of nurses in a tertiary level ICU, would be easily replicated in most 
developed countries. Some aspects may change, for example larger tertiary hospitals may have units independent from the ICU to care for CCI patients. In which case, the research could be replicated in that specialized environment. The findings of the study would be comparable, as the research aims to explore and describe the nurses' experience. Given the predicted increase in number of CCI patients in the future, there is no reason as to why the findings from this study would become dated or less meaningful. Rather these findings would act as a starting point for comparison of future research.

\subsubsection{Confirmability}

I have been careful to articulate my own views and assumptions, so that the reader can judge how I have interpreted the results. I have presented my own experience through the sharing of stories and experiences. The data has been presented in a way that allows the reader to read word-for-word answers by the participants, and then make an informed decision concerning my analysis of the findings. The data has been represented in as true a form as could be managed, to promote a true reflection of the participants’ experience.

During the interviews at both locations I kept a reflective journal, which I wrote in after each interview. Initially I focused on impressions of each participant, and then I included how I felt the environmental stressors had affected the interview. In earlier thesis drafts a section detailing these field notes was presented. Given the small number of eligible participants for this study in New Zealand, it was felt that inclusion of this data risked identifying participants. The data was therefore removed to promote participant confidentiality.

During the recruitment process I was concerned that my eagerness to find willing volunteers might risk me sharing my own views and assumptions about CCI patients. This could potentiality influence the participants and affect their answers during the interviews. Using the research synopsis to outline key aspects of the study proved to be a successful means of recruiting participants and maintain objectivity. I did not feel at any of these meetings that I imposed my views on the nurses. 
Depending on the participant's willingness to talk, I found that some questions were ineffective at eliciting the necessary information. I was required to adapt some of the interview questions as the interview unfolded and found that following the participant's own digressions was productive in producing insights and helping participants relax into a trusting rapport. As I gained more experience with the interview technique I learnt which questions generated conversation and dropped some questions, whilst adding new ones. The timeframe of 60 minutes allowed sufficient time for me to develop rapport with each of the participants. Establishing rapport is an essential component of the interview as it involves trust and a respect for the participant and the information they share (DiCicco-Bloom \& Crabtree, 2006).

It is important for the researcher to give thought to their own social role and that of the participant, as power differentials affect the dynamic of the interview and thus the content of information that is shared (DiCicco-Bloom \& Crabtree, 2006). Several strategies were employed to minimise the risk of bias during the interviews. As a novice interviewer I was careful not to miss useful information, by using probing questions and re-visiting key topics that had been discussed. After the first set of interviews I was worried that I had inadvertently directed participants with their answers. This concern was mostly due to lack of experience with encouraging dialogue when conversation had dried up. My supervisor checked the transcripts and found no indication of leading the participant or bias. The risk of not capturing the spoken words accurately during transcription was addressed by using Burnard's framework for data analysis (1997).

During transcription it became evident that one question was leading, with only one obvious answer: do you think CCI should be recognized as their own patient group? On reflection this question imposed an answer on the participant, thereby affecting the participants' response, and introduced bias (Rice \& Ezzy, 1999). The answer was rendered meaningless and excluded from the findings and data analysis.

\subsubsection{Transferability}

In terms of this study, the findings section has been described sufficiently to allow the reader to make informed decisions and generate an independent conclusion concerning the applicability of the data in other contexts. This study has some 
obvious restrictions as the unique environment of intensive care restricts applicability to other hospital or health care environments. However, the underlying principles of nursing long-stay patients, with compassion, adopting an effective multi-disciplinary approach, having a cohesive working environment and adequate training and resources, are all common aspects of hospital life that affect the provision of good nursing care. The findings related to these principles can be applied to many, if not all health care environments. The reality of this time and energy-consuming patient group, is one that necessitates a reality check in the intensive care unit.

In relative terms this study is small, using only five participants, and is conducted in only two ICUs in New Zealand. There is significant scope to replicate the study on a larger scale across multiple countries, which would generate more clinically significant results. However, as a starting point on which future research can be based, it is an exciting local study, which may encourage further exploration.

This is a small exploratory descriptive study that seeks to unpack some of the experiences of nursing staff, when caring for CCI patients, that are alluded to both in the literature and in the day-to-day experiences of ICU nursing. The small scale of this study makes it difficult to conclude any generalisability. The key however, is to recognise the potential importance of these findings in relation to the future of ICU nurses practice. The findings could certainly be considered in local New Zealand DHBs and challenges made to the current nursing management of CCI patients.

\subsubsection{Authenticity}

The way in which the findings have been analysed has been explicit, with sufficient explanation given to the procedures involved. This method of reporting has allowed the reader to critically appraise how the findings and discussion topics have emerged, and evaluate the conclusions I have reached (Vivar, McQueen, Armayor, 2007). Sufficient text from the participants has been shared, combined with my interpretation of the situation and key topics, to convey a true sense of the lived experiences of each participant. 


\subsection{Summary}

This chapter has described qualitative research methodologies, providing justification for using this approach in this study. Various methods for capturing descriptive data were explored, with reasoning given for choosing the method of semi-structured interviews. The structure of the interviews was outlined and some observations concerning the interview process are made. The chapter then led to a description of the data analysis process, and the stages of this process were presented. Ethical considerations that were addressed in order to proceed with this study were described and the study's quality and reliability established.

This research takes the form of an exploratory descriptive study using semi-structured interviews. The interviews explore ICU nurses' experiences of looking after CCI patients, allowing for discussion of variances and similarities between participants. A thematic analysis of the interviews is conducted in Chapter 4 to identify similarities of practice, gaps in knowledge and evidence of research-based practice. 


\section{CHAPTER FOUR}

\section{DATA FINDINGS AND ANALYSIS}

\subsection{Introduction and Overview}

This chapter revisits the research aims and presents the findings.Firstly a summary of the types of chronically critically ill(CCI) patient at both sites during 2008 is provided. The participant demographics are presented then the recruitment process described. The interview findings are explored using Burnard's (1991) framework to identify the themes. Six key themes are explored:

1.

utonomy and control

2.

ork-related stress, compassion fatigue and staff allocation

3.

he CCI patient in the intensive care unit (ICU)

4.

eamwork, nursing practice and continuity of care

5.

he culture of ICU

6.

ithdrawal of care and palliation.

From these categories the experiences of the participants can be summarised accordingly. The nurses used predominantly negative description to depict their experiences of CCI patients. Causes of frustration when caring for these patients included having a slower paced and unchallenging day, not feeling in control of the workload, inability to perform time-consuming tasks due to a lack of resources and equipment, having restricted access to the multi-disciplinary team (MDT), poor clinical direction and continuity of care and not being listened to by doctors. Documentation and care-planning was insufficient to meet CCI patient needs and the ICU environment was felt to be unsuitable for promoting their recovery. Family 
presence was recognised as important for patient recovery and generated both positive and negative experiences from participants. Throughout these topics participants linked caring for CCI patients with staff burnout. Participants' suggested comprehensive MDT involvement with weekly meetings, case management, careplans and having primary nurses/doctors as ways to improve CCI patient care. Also, emphasis was placed on careful staff allocation and having a spacious and quieter environment. The chapter concludes with a reflection on the interview and recruitment processes.

\subsection{Summary of Database Findings}

Both sites were approached to access the ICU database and retrieve information concerning the number and types of patient that stayed for more than 28 days. This length of stay was used at it is in keeping with the study definition of chronic critical illness. The data is summarised in Table 5. 
Table 5 Details of CCI patients admitted to NID and SID during 2008 


\begin{tabular}{|c|c|c|c|c|c|}
\hline $\begin{array}{c}\text { CCI admission } \\
\text { details }\end{array}$ & \multicolumn{2}{|l|}{ NID } & \multicolumn{3}{|c|}{ SID } \\
\hline $\begin{array}{l}\text { Total number of } \\
\text { admissions }\end{array}$ & \multicolumn{2}{|l|}{9} & \multicolumn{3}{|c|}{17} \\
\hline $\begin{array}{l}\text { Average age } \\
\text { (years) }\end{array}$ & \multicolumn{2}{|l|}{57} & \multicolumn{3}{|c|}{59} \\
\hline Age range (years) & \multicolumn{2}{|l|}{$43-76$} & \multicolumn{3}{|c|}{$18-81$} \\
\hline Gender & $\begin{array}{ll}\text { Male } & 6 \\
\text { Female } & 3 \\
\end{array}$ & $\begin{array}{l}(67 \%) \\
(33 \%)\end{array}$ & $\begin{array}{l}\text { Male } \\
\text { Female }\end{array}$ & $\begin{array}{l}11 \\
6\end{array}$ & $\begin{array}{l}(65 \%) \\
(35 \%)\end{array}$ \\
\hline Ethnicity & $\begin{array}{ll}\text { Maori } & 2 \\
\text { NZ/European } & 5 \\
\text { Other } & 2 \\
\end{array}$ & $\begin{array}{l}(22 \%) \\
(56 \%) \\
(22 \%)\end{array}$ & $\begin{array}{l}\text { Maori } \\
\text { NZ/European } \\
\text { Other }\end{array}$ & $\begin{array}{l}2 \\
10 \\
5\end{array}$ & $\begin{array}{l}(12 \%) \\
(59 \%) \\
(29 \%)\end{array}$ \\
\hline $\begin{array}{l}\text { Range of SAPS } 2 \\
\text { scores }\end{array}$ & \multicolumn{2}{|l|}{$35-74$} & \multicolumn{3}{|c|}{$17-71$} \\
\hline $\begin{array}{l}\text { Average APACHE } \\
3 \text { score }\end{array}$ & \multicolumn{2}{|l|}{93} & \multicolumn{3}{|c|}{ Not provided } \\
\hline $\begin{array}{l}\text { Range of APACHE } \\
3 \text { scores }\end{array}$ & \multicolumn{2}{|l|}{$62-139$} & \multicolumn{3}{|c|}{ Not provided } \\
\hline $\begin{array}{l}\text { Most common } \\
\text { admission } \\
\text { diagnosis }\end{array}$ & $\begin{array}{l}\text { Bacterial pneumonia } \\
\text { GI perforation }\end{array}$ & $\begin{array}{l}22 \% \\
22 \%\end{array}$ & $\begin{array}{l}\text { Multi-trauma } \\
\text { Pneumonia }\end{array}$ & & $\begin{array}{l}24 \% \\
24 \%\end{array}$ \\
\hline $\begin{array}{l}\text { Average number of } \\
\text { ventilated days }\end{array}$ & \multicolumn{2}{|l|}{39} & \multicolumn{3}{|c|}{29} \\
\hline $\begin{array}{l}\text { Range of ventilated } \\
\text { days }\end{array}$ & \multicolumn{2}{|l|}{$23-79$} & \multicolumn{3}{|c|}{$10-67$} \\
\hline $\begin{array}{l}\text { Vital status on } \\
\text { discharge from } \\
\text { ICU }\end{array}$ & $\begin{array}{l}\text { Alive } \\
\text { Dead }\end{array}$ & $\begin{array}{l}89 \% \\
11 \%\end{array}$ & $\begin{array}{l}\text { Alive } \\
\text { Dead }\end{array}$ & & $\begin{array}{l}88 \% \\
12 \%\end{array}$ \\
\hline $\begin{array}{l}\text { Vital status on } \\
\text { discharge from } \\
\text { Hospital }\end{array}$ & $\begin{array}{l}\text { Alive } \\
\text { Dead }\end{array}$ & $\begin{array}{l}78 \% \\
22 \%\end{array}$ & $\begin{array}{l}\text { Alive } \\
\text { Dead }\end{array}$ & & $\begin{array}{l}71 \% \\
29 \%\end{array}$ \\
\hline $\begin{array}{l}\text { Average ICU } \\
\text { length of stay }\end{array}$ & 43 days & & & days & \\
\hline $\begin{array}{l}\text { Range of ICU } \\
\text { length of stay }\end{array}$ & 30-80 days & & $28-7$ & 4 day & \\
\hline
\end{tabular}

The total number of CCI patients admitted to NID was approximately half the number admitted to SID. This was mostly due to SID being a larger hospital with a larger capacity ICU, hence the throughput of more patients who could potentially fall into this category. The average age of CCI patients at both sites was remarkably similar, as was the higher proportion of male patients (67\% at NID and $65 \%$ at SID). There were more patients of New Zealand/European descent than other ethnicities and 
Maori accounted for between 12-22\% of all CCI admissions. Patient ethnicity was provided by family members when completing the patient information form. The Simplified Acute Physiology Score 2 (SAPS 2) severity of illness score was higher at NID, reflecting a sicker group of patients than SID. There was a broader range of SAPS 2 scores at SID, indicating a more diverse range of acuity at this Unit. Pneumonia was one of the two most common admitting diagnoses for CCI patients. In NID the second most frequent admission diagnosis was gastrointestinal perforation, whereas SID’s was multi-trauma. Compared with international studies both sites had low mortality rates for CCI patients discharged from ICU: NID 11\% and SID 12\%. There was an increase in mortality for CCI patients when discharged from the hospital: NID 22\% and SID 29\%. These mortality rates were taken at time of patient discharge from hospital. No one-year post-hospital discharge data was retrieved. These mortality rates are reflective of findings in the literature review, concerning the variable prognosis and variable mortality rates of this patient group (Estenssoro et al., 2006; Carson \& Bach, 2002).

\subsection{Participant Demographics and Recruitment}

Six ICU nurses volunteered to take participate in the study. Only one nurse responded to the flyer advertising the study, whilst the remainder volunteered when I met staff during handover and morning tea breaks.One participant was retrospectively excluded as they did not meet the inclusion criteria. At the beginning of each interview three questions were used to elicit the level of experience and number of CCI patients they had cared for in that year(Table 6).

Table 6 Demographics of participants and exposure to CCI patients

\begin{tabular}{|c|c|c|c|c|}
\hline $\begin{array}{c}\text { Participant } \\
\text { code }\end{array}$ & $\begin{array}{c}\text { Years } \\
\text { worked in } \\
\text { ICU }\end{array}$ & PDRP level & $\begin{array}{l}\text { Number of CCI } \\
\text { patients cared for that } \\
\text { year (approximate) }\end{array}$ & Gender \\
\hline N2 & 17 & Expert & 6 & Female \\
\hline N3 & 7 & Proficient & 3 & Male \\
\hline S1 & 7 & Unknown & 12 & Female \\
\hline S2 & 2 & Proficient & 3 & Female \\
\hline S3 & 3 & Competent & 5 & Female \\
\hline
\end{tabular}

The participants were predominantly female with an average of 7 years nursing experience between them. Their level of ICU experience varied from competent to expert and they had cared for an average of 6 CCI patients in the last 12 months. 
A total of 6 participants across both study sites were interviewed. Three participants were recruited from each of the two hospitals, thereby having equal representation of the North and South Islands. The timeframe allowed sufficient time to recruit all 6 participants and obtain the database information. The interviews were carried out over July and August, which are busy winter months in New Zealand.

The research aims were to:

1. Identify the influencing factors that affect the nurses’ experience of caring for chronically critically ill patients (CCI).

2. Ascertain the availability and use of resources that intensive care (ICU) nurses' access when planning and implementing care to CCI patients.

3. Explore ICU nurses’ perceptions of CCI patient experience.

4. Explore topics of interest that are brought up by the participant in relation to CCI care.

5. Generate ideas for how nursing care of CCI patients might be improved.

From these aims key themes were identified during the interviews, using Burnard's framework (1991). The themes were:

1. Autonomy and control.

2. Work-related stress, compassion fatigue and staff allocation.

3. The CCI patient in the ICU environment.

4. Teamwork, nursing focus and continuity of care.

5. Withdrawal of care and palliation.

The final section addresses the last research aim by exploringparticipant suggestions for improving CCI patient care. The researcher's analysis of identified gaps in knowledge and practice is provided.

\subsection{Autonomy and Control}

Participants associated awake patients with being more interactive and demanding. Having an awake patient in ICU required the nurses to spend more time trying to understand their attempts at communication, which impacted on the nurses' ability to get other work done. 
S2 “they would call 'demanding patients.' You know, they want a lot more and they're communicating. Yeah, aware a bit more of what's going on and I think some nurses, ICU nurses don't like that."

With an awake patient, the ICU nurse could no longer simply do whatever they needed to in their own time-frame, rather their shift plan became a blend of negotiation and re-prioritising with the patient:

S1 "We also like things done our way, not the patients' way.. And I think we do get stuck in 'this is how we like to have it done and you have to fit our mould' sometimes.”

The focus of the day seemed to be planned more around the priorities of the ICU nurse than the patients. Continuing with the theme of CCI being time-consuming and hard work, was the issue of CCI patients being physically hard work, due to restlessness and agitation:

S1 "It can be exhausting looking after someone who repeatedly pulls out their trache."

N3 "You might be spending the whole time calming the patient down.. I was unable to do other work other than just stay with her and talk to her."

Participant answers demonstrated little understanding concerning the will of CCI patients in regards toplanning each shift. When asked how the patient's routine was accommodated into planning her shift, one nurse replied:

N1 "I don't go and say 'now do you usually have a wash in the morning?' because I sort of think 'well this is not your home.' I'm not going to say 'do you normally have it at 5? Oh I'll leave it for the afternoon at 5 O'Clock, because that's what you normally do.' So I don't do that." And later, "I try to accommodate, but I don't set out to find out when they normally have a shower." 
Similarly another nurse commented that when planning activities, there was a limitation to the number that could be done each day:

N2 “Going to go on the tilt table, you couldn't be taking the patient to the shower in the same day. You couldn't do both procedures."

Participants associated being in control with satisfaction:

S1 "I give the drug I see a result, I do something about it, I see a result. With the long-term patients you don't see that quick fix and I think that sometimes we don't feel we're getting that rewarding experience from it... You go home at the end of the day and you really don't know what you've achieved all day." And later, "We also like things done our way, not the patients way."

When applied to CCI this principle was incongruent, as the very nature of an awake rehabilitating patient is the reality of slower progress. At no point were CCI patients recognised as a unique patient category, who are different from the 'normal' ICU patient. One participant began to comprehend this when she was asked about the usefulness of the careplans:

S3 “This is a really different group of patients. And I haven't ever really looked at that before."

This may explain why the participants' experienced frustration due to the constant tug-of-war between staying in control of the day and trying to meet the needs of their CCI patient.

Both sites had similar ICU culture issues including ICU's focus on acutely unwell, fast-paced patients; physical approach to nursing, multi-disciplinary team (MDT) and rehabilitation, continuity of care in relation to medical and nursing staff, staff allocation, and conflicting views of CCI patients as either easy or difficult to care for. 
All participants shared the opinion that ICU nurses prefer either sedated, ventilated patients who are not awake, or the busy acutely unwell patients, rather than looking after a CCI patient:

N3 "In ICU most of the tasks we do are focused on a quick or early recovery." S2 "ICU nurses don't like that, they want their patient sedated and flat."

The perception that ICU only cares for acutely unwell patients was only challenged when participants described dying patients or issues around withdrawal of care. The use of the words fix, fixing, quick and fast, denoted a need for the ICU nurse to feel in control of both tasks and the patient. From this observation it can be argued that the point of frustration for the ICU nurse is not feeling in control of the patient or the workload, hence the reference to preferring sedated and flat patients.

\subsection{Work-related Stress, Compassion Fatigue and Staff Allocation}

\subsubsection{Work-related stress}

Identifying the influencing factors that affected the nurses' experiences of caring for CCI patients generated the largest volume of data. Participants described CCI patients as:

N2 “tedious," “boring," “isolating," "routine” "they're difficult, they're challenging, they're not always happy that you're nursing them...A lot of people don't see them as rewarding."

S2 " boring and it's routine."

S3 “demanding,"

Positive aspects of looking after CCI patients included the nurses' feeling appreciated for their effort, and getting to know the patient:

N2 "It's worth the effort."

S2 "Sometimes I get into it and really enjoy it" 
These comments showedthat the nurses strongly linked satisfaction with how hard they appliedthemselves to caring for CCI patients. The positivity is not a passive experience, but one that is earned by the nurse, one that he or she decides has been worth it. Another positive aspect for nurses was when they could visibly see an improvement in their patient, or when the patient told them they had a "good day."

\subsubsection{Compassion fatigue}

When describing the needs of CCI patients, participants predominantly focused on physical tasks. There was a strong emphasis on mobilising patients into chairs, tracheostomy management, promoting a healthy sleep pattern and keeping the patient entertained. Each of these issues was described as a frustration to the nurses, as they were time consuming tasks that were made difficult to achieve by lack of a suitable environment, support and equipment:

N2 "Sleep deprivation is a huge problem and just that whole quiet routine is very difficult to maintain."

S1 “I'd be happy just to keep people occupied. There's just a lack of things to do. What do you give people to keep them occupied and alert and interactive?"

However, by focusing on the physical tasks, the nurses were hoping to achieve some normality and routine for the patient:

S1 "often they're a bit dazed and confused anyway so they need a bit of reorientation."

S2 "You want to do the right things for them and you want everyone to do things the same for them, so that they are in a routine."

One participant used the physical tasks, such as taking patients outside, as a means of getting through their shift:

S1 “Outside because it just helps even fill my day." "It's when they're occupied there's a bit less of the bed rail shaking and a bit less of the banging and wanting something they can do for themselves.” 
There is an underlying negative resentment in these remarks: that the nurse's day needs to be filled because it is boring, and secondly, frustration at the patient's behaviour. Both support the argument that the ICU nurses are less sympathetic to their patient's needs, and will plan some tasks to make their day more enjoyable. That is not to say that the ICU nurses had no sympathy or compassion for the CCI patient. Compassion was evident particularly when a nurse felt she had got to know the patient:

N3 "you get really closely bonded to them: to the patient and the family also. It's a good thing yeah."

S2 "You feel like these patients might belong to you and you want to do the right thing for them."

In addition to the primary focus of physical needs and tasks, participants recognised CCI have different needs from other ICU patients. These needs were mostly supportive and rehabilitation focused:

N3 "The long-term ones I think you need to have a completely different approach. You're still trying to keep the patient comfortable, out of stress and trying to keep recovering."

S2 "With chronically ill patients you try and rehab them more."

These observations demonstrated some insight into the broader range of CCI needs, but lacked depth and detail. Participants found it challenging to effectively communicate with CCI patients, and they were aware of this as a cause of frustration both for themselves and the patient:

N3 "The most common challenge would be when we're not really able to understand what they're trying to tell us."

Nurses used lip-reading, alphabet charts and pen and paper to try and understand what their patient was saying. This skill was developed with time and patience, but was generally viewed as a time-consuming task that negatively impacted on their shift. 


\subsubsection{Staff allocation}

There were four predominant issues concerning allocation of nurses to CCI patients: new graduate nurses usually care for CCI patients, experienced nurses feel their time is better spent with sicker patients, CCI are the lowest priority patient when it comes to staff allocation, and the need to avoid burnout. Of these 4 issues, only one (the need to avoid burnout) was discussed in the literature as a risk for nurses caring for CCI patients (Roulin \& Spirig, 2006).

When discussing these topics it became apparent that the participants felt uncomfortable sharing their opinion. For example, both sites participants reported that it was common practice for new graduate nurses to be assigned to CCI patients. When asked to comment on whether they felt this was appropriate, participants struggled to provide a clear answer. Some felt that it was good for new graduates to look after CCI because it taught them the essentials of nursing care, while others stated poor skill mix and acutely unwell patients as legitimate reasons for experienced nurses not being able to care for them:

N2 "I think it's good for junior nurses to look after long-term patients. Cos I think to be a good ICU nurse you need to do the basics well.”

S1 "They need to build up their skill base on those patients and it's not necessarily always the best person to have in there."

These answers seemed to be each participant's personal justification for their own practice. There is an overarching assumption that it is acceptable for inexperienced nurses to practice on CCI patients. One participant recognised the complex nature of CCI patients:

S3 "I think a new nurse should go to a ventilated easy patient. Cos if you're new to intensive care then that's basically intensive care in a nutshell. But when you've got a new grad with a very anxious patient, and they're pooing every 5 minutes and nasogastric or PEG feeding and got a trache, it's quite complex." 
Another important factor that influenced nurses' decision to look after CCI patients, was their mood that day and the need to share the workload, to avoid burn-out. Several nurses linked their mood, with the high acuity of the CCI patient and needing to have breaks from looking after them:

N2 "You can work it to your advantage if you're in the mood to have a long-term patient, and you're prepared to put the effort in, then it's beneficial to you and the patient.. When you don't feel like having those patients I don't think they receive the care that they should."

N3 "If you have spent a day or two with the patient, let someone else come in," and "It feels good to look after them. But then to be fair there comes a time when you feel like you've had enough."

These answers compound the participants' view that CCI patients are hard work to look after. The nurses described needing to prepare themselves mentally so that they could try and make their shift as enjoyable for themselves as possible. Again the issue of patient needs versus nurse needs was influential in determining the type of care the patient received. When describing the need to have the right attitude for approaching a shift with a CCI patient, both sites had a group of nurses that were naturally skilled at caring for this group:

N2 "Some people really have that, who like those kinds of patients, actually get a lot out of them."

S2 "You just need to find nurses that like looking after those patients, and then they're going to get good care."

In these statements the participants recognised that some nurses have natural skills that lend them to being particularly effective at managing CCI patients. While these skilled nurses were acknowledged, there was no suggestion of needing to learn from them. This reflects published literature asserting that the science of technical healthcare within ICU can easily conceal the art of nursing (Dawson, 2006). Participants failed to recognise the complex nursing care and responsibilities demonstrated by their skilled peers. There is no research exploring the concept of nurses possessing natural skills for looking after CCI patients. However, the 
development of expertise in critical care relies on knowing the patient, both in terms of the patient's typical responses and as a person (Swanson, 1993). In order to know the patient, nurses must engage in purposeful activities to assess and understand the patient's situation (Roulin \& Spirig, 2006). Participants instead hoped that these skilled nurses would continue to look after the CCI patients.

Participants from SID felt if they were allocated a CCI patient they were either being punished, or were not considered a good nurse. The participants' use of language created a feeling of shame from the nurse, due to her colleagues viewing her as clinically incompetent:

S1 "you might think 'oh, did they think that I'm not good enough to take care of the really sick patient." And "who did I piss off?"

S3 “They don't really think I'm a very good nurse. They think I'm terrible. You've been allocated the easy patient."

A final concern that emerged from analysing the staff allocation was the issue of how CCI patients were prioritised in ICU:

N2 "It's just difficult 'cos they aren't the high focus, high priority on a daily basis." S3 "The doctors are just sick of them."

These answers imply that CCI are a low priority, which may account for the negative view and reluctance to look after them.

\subsection{The CCI Patient in the ICU Environment}

A pervading impression from the transcripts was that participants wereuncertain whether CCI patients were easy or difficult to care for. During the course of each interview participants’ contradicted themselves:

N3 It's easier to look after them," then "at the end of the day you think 'oh I should have just gone back to my patient... 'cos sometimes the patient gets more demanding, more awake." 
S2 "Yeah it's an easy day sort of, and maybe an annoying day," then "when you've got a patient like this everybody in the unit wants you to help them, because they think you've got an easy patient."

The confusion can be linked with the aforementioned focus of ICU staff on acutely unwell patients with many infusions, treatments and equipment. If CCI patients are viewed as having the same needs as critically unwell sedated ventilated patients, then on first impression, they might appear to be an easy patient. However, if the focus of the ICU nurse concerns not just the physical patient needs, but rehabilitation and patient autonomy, the challenges of that nurse's day might lead to an equally busy shift. Participants associated ICU patients with interventions, which included multiple infusions and support from various machines. Once these interventions were removed the perception was that the workload reduced. However, the fact that the patient was awake, needing assistance with rehabilitation and other everyday activities led to an increased workload.

During the interviews, participants were considerably more at ease when discussing patient-related experiences than describe their own personal experience. This led to interesting stories being shared, which provided detail to the overall experience of caring for CCI patients. A topic that produced the most uncertainty with participants' answers, concerned the appropriateness of CCI patients being cared for in ICU. Nurses described what they thought it must be like for the CCI patients to be in the ICU and the role that family play in supporting their CCI relative.

\subsubsection{ICU Environment}

The problem of where CCI patients should be cared for in order to receive the best care, was revealed as an underlying theme throughout the interviews. Not just as a physical environment, but as a fundamental reason why ICU nurses resent having to care for CCI patients because there is nowhere else for them to go:

N3 “I don't think there's any places in the hospital. I don't think there's anywhere." 
These opinions were magnified by the belief that the ICU environments were not suited to meet CCI patient needs. When asked if the ICU was a suitable environment for CCI patients to be cared for answers were short and decisive:

S1 “Completely inappropriate. Completely terrible," and "what a hole to be stuck here for more than 28 days. How awful to be stuck in this shambolic stinky place. It must be awful for them. Must be horrible. At least we get to leave after 12 hours.” S3 “Absolutely not. No way. Definite absolutely."

Reasons for the ICU being viewed as inappropriate predominantly focused on noise, lack of entertainment and restrictions to family visiting. Participants felt that the noisy ICU prevented CCI patients from sleeping, despite efforts to reduce noise and move patients to a side room. This in itself was considered an uphill battle:

S1 "It's not ideal, and when you try and get the whole unit to shut up so this person can get some sleep, and no-ones shutting up, and a really sick admission comes in next door...if they don't sleep they're never going to get better."

S3 “There's one area that is quieter, but it's right by the door to go through to the staff room. It's a really cold end of the intensive care as well. You can put them in a side room, but that brings bad issues of relief and staffing issues.”

There is real frustration here that despite their best efforts to help the patient rest and regain a normal sleep pattern, the inadequacies of the ICU environment prevent the nurse from achieving their goal. There was almost a tangible feeling that the nurses have given up on the physical environment, as it hindered their work and rendering their attempts at helping their patient futile.

\subsubsection{Patient experience}

The described experiences of CCI patients were parallels of some of the nurses' experiences in the nurses' description and nursing practice sections.It seemed as though participants projected their own issues onto the patients and then the needs of the patient began to become inseparable from that of the participants.For example, difficulty with communication was a cause of frustration for both patient and nurse. Participants felt their patients' frustration was due to not being understood, whereas 
their own frustrations were due to the time-consuming task of trying to understand their patient and yielding little success. Given that CCI patients were not interviewed as part of this study, these descriptions reveal how participants projected their personal experiences onto their patients. The descriptions of patient experiences were offered by participants to demonstrate familiarity with CCI patient needs, when in reality, the needs of these patients and their families were not considered as important as their own.

The word 'frustration' was used as a descriptive remark and to describe communication:

N3 “The patient also gets frustrated cos she's trying to tell us something."

S1 "By the time they are up for writing they are so weak that.. it's just chicken scratches on the page. So that's certainly a frustration.”

Nurses from the study by Roulin \& Spirig (2006) similarly reported frustration at communication impairment. Just as the nurses needed to be in the right mood to care for a CCI patient, so the patient needed to be in the right mood to participate in their rehabilitation:

N2 “Sometimes you can't even get the patient to go outside, they don't want to." N3 “Sometimes they don't physically feel like it. The patients don't always feel like doing it. They're tired or they've had a rough experience the previous day."

The sympathy of some participants for their CCI patient was evident when they tried to imagine how the CCI patient might have felt:

S1 "Looking around and seeing all the other sick people around them. It must be awful to see. Then suddenly that bed's empty and they're wondering 'well wonder where he went?' It must be awful for them to sit and watch all that go on."

Participants focused on physical needs, and provided vague answers concerning the emotional and psychological needs of CCI patients: 
N3 “They've got different needs because they've been here for a while. What we're doing is helping them and supporting them through their stay."

This reflects that the nurses did not see this patient group as having unique needs.

Nurses felt that keeping family members well informed and participating with simple activities of daily living (ADLs) were beneficial to the patient. Experiences of family varied from case to case, with several participants using physical ADLS to occupy the relatives' time and help them feel involved:

N2 "We're trying to include visitors into the ADLs and trying to make them feel that they're doing something useful as well. It's really important.”

N3 "Cares like hand massage, lotions and foot massage, they can be done with the families. So it's really empowering for families.”

It was recognised that not all family members wanted to be involved in personal cares, but it was still important for the patient to have their presence and support:

N2 "Patients that have strong family involvement do a lot better. They're certainly happier." "Once she had that family support she was calmer, she coped better."

The nurses observed that different families responded in different ways. General comments about interactions with family members were divided into positive and negative subheadings. The positive description concerned how the relatives supported the nurse and made their shift easier:

N3 "Most of the time the families are really helpful, cooperative and helpful."

Conversely, the negative description associated with relatives looked at how the nurses' shift was affected and causes of frustration for the family. Nurses observed that sometimes family became institutionalised and behaved in a manner that made the nurse feel frustrated and uncomfortable: 
S3 "Families become very institutionalised. They can sometimes play nurses off against each other." And "I found it fairly frustrating to see them staring. I removed myself from the bed space a wee bit."

Causes of frustration for family were seen to be restricted visiting and inconsistent allocation of nurses to their relative. Effective communication was found to relax and reduce stress amongst relatives. Frustrated families were a cause of nurses feeling frustrated in Roulin \& Spirig’s study (2006).

\subsection{Teamwork, Nursing Practice and Continuity of Care}

\subsubsection{Teamwork}

Across both sites there was an apparent lack of MDT involvement in the day-to-day life of ICU, and concerning the care of CCI patients. There was regular access to physiotherapy, but restricted use of occupational therapy (OT) and speech language therapy (SLT). This absence of extensive MDT referral was largely due to cultural dynamics within both ICUs. Participants were frustrated at the lack of MDT referrals due to the medically driven care their CCI patients received. This approach restricted access to valuable resources that might aid their patient's recovery:

S3 “We don't have a multi-team.. We're not really a cohesive team I guess."

N2 “Quite frankly there's not good team collaboration here. There's no weekly meetings that these people require: a multidisciplinary meeting. So it's not a 360 degree look at what their patient needs.”

One nurse had positive views concerning how the different teams and specialists worked together:

N3 “I think it's collaborative care. I don't think there's more of medical or more of nursing. The input's good - all still working together."

When asked to explain this statement more fully, the participant did not offer any further opinion, so deeper understanding of this experience was prevented. 
Having support from nursing and medical colleagues was articulated as influential in determining how enjoyable the shift was. When asked if they were well supported a range of opinions were offered:

S1 “The Associate Charge Nurse Managers are very good at 'why don't I come back in half an hour and give you a hand?”

S3 "Oh no, no, no. I get no support at all. Infact you would probably get an admission coming in 'you can double because you've got the lightest patient.", N3 "I think this Unit is very well supportive. With peers and colleagues and the seniors and everyone."

The variety of these experiences reflects the unique working dynamic and cultural influences within both sites. Issues, such as staffing for that particular shift, the cohesion of the medical and nursing teams and workload, all affected the extent to which fellow staff could be supported. It is worth observing here that these issues are not unique to CCI patients, or to either site, rather they are inherent throughout healthcare providers and hospitals, both locally and internationally (Opie, 1997). The significance here is that CCI patients were a low priority within both ICUs, so the nurses looking after them were the first people to lose staff support if the shift became busy.

\subsubsection{Nursing practice}

There appears to be common acceptance by participants that CCI patients did not belong in ICU, and that the only reason for them being in ICU was because there was nowhere better for them to be cared for. A second influence was the ICU nurses' focus on fast-paced, quick recovery and exciting patients, and hence boredom at having to look after slower-paced CCI patients:

S2 "I think a lot of nurses hate it because it's not intensive and acute."

The isolation associated with looking after CCI patients was brought up by several participants, in relation to being physically removed in a side room, lack of peer support, being missed out on the ward round and general lack of interest from other staff.Isolation of nursing staff caring for CCI patients is a concept not previously 
explored in the CCI literature. There were assumptions that nurses did not like looking after CCI patients:

S2 "So many nurses hate it," and "I don't think that ICU nurses generally like looking after these patients.”

N2 "A lot of people don't see them as rewarding."

Other assumptions were that CCI patients could be aggressive and were heavy. There was some understanding that long-term ICU patients may suffer from ICU psychosis, but this was not shared by all participants.

Neither site had clinical guidelines for long-stay patient care. NID had no long-stay careplan and adapted their ICU careplan to meet any additional needs that developed. SID had a long-stay careplan that was under-used and not suitable for CCI patients. There was overwhelming opinion at both sites, that the careplans were insufficient to meet the specific needs of CCI patients. Overall careplans for CCI patients were not a priority and were adaptations of a general ICU careplan:

N3 “There's a careplan which is meant for everyone, but really you can just amend a few things."

S1 "No-one uses it cos it's quite a labour-intensive document."

S3 “We do have careplans. I don't find them very user-friendly. I guess they're not really suitable for these kinds of patient."

All participants were profoundly unaware of the specific needs CCI patients have. This was evident when talking about the absence of training and specific therapies for CCI patients. The ICU nurses were without adequate guidance or training to carry out their duties effectively. This adaptive style of nursing was generally accepted as normal practice:

S2 "I just make it up," and "Maybe the speech therapy, or the swallowing thing. The rest I think is standard nursing."

S3 "You just basically are going through the motions of where you think you should be going." 
The nurses stated that documentation of medical and nursing plans in the patient's notes was poor. This resulted in the nurse not knowing the direction of care and using valuable time reading through the notes:

S3 "Frustrating area is having to go through all the notes too. It's huge, huge. Sometimes it can be 5, 6 hours later that I finally get to read some of the notes.”

These frustrations added to the difficulty of determining a clear medical direction of care for the patient.

As both ICUs expressed limited access to MDT, or to clinical guidelines, these answers were not altogether unsurprising. Without regular input from specialists in rehabilitation, the ICU nurses have little option but to 'make do' with the little support they have.

\subsubsection{Continuity of care}

Continuity of care was very important to the participants and brought out strong responses to questions. In particular the nurses drew attention to the working relationships between the medical and nursing staff and reflected on how this impacted on the plan of care for the CCI patient. A frequently discussed issue was that the plan of care changed frequently, thus affecting the consistency and continuity of care:

N2 “Consultant will come along one day and say 'ah this.' Another one will come along the next day and completely reverse it. So there's no continuity or consistency." S2 "Consultants had different ideas and each day it would change."

Even when the participant felt that teamwork was normally good, they observed that the constant introduction of new ideas led to daily changes to the patients planned care: 
S2 "They would agree one day, and then somebody would bring in a new idea and it would change. Like they were always agreeing, but new ideas were coming in each day."

Closely linked with this issue, was the frustration of nurses not being listened to during ward rounds, despite feeling that they really knew their patient and understood their clinical needs:

S1 “It's medical staff thinking they know best, but if you've looked after someone for 4 weeks you've got a pretty good feel for what they're up to. And you don't necessarily get listened to particularly.”

N2 "You know the patient best of all. And I find it constantly.. there is not the respect shown to the nurse's opinion."

\subsection{Withdrawal of Care and Palliation}

Four out of the five participants brought up the topic of withdrawing care from patients. These participants associated a high mortality rate with CCI patients and were unable to separate them from palliative patients. Interestingly, neither site had high CCI mortality rates during 2008 (Table 4). However, previous years CCI mortality rates may have been different which might explain why this assumption was made. When asked to clarify why she associated withdrawal of treatment with CCI patients, one participant corrected her answer:

S2 "Not necessarily withdrawing all the time, but capping it. Saying 'this is as far as we will go.”

There was emphasis on respecting the wishes of the patient, and moral distress associated with persisting in seemingly futile treatment:

S1 "You really wonder 'why on earth are we flogging this poor person?'... as nurses we wanna do no harm and sometimes you're actually not doing this person any favours."

S2 “And the Surgeons didn't want to withdraw... It was a cycle that went on and on and she was here for months, and it was horrible." 
The appropriateness of medical decisions regarding the direction of care was questioned in relation to inconsistent plans and causing nurses, patient and family distress:

S2 "She knew she could die.. and that is what she chose. The frustration was that then the next day it would be changed and there'd be full on active care again. The family didn't understand what we were doing.. Yeah I hated that."

Participants described developing close relationships with dying patients and their family:

S2 "I had her for a long time and I did feel quite attached with her," and "I did have good rapport with them."

This was probably due to the frequency of looking after a patient who had been in ICU for several days or weeks. Another topic that was echoed from the CCI experiences was respecting the patients' wishes and listening to them. During these reflections the nurses' sense of achievement was clearly evident:

S2 "I was happy that the patient got what she wanted, was heard, and that was going to be the plan." And "I felt like I had achieved a lot because we had listened to the patient."

\subsection{Suggestions for Improving CCI Care}

The participants were asked how the care of CCI patients in their ICU could be improved. This part of the interview proved to be the most difficult, with most participants struggling to think of realistic or practical solutions and offering vague answers. Most of the suggestions echoed the frustrations they had articulated earlier in the interview. For example, nurses that found the lack of teamwork referral frustrating, felt strongly that MDT input and rehabilitation would help improve CCI patient care. Better teamwork was commonly seen as an important way to improve CCI care: 
N2 "I'd just like to see multidisciplinary care be a high priority for these people." S3 “A multi D meeting. It would be very beneficial."

Participants remained focused on tending to the physical tasks, such as mobility, swallow assessments and removal of lines and catheters. Weekly meetings with the MDT were suggested as a possible opportunity where the care of CCI patients could be strategically planned. Participants felt that having a primary nurse and doctor overseeing CCI patient care would provide consistent and clear patient-centred plans of care:

N2 "To have the patient as the centre-focus. Have clear plans established early." S1 "I think anyone that's here more than 2 weeks you have a Primary Consultant."

Similarly implementing case management(where a nurse oversees the care provided to a CCI patient) was considered a possible solution to improve continuity of care. Continuity of care was further discussed in relation to needing guidelines and developing better careplans:

$N 3$ "I think for the long-term ones a change in plans and stuff would be good also because sometimes there's not much covering the patient."

S1 "I think careplans that everyone follows."

None of the participants offered specific suggestions for how the careplans could be improved. This was not surprising, as very little interest was shown in this topic and most of the answers were coaxed from participants using prompts.

Staff allocation was considered fundamental to the successful provision of good care to CCI patients. Some participants felt that nurses should take it in turns to care for CCI patients, to avoid burnout, whilst others felt that having the same nurses provided consistency:

S2 "It would be quite nice to keep sort of the same nurses looking after these patients. It has to be the ones that enjoy looking after these patients." 
S1 "Look after this person once a week, to certainly keep your foot in, but you didn't get burnt out."

Environmental improvements that were suggested included having bed spaces that were larger, quieter, more comfortable, with windows that open. One participant felt that a purpose-built unit was required, but lamented this was unlikely to happen due to budget restrictions.

Participants did not consider teaching or education as an effective strategy to improve patient care. When asked whether they thought education would help, one nurse simply agreed, whilst another talked about an ICU weaning intervention unspecific to CCI patients:

S2 "Yeah, and maybe to just like saying how important the role is."

S3 "Education. We need to educate the nurses. What I do find a lot within the unit is that a lot of sedation gets given. And they're here for another week... So I'm for more education."

\subsection{Researcher Reflections}

As a researcher who is new to conducting qualitative interviews, I felt it was important to iterate the challenges I encountered and make honest reflections about the interview process. Using a journal to follow each step of the methodology process helped to shape my thoughts and guide my reflection. I felt that using semi-structured interviews was effective in obtaining a true depiction of participants' experiences. As a novice interviewer I initially lacked confidence and skill at prompting and guiding discussions, but I developed these skills more effectively as each interview progressed. Participants offered honest and frank descriptions, making it easy to identify the key themes.

My dual role as interviewer and ICU nurse provided me with a unique position that influenced the recruitment and interview processes. As researcher, I felt the nurses viewed me as an authoritative figure. The formal clothes I wore, audio-tape equipment and recruitment discussions compounded this impression. However, as an ICU nurse, I was able to empathise with the nurses and their workload, thereby 
generating conversations that demonstrated a genuine understanding of their job. This role as ICU nurse proved to be the most effective role regarding recruitment of participants. Several nurses commented that they too were studying at post-graduate level and therefore would agree to be interviewed, if no other nurses volunteered. During interviews my role as nurse allowed discussions to flow uninterrupted, as I understood complex medical terminology and nursing concepts without needing explanations from participants. Being able to communicate in this manner added to the rapport being developed and trusting relationships established quickly(DiCiccoBloom \& Crabtree, 2006).

As the participants shared sensitive information, I was careful at the end of each interview to ask if there was anything they would like to discuss in more detail. This was based on the advice of Alty \& Rodham (1998), who warn that whether or not participants appear to be upset, reflection following the interview may invoke disturbing or intense emotions. Allowing time for the participant to reflect on their feelings and the sensitive information they have shared, produced sympathetic remarks from participants, but no indication of anxiety. There was a true awareness of the sensitive nature of some of their answers, but no indication of regret or worry that they might have felt vulnerable in disclosing such personal information (Alty \& Rodham, 1998). I feel I have maintained the integrity of each participant by providing clear intentions of the research prior to consent being obtained, providing emotional support and time to reflect during the interviews. The data has been presented in an honest and respectful manner, with careful attention to removing all identifying features of both participant and location, which has promoted confidentiality.

Determining when enough data has been collected to allow data collection to end is an important issue within qualitative research (Denzin \& Lincoln, 2005). Reasons for stopping each interview were due to participants losing interest, time-constraints, and interruptions from other nurses, patients and alarming equipment. 


\subsection{Summary}

Participants expressed many frustrations when caring for CCI patients and used predominantly negative description to articulate these experiences. The findings were presented using the final list of themes that were identified using Burnard's (1991) framework.Firstly, the level of participant autonomy and control concerning their shift plan, patient behaviour and ward rounds directly affected their experience of caring for CCI patients. Symptoms of work-related stress and compassion fatigue were not recognised by participants in relation to caring for CCI patients. However, avoidance strategies were discussed and frustrations shared concerning the insufficiencies of the work environment, medically focused care, resources, interdisciplinary involvement, careplans and continuity of care. Participants associated CCI patients with withdrawal of care and palliation due to the emphasis on respecting patient wishes, symptom-based approach to care and distress at persisting with seemingly futile treatment. 


\section{CHAPTER FIVE}

\section{DISCUSSION AND THESIS CONCLUSION}

\subsection{Introduction}

This chapter re-visits the main themes and explores reasons for the participants' experiences and views.The final list of themes identified from the interviews were nursing autonomy and control; work-related stress, compassion fatigue and staff allocation; the chronically critically ill (CCI) patient's experience in the intensive care(ICU) environment;teamwork, nursing practice and continuity of care; the culture of ICU and similarities between ICU nurses' approach to withdrawal of care and palliation and their approachto caring for CCI patients. These main themes are discussed using the research aims to structure each section of this chapter. The aims and associated themes are presented in Table 7:

Table 7 Research aims and their associated themes

\begin{tabular}{|c|c|}
\hline Research Aims & $\begin{array}{l}\text { Associated Themes from the 'final } \\
\text { list' }\end{array}$ \\
\hline $\begin{array}{l}\text { Identify influencing factors that affect the } \\
\text { nurses' experience of caring for CCI } \\
\text { patients }\end{array}$ & $\begin{array}{l}\text { - Autonomy and control } \\
\text { - Work-related stress, } \\
\text { compassion fatigue and staff } \\
\text { allocation } \\
\text { - The culture of ICU }\end{array}$ \\
\hline $\begin{array}{l}\text { Ascertain availability and use of resources } \\
\text { that ICU nurses' access when caring for } \\
\text { CCI patients }\end{array}$ & $\begin{array}{l}\text { - Teamwork, nursing practice } \\
\text { and continuity of care }\end{array}$ \\
\hline $\begin{array}{l}\text { Explore ICU nurses’ perceptions of CCI } \\
\text { patient experience }\end{array}$ & - The CCI patient in ICU \\
\hline $\begin{array}{l}\text { Explore topics of interest that are } \\
\text { volunteered by participants in relation to } \\
\text { CCI care }\end{array}$ & $\begin{array}{l}\text { - Withdrawal of care and } \\
\text { palliation }\end{array}$ \\
\hline Generate ideas for improving CCI care & $\begin{array}{l}\text { - Teamwork, nursing practice } \\
\text { and continuity of care } \\
\text { - The CCI patient in the ICU } \\
\text { environment } \\
\text { - The culture of ICU } \\
\text { - Work-related stress, } \\
\text { compassion fatigue and staff }\end{array}$ \\
\hline
\end{tabular}


The first section discusses the need for a clear definition of CCI. Exploration of the key categories and themes is then presented. Participant experiences are analysed in context with findings from the literature review. These exploratory discussions help informour understanding of participant experiences when caring for CCI patients.The implications of these findings on nursing practice and patient experience are then considered. The next section presents recommendations for changes to nursing practice in relation to CCI patients, before describing practical methods for implementing these changes.Limitations of this study, implications for improving nursing practice and thesis conclusions are made.

\subsection{Defining CCI Patients}

The literature revealed several definitions of chronic critical illness. Definitions are likely to change according to investigator's interests and priorities (Carson \& Bach, 2002). Lack of clarity regarding this patient population was reflected in participant answers, for example when associating dying patients and withdrawal of care with CCI patients. There is need for a robust definition of CCI and clarity about their defining attributes, so that they are easily identified as a unique group. Having an agreed definition would contribute to the generalisability of future research studies.

\subsection{Exploration of Key Categories and Themes}

During data analysis the category concerning factors that affected the participants' experience of caring for CCI patients, generated a significant volume of data. Although several subthemes were identified within this category, on reflection many of these should not be viewed in isolation, rather as a series of influencing reasons that combine to create a rich understanding of the experience described. In many respects the data spoke for itself with clear themes and categories being identified in the first and second read. The nurses' description of CCI patients was vivid and set the scene for understanding why the participants viewed these patients in such a negative light. Nurses' description of CCI patients often used the word frustration in connection with these patients.It is important to be aware of these causes of frustration as they impact on work-related stress and compassion fatigue of the nurses 
(Sabo, 2006). The main types of frustration for participants when caring for CCI are summarised in Table 8.

Table 8 Types of frustration and negative association with CCI patients in relation to participant principles.

\begin{tabular}{|c|c|}
\hline $\begin{array}{l}\text { Participant } \\
\text { principles }\end{array}$ & Frustration and negative association with CCI patients \\
\hline Not belonging & $\begin{array}{l}\text { Resentment thatCCI patients can only be cared for in ICU. } \\
\text { The nurses' job was made difficult by an unsuitable environment, lack } \\
\text { of equipment and interest from colleagues, absence of careplans and } \\
\text { guidelines and lack of MDT involvement. }\end{array}$ \\
\hline $\begin{array}{l}\text { Fast-paced ICU } \\
\text { work }\end{array}$ & $\begin{array}{l}\text { The slower pace of CCI patients and rehabilitation were considered } \\
\text { boring. } \\
\text { Lack of autonomy and control as the patient interrupted the flow of the } \\
\text { shift. }\end{array}$ \\
\hline Clinical competence & $\begin{array}{l}\text { Nurses felt punished and ashamed when allocated a CCI patient. Some } \\
\text { felt they had upset a senior nurse. }\end{array}$ \\
\hline Conscious patients & $\begin{array}{l}\text { Nurses felt they were wasting time at attempts to try and effectively } \\
\text { communicate with CCI patients. } \\
\text { Nurses were unable to complete physical tasks in a timely manner. } \\
\text { Nurses felt frustration at their patient's behaviour and lacked } \\
\text { sympathy. } \\
\text { Nurses lost control of their shift due to negotiating with the patient. } \\
\text { Restless and agitated patients were considered physically and } \\
\text { emotionally exhausting to look after. } \\
\text { Staff experienced work-realted stress due to the demanding nature of } \\
\text { CCI patients. }\end{array}$ \\
\hline Isolation & $\begin{array}{l}\text { Nurses felt physically removed in side rooms, lacked peer support and } \\
\text { interest from colleagues }\end{array}$ \\
\hline No enjoyment & $\begin{array}{l}\text { Nurses resented that these patients had to be looked after in ICU. } \\
\text { Nurses did not feelany personal satisfaction from caring for them. } \\
\text { As CCI patients were a low priority within ICU, experienced nurses } \\
\text { felt their time was better spent caring for acutely unwell patients. }\end{array}$ \\
\hline Unpopular patients & $\begin{array}{l}\text { Nurses associated aggression and heaviness with CCI patients. These } \\
\text { descriptions carry direct implications on the nurses' shift and justify (in } \\
\text { the participants' mind) why it might be 'ok' to not want to look after a } \\
\text { CCI patient. }\end{array}$ \\
\hline $\begin{array}{l}\text { Withdrawal and } \\
\text { palliation }\end{array}$ & $\begin{array}{l}\text { Nurses experienced moral distress at persisting in futile treatment and } \\
\text { inconsistent medical plans. }\end{array}$ \\
\hline Continuity of care & $\begin{array}{l}\text { Nurses suffered distress and frustration at not being listened to by } \\
\text { medical teams and watching a slow and laboured recovery. }\end{array}$ \\
\hline Workload & $\begin{array}{l}\text { Nurses linked physical tasks and treatments with being busy. They felt } \\
\text { frustrated that their shift was boring, yet lamented that they were often } \\
\text { just as busy when caring for CCI patients. Nurses found it difficult to } \\
\text { quantify the emotional and social costs of their shift. For this reason } \\
\text { there was confusion in deciding whether CCI patients were easy or } \\
\text { difficult to care for. }\end{array}$ \\
\hline Documentation & $\begin{array}{l}\text { Poor continuity of care and a lack of medical direction during the shift } \\
\text { caused the nurses frustration. This was considered a time-wasting } \\
\text { aspect of caring for CCI patients. }\end{array}$ \\
\hline
\end{tabular}




\subsection{Nurse Autonomy and Control}

The issue of nurses' lacking autonomy was a recurrent theme that encompassed several issues. This was particularly relevant for participants when describing decision-making for patient care decisions. They felt largely excluded from involvement in decision-making, which led to a loss of autonomy and control over their patient's care. Participant's felt powerless to change unsatisfactory situations and unable to make decisions due to a lack of autonomy in their practice. These phenomena have been previouslyexplored and discussed by researchers McGrath, Reid \& Boore(2003). McGrath et al., (2003) argued thatthis powerlessness and lacking of autonomy was in part due to inadequate training and under-utilising nurses skills and experience.

Throughout the interviews, there was reference to needing to control the day, predominantly from the nurses' perspective. When participants were interrupted by their patients, or were slowed down by the medical team not listening to their opinion, these were causes of frustration and deemed time-wasting. Participants related this to preferring acutely unwell, sedated patients. Participants' attempts to gain control were constantly challenged in day-to-day practice, for example, not being able to take a patient outside due to poor weather or insufficient staffing; not being able to shower a patient because the bed wouldn't fit in the bathroom. These were sources of participant disappointment and frustration.

Some participants felt that patient's interests conflicted with their own. This was evident in participants' reluctance to allow CCI patients any influence regarding the content or structure of the shift. When asking patients to make choices in their care, nurses limited the options available. In this way, either answer would be acceptable to the nurse. For example, patients were offered either a wash or shower in the morning but not asked about their normal daily routine(whether they preferred an evening shower, a daily shave or wash after breakfast). Despite this behaviour participants believed they were responsive to the individual needs of patients. None showed any understanding that this practice was, albeit unintentionally, restrictive and manipulative. In this regard, the notion of trying to normalise CCI patients was brought up, in attempt to justify the structure of the shifts. References to day and 
night routines were common examples of normalising CCI patients. This disparity between patient and nurses' interests has been observed previously by Elander, Dreschler \& Persson (1993). Nurses were found to have conflict between patient interests and those of physicians, relatives and other patients (Elander et al., 1993).

Participants offered little insight into the controlling approach evident in their nursing practice. Not having control was used as a justification for not wanting to care for CCI patients. Due to this unrecognised conflict, participants had not reflected on the causes of frustration related to autonomy when caring for CCI patients. In practice it seemed that an unacknowledged vicious cycle had developed that was affecting their perspective and nursing practice (Figure 3). This cycle is reflective of findings from McGrath et al., (2003).

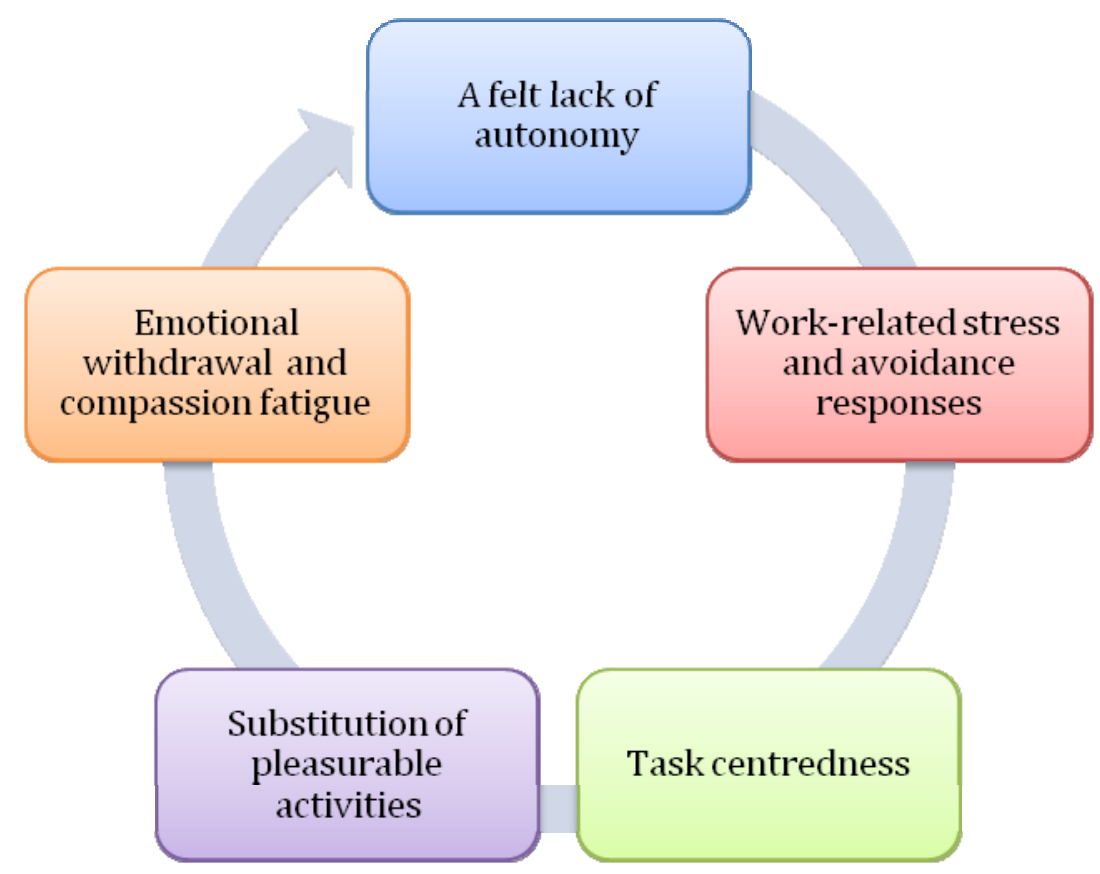

Figure 3 Cycle linking participant lack of autonomy with compassion fatigue.

By avoiding stressful tasks, participants were compromising the caring aspect of their job and distancing themselves from close involvement with their patient. There was no mention of assistance or support from employers, although peer support was found to be useful when caring for CCI patients. McGrath et al., (2003) argue that if caring for others is to be a continuing possibility, then employers and senior staff need to 
start caring for nurses. Suggestions of caring for staff include enhancing the ability of work groups to support each other and have more counseling services (McGrath et al., 2003). Also to recognise the stresses associated with providing holistic care, and the implications of avoiding patients' emotional demands in dealing with these stressors (McGrath et al., 2003).

\subsection{Work-related Stress and Compassion Fatigue}

Avoidance strategies were evident in participants who carried out physical objectives but avoided the emotional demands, thus impairing the provision of holistic care. By avoiding the stressful job of managing emotional demands from CCI patients, participants distanced themselves from close involvement.This phenomenon of avoidance and distancing from patients is a common feature of compassion fatigue (Sabo, 2006; Badger, 2001). Participants showed little understanding that they had experienced work-related stress in relation to caring for CCI patients. Neither did they recognise the transference of previous negative experiences of CCI patients in their nursing practice.

Participants displayed a number of behaviours that might be linked to vicarious traumatisation. In terms of the frame of reference and imagery(Pearlman \& Saakvitne, 1995a), nurses found the experience of caring for a slowly rehabilitating CCI patient distressing. Especially given the multiple medical problems that CCI patients typically experience, the empathetic nurses found this upsetting and were able to describe images and smells of the experience, long after having cared for them. Concerning ego resources(Pearlman \& Saakvitne, 1995a), participants were uniformly stunted in their personal growth concerning meeting the personal needs of CCI patients. In part this was due to sparse teaching and training, but may also be due to a traumatising experience that subsequently led to poor clinical decision-making coupled with a lack of insight and insensitivity concerning the experience of CCI patients. Finally, in relation to self-capacities, participants described experiencing little enjoyment and were reluctant to care for CCI patients, which may be accounted for by an impaired ability to deal with interpersonal difficulties.

There was overwhelming opinion that CCI patients were exhausting to look after and because of this, nurses should take regular breaks from caring for them. Solutions for 
how staff allocation could be more effective varied greatly between participants. Some felt that having the same nurse take care of CCI patients would promote continuity of care, whilst others felt having a change of nurse introduced fresh ideas to the patient's care and helped avoid staff burnout. CCI patients were considered less complex than conventional ICU patients, with lower acuity and suitable for high dependency units (HDUs). The significance of viewing CCI patients as suitable for HDUs concerns allocation, as this assumption justifies nurse-to-patient ratios changing from 1:1 to 1:2. Compared with international HDU staffing levels, these ratios are relatively safe, as nurse-patient ratios vary from 1:3 (Boots \& Lipman, 2002) 2:3 (Garfield, Jeffrey \& Ridley, 2000) to 1:2 (Department of Health, 1996). The concern is that CCI patients are not seen as complex patients who need intense and skilled nursing from one nurse. Rather than looking at nursing ratios as an option for staffing CCI patients, a more useful approach would be to adequately support the nursing staff with guidance and resources to carry out duties effectively and at an excellent standard.

\subsection{The CCI Patient in the ICU Environment}

The perceived experiences of CCI patients included patient frustration, lethargy, weakness, difficulty concentrating, stress due to poor communication, feeling worried and need for family involvement in their rehabilitation. These perceived experiences were parallels of findings from studies by Roulin \& Spirig (2006) and Nelson et al., (2004). As the primary focus of this thesis concerns the nurses' experiences, rather than patient experiences, participants were encouraged to discuss influencing factors that contributed towards these perceived experiences. This yielded participant discussion concerning how the ICU environment impacted on the patient, themselves and the care given.

The intensive care environment was repeatedly questioned by participants, regarding its suitability for meeting CCI patient needs. There was overwhelming opinion that ICU was not the best place for CCI to be cared for, with some suggesting HDUs as a possible alternative. The participants' observations were not unreasonable, and were in keeping with Bersten and Soni’s (2003) recommendations for how an ICU should be designed: bed areas should be large enough to accommodate patient, staff and 
equipment without overcrowding, single rooms are necessary for isolation cases and for conscious long-stay patients, all staff and patient areas must have large windows to reduce patient disorientation and stress.

It is important to acknowledge the relevant aspects of custom-built CCI care units that have been developed internationally. Although building specialist care units (SCUs) and respiratory care units (RCUs) is unrealistic for New Zealand hospitals, some components of their structure and management could be incorporated into CCI patient care. Combining a suitable low technology working environment (Douglas et al., 1996; Song et al., 1997) and coordinating CCI care by a senior nurse working within a multi-disciplinary team (Roulin \& Spirig, 2006; Carasa \& Polycarpe, 2004) would be achievable.

There was a strong impression from all participants that CCI patients were not viewed as true ICU patients. An underlying resentment pervaded from this viewpoint because this denotes that if CCI patients do not belong in ICU, then why should a nurse trained to treat the intensity of a critically unwell ICU patient, have to look after this type of HDU patient? CCI were not viewed as a discreet group within ICU and hence were not seen as fitting into this specialty. On deeper thought, the notion of patient groups not 'fitting in' to ICU was familiar. From practice there are distinct groups of patients who are unpopular and slightly resented, including bariatric, overdose and psychotic patients (Brown, 2006; Ross \& Goldner, 2009). Participants applied some of these unpopular patient attributes to CCI patients. For example, nurses described a frustrating day as one where the patient "pulls off things" and "is psychotic," while others commented that CCI patients could be "aggressive," "heavy” and "not helping themselves." These descriptions reflect CCI patient characteristics that caused frustration to nurses in Roulin \& Spirig's (2006) study, including patient confusion, depression, difficulty concentrating and immobility (Roulin \& Spirig, 2006). It seems then that participants' felt justified in having negative opinions towards specific patient groups. According to Binnie \& Titchen, (2001) nurses fear being 'stuck' with an unpopular patient and discriminate against them by simply ignoring them. 


\subsection{Teamwork, Nursing Practice and Continuity of Care}

Continuing with the view that CCI patients are not perceived as belonging within ICU is the concern that they are a low priority to the ICU team. The view that these patients are not as important as other ICU patients is worrying, as this carries implications for appropriate allocation of nurses, resources, training and amount of effort afforded to caring for these patients. In one respect the lack of interest concerning CCI patients is not altogether surprising. None of the participants had received any formal or informal training concerning how to assess, plan and implement care specific to the needs of a CCI patient. I could relate to this as a nurse who has attended several ICU study days and studied postgraduate papers, but has only once been formally taught about how to care for long-stay patients. On investigation, Otago, Auckland and Victoria Universities offer no postgraduate papers specific to this patient population. The revised NZNO Critical Care Curriculum for Education (2009) does incorporate 'care of the long-term patient' into its $9^{\text {th }}$ (and final) psychosocial section. Interestingly, it is placed immediately before the section 'death, dying and withdrawal of treatment.'

The lack of multi-disciplinary team involvement caused further frustration to participants. Bersten \& Soni (2006) recommend ICUs have access to dieticians, social workers and other therapists should be available and on-going academic and teaching programmes must be instituted (Bersten \& Soni, 2006). Furthermore, communication should be effective and honest between senior doctors and family, with one doctor being identified as the ICU representative to liaise with a particular family (Bersten \& Soni, 2006). All of these issues were felt to be sub-standard at both sites, causing participants frustration, as these restricted the nurses' ability to provide effective care to their patients. The cumulative effect of an inadequate physical environment, with insufficient training and poor communication between doctors and family created a difficult and unsupportive working environment. Given that the provision of excellent nursing care requires nurses to be equipped with the best tools, most effective methods of delivering care and knowledge of the latest critical care research (Wlody, 2007), it is unsurprising that participants felt unsupported and ill-equipped to achieve excellent nursing care for their CCI patients. 
To summarise, participants felt they were looking after patients who should not be in ICU, in an unsuitable environment, with limited resources, which made the nurse's job even harder. Add to this the lack of guidance, training, and continuity of care, and a bigger picture evolves, which largely explains the participants' negativity towards CCI patients.

\subsection{The Culture of ICU}

The impact of the ICU culture upon individual and collective nursing practice was profound. Organisational culture refers to the unique pattern of norms, values, attitudes, beliefs and behaviours, which characterise the interactions of groups and individuals as they attempt to achieve organisational goals (Eldridge \& Crombie, 1974). One aspect of this was that participants focused on the physical essential tasks when caring for CCI patients, which were considered fairly simple, dull and repetitive. For example, a bed-bath was seen as one of many personal care tasks that had to be done, not as an opportunity to make detailed observations of the patient's physical well-being and to address any identified concerns. In this regard participants viewed CCI patients as recipients of tasks, rather than vulnerable people, deprived of normal independence and struggling to cope with being ill (Binnie \& Titchen, 2001). The participants struggled to match their compassion for this group of patients with the feeling that caring for them was tedious and boring. These findings reflect the study by Roulin \& Spirig (2006), who found nurses deemed the slow progress of CCI patients as frustrating.This mismatch between what nurses said and what they actually experienced could lead to feelings of guilt, frustration, dissatisfaction and a feeling that their nursing is not what it ought to be (Binnie, 1988).

The doctor-nurse interactions were also influential on the experiences of the participants. Many expressed having to make their recommendations in an overt and subtle manner, which reflected a lack of confidence and skill between the nurse and doctor. Participants felt there was a lack of mutual respect, trust and co-operation, which impacted on a collaborative approach to caring for CCI patients. This reflects previous study findings that the role of the intensive care nurse is pivotal in implementing clinical decisions, yet remains devalued and unacknowledged due to medical dominance and control (Coombs \& Ersser, 2003). 


\subsection{Withdrawal of Care and Palliation}

Several participants raised the topic of withdrawing care from ICU patients as an important issue. As I reflected upon this anomaly, I began to think about the types of patient that are admitted to ICU, and then viewed them as a continuum. This was similar to the dying trajectory created by Strauss and Glaser (1970). Strauss and Glaser (1970) identified four types of death expectation: certain death at a certain time, certain death at an uncertain time, uncertain death but a known time, uncertain death and an uncertain time. In a similar thread to this trajectory, ICU patients can be viewed with a degree of certainty and uncertainty. At one end of the spectrum are the acutely unwell patients admitted to ICU who are prevented from dying, at the other end those who ICU allows to die through the withdrawal of care. Both extremes generate sympathy and interest from the nurses and clinicians (Simpson, 1997), yet CCI patients have been viewed with resentment and little compassion. My question was 'where do CCI fit on the continuum?' They seem to slot in just under the 'being allowed to die' stage. If this is true, then this adds to our understanding of why CCI patients are viewed as exhausting to look after. Not only are the nurses dealing with the emotional, psychological and family-related issues concerning fear of death, uncertainty and hope, but also the physical endeavours of pushing on towards an intangible goal. Participants discussed the importance of ensuring CCI patient's dignity and comfort, making environmental changes, managing patient's discomfort and promoting family presence, which all reflect suggestions for improving end-oflife care in ICUs (Beckstrand, Callister \& Kirchhoff, 2006).

Participants found the physical environment of ICU as having a major impact on the nurses' ability to provide dignified care for patients and their families, particularly given the lack of privacy, side rooms and the restrictive number of family allowed to visit (Fridh et al., 2009). Participants prioritised patient's comfort and dignity, caring for family and ensuring patients were not left unaccompanied (Fridh et al., 2009). As these findings share similarities with that of the participants in this study, it is not surprising that links were made between the nurses' experience of CCI patients and that of dying patients. 
Participants from this study expressed exerting a lot of physical and emotional effort without a visible end point. Given that the ICU nurses have described their preference for fast-paced and results-focused care, this might cause considerable frustration and work-related stress. The participants seemed to be more compassionate for patients who were dying or had treatment withdrawn, than for CCI patients. In order to understand how the withdrawal of care might relate to CCI patients, palliative care in ICU and withdrawal of care literature was revisited.

None of the participants talked about the need for palliative care involvement with CCI patients. However, participants expressed distress concerning patient symptoms and communication problems, which are common issues related to palliative care. This was an interesting paradox that was not acknowledged by any participant. In particular, participants felt it was important to respect patients' wishes and incorporate these into their care. Koesel (2008) articulates the same points of concern that were causes of frustration by this study's participants, including impaired communication and symptom burden. The distressing experience of aggressively treating a dying patient, as discussed by several participants in Koesel’s study (2008), share similarities with the distressing experience of mismanaging symptom based care for CCI patients.

The findings from Psirides \& Sturland (2009) study concerning withdrawal of active treatment provide resultsthat reflect the participants' experiences and help to explain why they linked decision-making of CCI care, with withdrawal of curative therapy. Just as previous studies have found that ICU nurses are not always involved in withdrawal decisions (Viney, 1996), so the participants were not always involved in the direction of care their CCI patients received. This is an unusual situation for an ICU nurse to be, as typically, ICU nurses contribute to decision-making processes, as there are usually high nurse/patient ratios, close relationships with the family and patient, and providing daily care (McMillen, 2008). This closeness with the patient and their care provides the opportunity to discuss the wishes of the patient regarding treatment, death and dying (Watson, 1993). In particular, nurses are recognised to have particular insight into patients' wishes as they spend most of their time with the patient and family (British Medical Association, 2001). These certainly echo some of the issues that participants voiced as causes of frustration and distress. 


\subsection{Summary of Exploration Discussion}

Lack of autonomy led to participants feeling powerless in decision-making for patient care decisions and led to feelings of frustration, nonchalance and exclusion. Participants felt powerless to change this unsatisfactory situation and coped with this stress through avoidance strategies and task-centred approaches to their care. Participants believed their nursing allowed patients a choice in day-to-day activities, but their practice was restrictive, with priority to tasks that made the nurses' shift more enjoyable. Work-related stress was evident due to patient care, interpersonal relationships with colleagues and bureaucratic constraints. A link was made between some of the participants' behaviour and the concept of vicarious traumatisation, arguing that nurses may find caring for CCI traumatising, which could lead to avoidance and reluctance to care for CCI patients. The implications of effective staff allocation with sufficient resources, training and peer support were explored, with reference to the impact that organisational culture of ICU has upon staff. From this the appropriateness of ICU as a rehabilitation environment was debated and the notion of the unpopular patient was discussed. Parallels were made and then articulated between nursing dying patients and nursing CCI patients. Of note, symptom based care, prioritising comfort and promoting clear communication were shared aspects of palliative and CCI care. The integration of palliative and critical care was found to be reasonable for CCI patients.

It is interesting given the participants' strong responses that no previous researchers have focused on these important nursing issues before. This is especially topical when considering the documented incidence of work-place stressors and burnout within ICUs internationally, and their effects on job satisfaction and staff retention (Mealer, Shelton, Berg, Rothbaum \& Moss, 2007; Stone et al., 2007). 


\subsection{Implications for Improving Nursing Practice}

From the discussion, there are several areas warranting improvements in practiceand needing further research.

\subsubsection{The culture of ICU}

First and foremost is the need for ICU staff to recognise CCI patients as a unique patient group, needing intensive and compassionate care that address their physical, emotional and social needs. In order to achieve this, a suitable environment with sufficient investment in teaching, training and resources is required. An ICU culture that embraces CCI patients as belonging to them is also necessary.

Given the complex needs of CCI patients and the perceived benefits of clinical supervision, incorporating reflective dialogue into the ICU management of these patients may be beneficial to nursing staff and quality of patient care (SextonBradshaw, 1999). Nurses need to be offered regular counseling and psychological support that promotes reflective practice. This would help reduce the risk of developing secondary traumatic stress syndrome and compassion fatigue (Badger, 2001). As part of recognising the emotional, social and symptom-based needs of CCI patients, ICU nurses would benefit from being taught basic counseling skills. Given the vast array of specialist needs, rather than train ICU nurses to become proficient in each of these skills, it would be prudent to invite inter-disciplinary practitioners to become involved in CCI care. This would enable the most skilled practitioners to provide interventions and therapies that would directly meet the needs of CCI patients. The incorporation of interdisciplinary care into ICUs management of CCI patients would raise their clinical profile, establish multi-disciplinary goals and provide support and education to the nursing staff (Opie, 1997).

\subsubsection{The CCI patient in the ICU environment}

As New Zealand has a relatively small population and associated health budget, compared with wealthier and more populated countries, it is important to generate recommendations that are within the scope of New Zealand's health care budget. Although building specialist care units (SCUs) have increased nursing satisfaction and staff retention (Song et al., 1997), this is an impractical and expensive option for New Zealand hospitals. Instead, reviewing the structure of ICUs within tertiary level 
hospitals is advised, with a view to locating under-used areas in the ICU for CCI patients. Creating a spacious area for CCI patients, that is empty of unnecessary equipment, and that can be tailored to suit the individual needs of the CCI patient is a manageable option. Certainly some of New Zealand's older ICUs are restricted due to a lack of modern fixtures and space, and require the nurses to be creative when planning innovative nursing care. For example, moving patients from noisy bed spaces to quieter side rooms so they can sleep at night, is achievable if the culture of that ICU perceives this to be practical and important for the patient's wellbeing. If the culture of the ICU dismisses this idea as time-wasting and un-important, then the likelihood of this task proceeding is greatly reduced. In newer ICUs, patients and nurses benefit from larger bed spaces, patient showers, in-built TVs at bed spaces, more natural light from windows and greater noise reduction from insulation. These help meet some of the social and entertainment needs of CCI patients.

Fundamental to future planning and implementation of care that meets CCI patient needs,is the recognition of CCI patients as a complex and distinct ICU group. Raising the profile of these patients as a unique group within ICU, through further research and publication of studies in journals and at international conferences is recommended. In so doing, CCI patients may finally receive the attention and interest of interdisciplinary ICU staff that has thus far eluded them.

\subsubsection{Teamwork, nursing practice and continuity of care}

Participants were critical of the level of interdisciplinary care in their ICUs. Many felt that CCI patient care was medically driven, with limited interest and respect shown towards specialties and therapists by the ICU doctors. This impacted on the nurses' ability to provide comprehensive rehabilitation and caused frustration and stress. Creating a working environment where interdisciplinary, patient-centred care can thrive requires skilled communication and true collaboration from health care providers (McCauley \& Irwin, 2006). The role of ICU nurses within this collaborative interdisciplinary model would be to communicate effectively, improve working relationships, manage difficult interactions and implement commonly agreed patientcentred goals and strategies (McCauley \& Irwin, 2006). The importance of education and training to support such developments are likely to be considerable (Coombs \& Lattimer, 2007). 
Teaching health care professionals is largely accepted as fundamental to maintaining clinical proficiency (Binnie \& Titchen, 2001). Just as many ICUs provide study days and teaching sessions concerning ventilation, advanced cardiac and neuro-surgical management, so there is the need to include management of CCI patients. Key topics for these teaching sessions should include the CCI patient and nursing experience, exploration of the emotional, physical and social needs with practical suggestions for optimising care delivery and meeting these patient-centred needs. The teaching sessions should be targeted at the main providers of CCI patient care, including doctors, nurses and health care assistants.

In addition to formal teaching, ICU-based training should be arranged between other therapists, so that the nurses are adequately skilled to provide specific interventions that complement that of the therapists. It is not advised for ICU nurses to become expert therapists themselves, rather to work alongside the specialists and complement their therapies.For example, speech language therapists (SLT) could be asked to teach how to conduct accurate swallow assessments on CCI patients. This might lead to the design and implementation of a nurse-initiated algorithm for conducting swallow assessments on ICU patients. Potential benefits of this for CCI patients include timely swallow assessments over weekends or evenings, when SLT are not available. Similarly, physiotherapists could train ICU nurses to practice passive exercises, use the intermittent positive pressure ventilation equipment, and use the tilt table for CCI patients. These additional skills would help ICU nurses feel a degree of skill and expertise when caring for the specialist group CCI.

Supplemental to education and training, is the need for an evidence-based policy from which a useful CCI patient careplan can be designed. Evidence-based practice refers to the integration of best research evidence with clinical expertise and patient values to facilitate clinical decision-making (DiCenso, Guyatt \& Ciliska, 2005). A clinical policy would promote evidence-based practice within the clinically setting and improve both patient and nursing experiences.

Having a primary nurse or primary team to oversee the care of CCI patients is also advised, to promote interest, consistency and continuity of CCI patient care. Primary 
nursing has been shown to improve levels of responsibility and continuity of care, improve the standard of patient care and has a positive effect on staff retention and job satisfaction (Goode \& Rowe, 2001). A primary team might consist of a senior ICU nurse and ICU Consultant who meet once a week to both review the direction of care and support its implementation. Another aspect to their role would be to ensure open communication between themselves and the patient and family, and establish new initiatives that are patient-centred. Although the thought of being assigned to a CCI patient might seem unappealing to some nurses, it has been observed that primary nurses are often able to develop comfortable relationships with unpopular patients, which helps make it easier for nurses to cope with the intensity of working with them (Binnie \& Titchen, 2001).

\subsubsection{Work-related stress, compassion fatigue and staff allocation}

As part of recognising CCI patients as their own unique patient group, there is the need tolook after the nurses welland support them. Care should be given during allocation of staff to patients, that CCI patients are not always given to the inexperienced new graduate, or repeatedly to the same nurse. Instead a nurse should be allocated who possesses sufficient skill, patience and dedication to provide the CCI patient with everything they need so they can progress with their rehabilitation. The allocation process must also be flexible to accommodate a nurse's request to take a break from caring for a CCI patient, or there is risk of developing work-related stress and vicarious traumatisation. As mentioned previously, work-related stress is common among ICU staff and leads to dissatisfaction and staff retention problems. To minimise the risk of this happening, ICUs would benefit from offering supervision, guidance and counseling to their staff (McGrath, Reid \& Boore, 2003). Regular clinical supervision is recommended as a supportive initiative that would encourage reflective dialogue and develop sensitive nursing practice (Lindahl \& Norberg, 2002).Peer support throughout the shift is also recommended as a means of sharing ideas, planning coordinated care, helping with physical tasks and to feel part of the unit.

Support for nursing staff is further recommended through investing in adequate equipment and resources. Improved resources would support the nurses in providing efficient and better care to CCI patients and make the experience of doing this more 
pleasurable. Resources range from specialist equipment supplied by occupational therapy (easy-grip utensils), to small items that help normalise the patient's day (daily newspaper).

The aforementioned recommendations cover a wide range of issues, ranging from education and training, resources, changing the ICU environment and staff allocation. The focus of these innovations is to provide patient-focused care, which optimises the experience and progress of CCI patients. It is also necessary to try and make the nurse's experience of caring for these patients fulfilling and challenging, in a supportive environment. In order to implement these recommendations successfully, anurse-led care programme that oversees all aspects of CCI care is advised. The programme would incorporate evidence-based practice into the design and implementation of all innovations and would create a supportive and innovative working environment. Through the design of CCI patient care programmes,the effects of compassion fatigue, work-related stress and poor staffingon nurses are likely to reduce considerably (Song et al., 1997).

\subsection{Limitations of the Study}

The interview locations affected the quality of the interviews. When interviewing at SID there were telephone interruptions and the occasional person walking into the room, however the interviews were in a calm and quiet environment. This allowed both the interviewer and participant to really embrace the topics being discussed.

I felt my presence in NID was verging on intrusive when I was required to conduct the interviews at the bed spaces whilst the ICU nurse worked. It was impressed upon me how busy the ICU was and that no nurse could be freed up for interview. The working dynamic at NID was that I fit around them. Having to conduct the interviews at the bedside had a negative impact upon the flow and quality of the interviews. The environment was noisy, with many distractions from passing relatives, nurses, the patient and alarming equipment. Participants were seldom able to fully concentrate or engage with the topic being discussed as their attention was on their patient and clinical jobs. This led to the interviews feeling slightly desperate and unimportant and finishing well short of the allotted 60 minutes timeframe. There were constant interruptions, which led to trains of thought being interrupted and 
valuable detail slipping from the conversation. When I finished my final interview at NID I felt that despite obtaining valuable data, I had not been able to make the most of discussions. I regretted that the ICU cicumstances had prevented the interviews from being conducted privately, as an opportunity to retrieve important data had not been optimised.

\subsection{Future Research}

This study has generated knowledge and understanding about nurses' experiences of caring for CCI patients. Although the size and scale of the study is small, it is the first of its kind due to the absence of research exploring this important stakeholder group. This under-studied patient group has a significant impact on nursing and medical staff, relatives, resources and future planning of health care initiatives. Unless CCI patients are managed in an appropriate manner, there is real risk of neglecting their needs, exposing staff to compassion fatigue and work-related stress and inappropriately resourcing this group of patients. In the current economic climate, where cost-saving initiatives are necessary and staff satisfaction is vital to hospital staff retention there are compelling reasons to continue researching this patient group. There are several areas that need further investigation, before a more complete understanding of nursing CCI patients can be understood. Future research topics include:

- The impact of the ICU environment on nurses looking after CCI patients.

- Coping strategies of ICU nurses caring for CCI patients.

- Allocation of nursing staff to CCI patients.

- Comparing 'standard practice' of CCI patients with a nurse-led care programme specific to CCI patient needs.

- Exploration of multi-disciplinary involvement in CCI patient care and how this affects nursing experience and practice.

- ICU management perceptions of work-related stress in relation to nurses caring for CCI patients.

- Exploring education and training strategies for ICU nurses so they can develop skills specific to caring for CCI patients.

- Exploring models of care appropriate for intensive care and CCI patients. 


\subsection{Thesis Conclusion}

The study highlighted the variety of experiences that ICU nurses have when caring for CCI patients. A lack of literature made it difficult to compare participant experiences with those from other international ICUs. This detracts from the study being used to gauge the range and depth of all ICU nurses caring for this population. However, this study is important, as it is the first piece of research that articulates nurses' experiences. The impact of the ICU environment, education, staffing and cultural dynamics of ICU were found to be influential in the nurses' ability to perform care specific to CCI patients. Compassion for this group of patients was scarce due to nurses’ losing control of their shift, viewing CCI patients as not belonging in ICU, lacking evidence-based understanding about CCI patients and experiencing workrelated stress. An association was made between caring for CCI patients and caring for dying patients and those where care is withdrawn. Several similarities between these two practice groups were identified and the opportunity for palliative care involvement with CCI care was considered. Findings from this study revealed a considerable volume of negative criticism from nurses in association with CCI patients.

Overall the findings evoked feelings of sadness and frustration in me, despite understanding the manifold reasons for their occurrence. However, I am encouraged that this study presents an exciting opportunity to challenge current practice.Given the lack of research into nurses' experience of caring for CCI patients, it is imperative that the findings of this study are disseminated to local tertiary ICUs and district health boards. Due to the limited budget within New Zealand health care, it is unrealistic to expect that the study findings will lead to investment in customdesigned care units for CCI patients. A more realistic outcome is to shape interdisciplinary care-packages using research-based findings and invest in research that explores this complex and distinct patient group. 


\section{REFERENCES}

Aari, R-L., Tarja, S., \& Helena, L-K. (2008). Competence in intensive and critical care nursing: A literature review. Intensive and Critical Care Nursing, 24, 7889.

Alasad, J. (2001). Managing technology in the intensive care unit: The nurses' experience. International Journal of Nursing Studies, 39, 407-413.

Almerud, S., Alapack, R. J., Fridlund, B., \& Ekebergh, M. (2007). Of vigilance and invisibility - being a patient in technology intense environments. Nursing in Critical Care, 12(3), 151-158.

Alty, A., \& Rodham, K. (1998). The ouch! factor: Problems in conducting sensitive research. Qualitative Health Research, 8(2), 275-282.

American Association of Critical Care Nurses. (2005). AACN standards for establishing and sustaining healthy work environments: A journey to excellence. American Journal of Critical Care, 14, 187-197.

Ames, A., Adkins, S., Rutledge, D., Hughart, K., Greeno, S., Foss, J., Gentry, J., \& Trent, M. (1992). Assessing work retention issues. Journal of Nursing Administration, 22(4), 37-41.

Appleton, J. V. (1995). Analysing qualitative data: Addressing issues of validity and reliability. Journal of Advanced Nursing, 22, 993-999.

Badger, J. M. (2001). Understanding secondary traumatic stress. American Journal of Nursing, 101(7), 26-32.

Badger, J. M., \& O'Connor, B. (2006). Moral discord, cognitive coping strategies, and medical intensive care unit nurses: Insight from a focus group study. Critical Care Nurses Quarterly, 29(2), 147-151.

Bailey, R. D. (1985). Coping with stress in caring. Oxford: Blackwell.

Ballou, K. A. (1998). A concept analysis of autonomy. Journal of Professional Nursing, 14(2), 102-110.

Bashour, C. A., Yared, J-P., Ryan, T. A., Rady, M. Y., Mascha, E., Leventhal, M. J., \& Starr, N. J. (2000). Long-term survival and functional capacity in cardiac surgery patients after prolonged intensive care. Critical Care Medicine, 28(12), 3847-3853.

Becker, H. S. (1996). The epistemology of qualitative research. In Jessor, R., Colby, A., \&Shweder, R. A. (Eds.), Ethnography and human development: Context and meaning in social inquiry(pp. 53-71). Chicago: University of Chicago Press. 
Beckstrand, R. L., Callister, L. C., Kirchhoff, K. T. (2006). Providing a "good death": Critical care nurses' suggestions for improving end-of-life care. American Journal of Critical Care, 15, 38-45.

Beeby, J. (2000). Intensive Care nurses' experiences of caring. Intensive and Critical Care Nursing, 16, 151-163.

Bersten, A. D., \& Soni, N. (2003). Oh's Intensive Care Manual (5th. ed.): Butterworth Heinemann: Edinburgh.

Binnie, A., \& Titchen, A. (2001). Freedom to Practice: The development of patientcentred nursing. Edinburgh: Butterworth-Heinemann.

Binnie, A. J. (1988). The working lives of staff nurses: A sociological perspective. Warwick University.

Blegen, M. A., Goode, C., Johnson, M., Maas, M., Chen, L., \& Moorhead, S. (1993). Preferences for decision-making autonomy. Image: Journal of Nursing Scholarship, 25(4), 339-344.

Boots, R., \& Lipman, J. (2002). High dependency units: Issues to consider in their planning. Anaesthesia and Intensive Care, 30(3), 348-354.

Boyle, D. K., Bott, M. J., Hansen, H. E., Woods, C., \& Taunton, R. L. (1999). Manager's leadership and critical care nurses' intent to stay. American Journal of Critical Care, 8(6), 361-371.

British Medical Association (2001). Witholding and withdrawing life-prolonging medical treatment: Guidance for decision making. London: BMJ Books.

Brown, I. (2006). Nurses' attitudes towards adult patients who are obese: A literature review. Journal of Advanced Nursing, 53(2), 221-232.

Buerhaus, P. I., Donelan, K., Ulrich, B. T., Norman, L., \& Dittus, R. (2005). Is the shortage of hospital registered nurses getting better or worse? Findings from two recent national surveys of RNs. Nursing Economic, 23(2), 61-96.

Burnard, P. (1991). A method of analysing interview transcripts in qualitative research. Nurse Education Today, 11, 461-466.

Burns, N., \& Grove, S. K. (2005). The practice of nursing research, conduct, critique and utilisation. (5th ed.). Philadelphia: WB Saunders.

Carasa, M., \& Nespoli, G. (2002). Nursing the chronically critically ill patient. Critical Care Clinics, 18, 493-507.

Carasa, M., \& Polycarpe, M. (2004). Caring for the chronically critically ill: Establishing a wound-healing program in a respiratory care unit. The American Journal of Surgery, 188, 18S-21S. 
Carson, S. S., \& Bach, P. B. (2002). The epidemiology and costs of chronic critical illness. Critical Care Clinics, 18, 461-477.

Cheater, F. M., \& Hale, C. (2001). An evaluation of a local clinical supervision scheme for practice nurses. Journal of Clinical Nursing, 10(1), 119-130.

Combes, A., Costa, M-A., Trouillet, J-L., Baudot, J., Mokhtari, M., Gibert, C., \& Chastre, J. (2003). Morbidity, mortality, and quality of life outcomes of patients requiring $>14$ days of mechanical ventilation. Critical Care Medicine, 31(5), 1373-1381.

Coombs, M., \& Ersser, S. (2003). Medical hegemony in decision-making: A barrier to interdisciplinary working in intensive care? Journal of Advanced Nursing, 46(3), 245-252.

Coombs, M., \& Lattimer, V. (2007). Safety, effectiveness and costs of different models of organising care for critically ill patients: Literature review. International Journal of Nursing Studies, 44, 115-129.

Coren, A. (2001). Short-term psychotherapy: A psychodynamic approach. Basingstoke, England: Palgrave.

Creswell, J. W. (1998). Qualitative inquiry and research design: Choosing among five traditions. London: Sage.

Currey, J., \& Botti, M. (2006). The influence of patient complexity and nurses' experience on haemodynamic decision-making following cardiac surgery. Intensive and Critical Care Nursing, 22, 194-205.

Daly, B. J., Rudy, E. B., Thompson, K. S., \& Happ, M. B. (1991). Development of a special care unit for chronically critically ill patients. Heart and Lung, 20, 4552.

Daly, B. J., Douglas, S. L., Kelley, C. G., O'Toole, E., \& Montenegro, H. (2005). Trial of a disease management program to reduce hospital readmissions of the chronically critically ill. Chest, 128(2), 507-517.

Davis, B., Ward, C., Woodall, M., Shulz, S., \& Davis, H. (2007). Comparison of job satisfaction between experienced medical-surgical nurses and experienced critical care nurses. MEDSURG Nursing, 16(5), 311-316.

Dawson, D. (2006). The art of nursing: A hidden science? [Editorial].Intensive and Critical Care Nursing, 22, 313-314.

DeKeyser, F. (2003). Psychoneuroimmunology in critically ill patients. AACN Clinical Issues, 14(1), 25-32.

Denzin, N., \& Lincoln, Y. (2005). Handbook of Qualitative Research. (3rd ed.). Thousand Oaks, California: Sage. 
Department of Health (1996). Guidelines on admission to and discharge from intensive care and high dependency units. London: Department of Health.

DiCenso, A., Guyatt, G., \& Ciliska, D. (2005). Evidence-Based Nursing. St. Louis: Elsevier Mosby.

DiCicco-Bloom, B., \&Crabtree, B. F. (2006). The qualitative research interview. Medical Education, 40, 314-321.

Douglas, S., Daly, B. J., Rudy, E. B., Sereika, S. M., Menzel, L., Song, R., Dyer, M. A., \& Montenegro, H. D. (1996). Survival experience of chronically critically ill patients. Nurse Researcher, 45, 73-77.

Downe-Wamboldt, B. (1992). Content analysis: Method, applications, and issues. Health care Women International, 13(3), 313-321.

Elander, G., Dreschler, K., \& Persson, K. W. (1993). Ethical dilemmas in long-term care settings; interviews with nurses in Sweden and England. International Journal of Nursing Studies, 30(1), 91-97.

Eldridge, J. E. T., \& Crombie, A. D. (1974). A Sociology of Organisations. London: Allen and Unwin.

Engstrom, A., \& Soderberg, S. (2007). Close relatives in intensive care from the perspective of critical care nurses. Journal of Clinical Nursing, 16, 1651-1659.

Estenssoro, E. Reina, R., Canales, H. S., Saenz, M. G., Gonzalez, F. E., Aprea, M. M., Laffaire, E., Gola, V., \& Dubin, A. (2006). The distinct clinical profile of chronically critically ill patients: A cohort study. Critical Care, 10(3), R89.

Figley, C. R. (1995). Compassion fatigue: Coping with secondary traumatic stress disorder in those who treat the traumatized. New York: Brunner/Mazel.

Figley, C. R. (1998). Burnout in families: The systemic costs of caring. Boca Raton, Fl: CRC Press.

Fridh, I., Forsberg, A., \& Bergbom, I. (2009). Doing one's utmost: Nurses' descriptions of caring for dying patients in an intensive care environment. Intensive and Critical Care Nursing, 25, 233-241.

Garfield, M., Jeffrey, R., \& Ridley, S. (2000). An assessment of the staffing level required for a high-dependency unit. Anaesthesia, 55, 137-143.

Gillis, A., \& Jackson, W. (2002). Research for nurses: Methods and interpretation. Philadelphia: F.A. Davis Company

Girard, K., \& Raffin, T.A. (1985). The chronically critically ill: To save or let die? Respiratory Care, 30, 339-347. 
Goldstein, R, L., Campion, E. W., Thibault, G. E., Mulley, A. G., \& Skinner, E. (1986). Functional outcomes following medical intensive care. Critical Care Medicine, 14(9), 783-788.

Goode, D., \& Rowe, K. (2001). Perceptions and experiences of primary nursing in an ICU: A combined methods approach. Intensive and Critical Care Nursing, 17, 294-303.

Granberg, A., Engberg, I. B., \& Lunderg, D. (1996). Intensive care syndrome: A literature review. Intensive and Critical Care Nursing, 12, 173-182.

Granja, C., Lopes, A., Moreira, S., Dias, C., Costa-Pereira, A., \& Carneiro, A., (2005). Patients' recollections of experiences in the intensive care unit may affect their quality of life. Critical Care, 9(2), R96-R109.

Griffiths, R. D., \& Jones, C. (2001). Filling the intensive care memory gap? Critical Care Medicine, 27, 344-346.

Guba, E. G., \& Lincoln, Y. S. (1994). Competing paradigms in qualitative research. In: Denzin, N. K., \& Lincoln, Y. S. (Eds.), Handbook of Qualitative Research (pp. 105-117). Thousand Oaks, California: Sage Publications.

Hafsteindottir, T. B. (1996). Patient's experiences of communication during the respiratory treatment period. Intensive and Critical Care Nursing, 12, 261271.

Halcomb, E., Daly, J., Jackson, D., \& Davidson, P. (2004). An insight into Australian nurses' experiences of withdrawal/withholding of treatment in the ICU. Intensive and Critical Care Nursing, 20, 214-222.

Halm, M. A., Gagner, S., Goering, M., Sabo, J., Smth, M., \& Zaccagnini, M. (2003). Interdisciplinary rounds: Impact patients, families and staff. Clinical Nurse Specialist: Journal of Advanced Nursing Practice, 17, 133-142.

Hammersley, P., \& Mairs, H. (2004). Sampling methods. Nurse Researcher, 12(1), 46.

Hartl, W. H., Wolf, H., Schneider, C. P., Kuchenhoff, H., \& Jauch, K-W. (2007). Acute and long-term survival in chronically ill surgical patients: A retrospective observational study. Critical Care 11, R55.

Harwood, E. M., \& Hutchison, E. (2009). Data collection method series Part 2: Select the most feasible data collection mode. Journal of Wound, Ostomy and Continence Nursing, 36(2), 129-135.

Heland, M. (2006). Frutiful or futile: Intensive care nurses' experiences and perceptions of medical futility. Australian Critical Care, 19(1), 25-31. 
Heyland, D. K., Konopad, E., Noseworthy, T. W., Johnston, R., \& Gafani, A. (1998). Is it 'worthwhile' to continue treating patients with a prolonged stay ( $>14$ days) in the ICU: An economic evaluation. Chest, 114, 192-198.

Higginbottom, G. M. A. (2004). Sampling issues in qualitative research. Nurse Researcher, 12(1), 7-19.

Hsieh, H-F., \& Shannon, S. E. (2005). Three approaches to qualitative content analysis. Qualitative Health Research, 15(9), 1277-1288.

Hsu, C. L., Chen, K. Y., Chang, C. H., Jerng, J. S., Yu, C. J., \& Yang, P. C. (2005). Timing of tracheostomy as a determinant of weaning success in critically ill patients: A retrospective study. Critical Care, 9, R46-R52.

Hurst, S.,\& Koplin-Baucum, S. (2005). A pilot qualitative study relating to hardiness in ICU nurses. Dimensions of Critical Care Nursing, 24(2), 97-100.

Hweidi, I. M. (2007). Jordanian patients' perception of stressors in critical care units: A questionnaire survey. International Journal of Nursing Studies, 44, 227235.

Jones, A. C. (2004). Transference and countertransference. Perspectives in Psychiatric Care, 40(1), 13-19.

Koesel, N. (2008). The chronically critically ill: Opportunities for the palliative care team. Journal of Hospice and Palliative Nursing, 10(2), 83-88.

Kondracki, N. L., \& Wellman, N. S. (2002). Content analysis: Review of methods and their applications in nutrition education. Journal of Nutrition Education and Behaviour, 34, 224-230.

Letvak, S., \& Buck, R. (2008). Factors influencing work productivity and intent to stay in nursing. Nursing Economics, 26(3), 159-165.

Lindahl, B., \& Norberg, A. (2002). Clinical group supervision in an intensive care unit: A space for relief, and for sharing emotions and experiences of care. Journal of Clinical Nursing, 11, 809-818.

Mays, N., \& Pope, C. (2000). Assessing quality in qualitative research. British Medical Journal, 320(7226), 50-52.

McCauley, K., \& Irwin, R. S. (2006). Changing the work environment in ICUs to achieve patient-focused care. Chest, 130(5), 1571-1578.

McCloskey, J. K. (1990). Two requirements for job contentment: Autonomy and social integration. Image: Journal of Nursing Scholarship, 22(3), 140-143.

McEvoy, P. (2001). Interviewing colleagues: Addressing the issue of perspective, inquiry and representation. Nurse Researcher, 9(2), 49-59. 
McGrath, A., Reid, N., \& Boore, J. (2003). Occupational stress in nursing. International Journal of Nursing Studies, 40, 555-565.

McMillen, R. E. (2008). End of life decisions: Nurses perceptions, feelings and experiences. Intensive and Critical Care Nursing, 24, 251-259.

Meadors, P., \& Lamson, A. (2008). Compassion fatigue and secondary traumatisation: Provider self care on intensive care units for children. Journal of Pediatric Health Care, 22(1), 24-34.

Mealer, M. L., Shelton, A., Berg, B., Rothbaum, B., \& Moss, M. (2007). Increased prevalence of post-traumatic stress disorder symptoms in critical care nurses. American Journal of Respiratory and Critical Care Medicine, 175, 693-697.

Ministry of Health. (2002). Toward Clinical Excellence: An introduction to clinical audit, peer review and other clinical practice improvement activities. Retrieved from http://www.moh.govt.nz/moh.nsf/82f4780aa066f8d7cc2570b b006b5d4d/3b8bfa503ae2a522cc256bba00772848/\$FILE/MOH_TCE_2002.p df.

Montuclard, L., Garrouste-Orgeas, M., Timsit, J-F., Misset, B., De Jonghe, B., \& Carlet, J. (2000). Outcome, functional autonomy, and quality of life of elderly patients with a long-term intensive care unit stay. Critical Care Medicine, 28(10), 3389-3395.

Morgan. D. L. (1993). Qualitative content analysis: A guide to paths not taken. Qualitative Health Research, 3(1), 112-121.

Morse, J. (1991). Strategies for sampling. In Morse, J. (Ed.), Qualitative Nursing Research: A contemporary dialogue ( $2^{\text {nd }}$ ed.). Newbury Park CA: Sage.

Nelson, J. E., Kinjo, K., Meier, D. E., Ahmad, K., \& Morrison, R. S. (2002). Palliative care of the chronically critically ill patient. Critical Care Clinics, 18, 659-681.

Nelson, J. E., Meier, D. E., Litke, A., Natale, D. A., Siegel, R. E., \& Morrison, R. S. (2004). The symptom burden of chronic critical illness. Critical Care Medicine, 32(7), 1527-1534.

Nelson, J. E., Tandon, N., Mercado, A. F., Camhi, S. L., Ely, W., \& Morrison, R. S. (2006). Brain dysfunction: Another burden for the chronically critically ill. Archives of International Medicine, 166, 1993-1999.

Nierman, D. M., \& Mechanick, J. I. (1998). Bone hyper-reabsorption is prevalent in chronically critically ill patients. Chest, 114, 1122-1128.

Nunkoosing, K. (2005). The problems with interviews. Qualitative Health Research, 15(5), 698-706. 
Nursing Council of New Zealand (2007). Competencies for registered nurses. Retrievedfrom http://www.nursingcouncil.org.nz/RN\%20Comps\%20final.pdf

Opie, A. (1997).Effective team work in health care: A review of issues discussed in recent research literature. Health Care Analysis, 5(1), 62-70.

O’Riordan, B. (2002). Why nurses choose not to undertake clinical supervision: The findings from one ICU. Nursing in Critical Care, 7(2), 59-66.

O'Sullivan, S., Preston, D. B., \& Forti, E. M. (2000). Predictors of rural critical care nurses' willingness to care for people with AIDS. Intensive and Critical Care Nursing, 16, 181-190.

Patton, M. Q. (1990). Qualitative evaluation and research methods (2nd ed.). Newbury Park, California: Sage.

Pearlman, L. A., \& Saakvitne, K. W. (1995a). Treating therapists with vicarious traumatisation and secondary traumatic stress disorders. In: Figley, C. R. (Ed.), Compassion Fatigue: Coping with secondary traumatic stress disorder in those who treat the traumatized (pp. 150-177). New York: Brunner/Mazel.

Pearlman, L. A., \& Saakvitne, K. W. (1995b). Trauma and the therapist countertransferance and vicarious traumatisation in psychotherapy with incest survivors. New York: W. W. Norton \& Company.

Persenius, M. W., Larsson, B. W., \& Hall-Lord, M-L. (2006). Enteral nutrition in intensive care: Nurses' perceptions and bedside observations. Intensive and Critical Care Nursing, 22, 82-94.

Pitts, M. J., \& Miller-Day, M. (2007). Upward turning points and positive rapportdevelopment across time in researcher-participant relationships. Qualitative Research, 7(2), 177-201.

Polit, D. E., \& Beck, C. T. (2004). Nursing Research: Generating and assessing evidence for nursing practice. ( $8^{\text {th }} \mathrm{ed}$.). Philadelphia: Wolters Kluwer/Lippincott Williams \& Wilkins.

Potter, W. J., \& Levine-Donnerstein, D. (1999). Rethinking validity and reliability in content analysis. Journal of Applied Communication Research, 27, 477-493.

Price, A. M., \& Chalker, M. (2000). Our journey with clinical supervision in an intensive care unit. Intensive and Critical Care Nursing, 16, 51-55.

Psirides, A., \& Sturland, S. (2009). Withdrawal of active treatment in intensive care: What is stopped - comparison between belief and practice. Critical Care and Resuscitation, 11(3), 210-214.

Rafferty, A. M., Ball, J., \& Aiken, L. H. (2001). Are teamwork and professional autonomy compatible, and do they result in improved hospital care? Quality in Health Care, 10, S32-S37. 
Redmond, R., \& Curtis, E. (2009). Focus groups: Principles and processes. Nurse Researcher, 16(3), 57-69.

Rice, P. L., \& Ezzy, D. (1999). Qualitative research methods: A health focus. Oxford: Oxford University Press.

Roberts, K., \& Taylor, B. (2002). Nursing Research Process: An Australian perspective. (2nd ed.). Victoria: Nelson Australia Pty Limited.

Ross, C. A., \& Goldner, E. M. (2009). Stigma, negative attitudes and discrimination towards mental illness within the nursing profession: A review of the literature. Journal of Psychiatric and Mental Health Nursing, 16, 558-567.

Roulin, M-J., \& Spirig, R. (2006). Developing a care program to better know the chronically critically ill. Intensive and Critical Care Nursing, 22, 355-361.

Rubin, H \& Rubin, I. (2005). Qualitative interviewing: The art of hearing data. Thousand Oaks, California: Sage.

Rudy, E. B., Daly, B. J., Douglas, S., Montenegro, D., Song, R., Dyer, M.A. (1995). Patient outcomes for the chronically critically ill: Special versus intensive care unit. Nursing Research, 44, 324-331.

Sabo, B. M. (2006). Compassion fatigue and nursing work: Can we accurately capture the consequences of caring work? International Journal of Nursing Practice, $12,136-142$.

Sandelowski, M. (1997). "To be of use": Enhancing the utility of qualitative research. Nursing Outlook, May/June, 125-132.

Sandelowski, M. (2000). Whatever happened to qualitative description? Research in Nursing \& Health, 23, 334-340.

Sandelowski, M., \& Barroso, J. (2003). Classifying the findings in qualitative studies. Qualitative Health Research, 13(7), 905-923.

Schauer, J. M., Engle, L. L., Maugher, D. T., \& Cherry, R. A. (2009). Does acuity matter? Optimal timing of tracheostomy stratified by injury severity. The Journal of Trauma: Injury, Infection and Critical Care, 66(1), 220-225.

Sexton-Bradshaw, D. (1999). Clinical supervision.Paediatric Nursing, 11(3), 34-37.

Simpson, S. H. (1997). Reconnecting: The experiences of nurses caring for hopelessly ill patients in intensive care. Intensive and Critical Care Nursing, 13, 189-197.

Sinclair, H. A. H., \& Hamill, C. (2007). Does vicarious traumatisation affect oncology nurses? A literature review. Journal of Oncology Nursing, 11, 348356. 
So, H. M., \& Chan, D. S. K. (2003). Perception of stressors by patients and nurses of critical care units in Hong Kong. International Journal of Nursing Studies, 41, 77-84.

Song, R., Daly, B. J., Rudy, E. B., Douglas, S., \& Dyer, M. A. (1997). Nurses’ job satisfaction, absenteeism, and turnover after implementing a special care unit practice model. Research in Nursing and Health, 20, 443-452.

Spencer, M., Kinnear, K., \& Vieira, D. (2000). Clinical supervision: A challenge for critical care nurses. Nursing in Critical Care, 5(3), 142-147.

Strauss, A. L., \& Glaser, B. J. (1970). Angush: A case history of a dying trajectory. London: Mark Robinson \& Co.

Swanson, K. M. (1993). Nursing as informed caring for the well-being of others. Image: Journal of Nursing Scholarship, 25, 352-357.

Teno, J. M., Fisher, E., Hamel, M. B., Wo, A. W., Murphy, D. J., Wenger, N. S., Lynn, J., \& Harrell, F. E. (2000). Decision-making and outcomes of prolonged ICU stays in seriously ill patients. Journal of American Geriatrics Society, 48, S70-S74.

The World Federation of Critical Care Nurses (2005). Position statement on the provision of critical care nursing education. Retrieved from http://en.wfccn.org/pub_education.php.

Thomas, D. C., Kreizman, I. J., Melchiorre, P., \& Ragnarsson, K. T. (2002). Rehabilitation of the patient with chronic critical illness.Critical Care Clinics, $18,695-715$.

Thorne, S., Kirkham, S. R., \& MacDonald-Emes, J. (1997). Interpretive description: A noncategorical qualitative alternative for developing nursing knowledge. Research in Nursing \& Health, 20, 169-177.

Varjus, S. L., Suominen, T., \& Leino-Kilpi, H. (2003). Autonomy among intensive care nurses in Finland. Intensive and Critical Care Nursing, 19, 31-40.

Viney, C. (1996). A phenomenological study of ethical decision-making experiences among senior intensive care nurses and doctors concerning withdrawal of treatment. Nursing in Critical Care, 1(4), 182-187.

Vivar, C. G., McQueen, A., \& Armayor, N. C. (2007). Getting started with qualitative research: Developing a research proposal. Nurse Researcher, 14(3), 60-73.

Wagner, D. P. (1989). Economics of prolonged mechanical ventilation. American Journal of Respiratory Disease, 140, S14-S18.

Warren, C., \& Karner, T. (2005). Interview. Discovering qualitative methods: Field research, interviews and analysis. Los Angeles: Roxbury. 
Watson, C. (1993). The role of the nurse in ethical decision-making in intensive care units. Intensive and Critical Care Nursing, 9, 191-194.

Whiting, L. S. (2008). Semi-structured interviews: Guidance for novice researchers. Nursing Standard, 22(23), 35-40.

Wilkin, K., \& Slevin, E. (2004). The meaning of caring to nurses: An investigation into the nature of caring work in an intensive care unit. Journal of Clinical Nursing, 13(1), 50-59.

Wilkinson, J. (1997). Developing a concept analysis of autonomy in nursing practice. British Journal of Nursing, 6(12), 703-707.

Wlody, G. S. (2007). Nursing management and organisational ethics in the intensive care unit. Critical Care Medicine, 35(2), S29-S35.

Young, J. (2003). Vicarious traumatisation in nurses. Journal of Chi Eta Phi Society, 49(1), 21-22. 


\section{RESEARCH PARTICIPANTS}

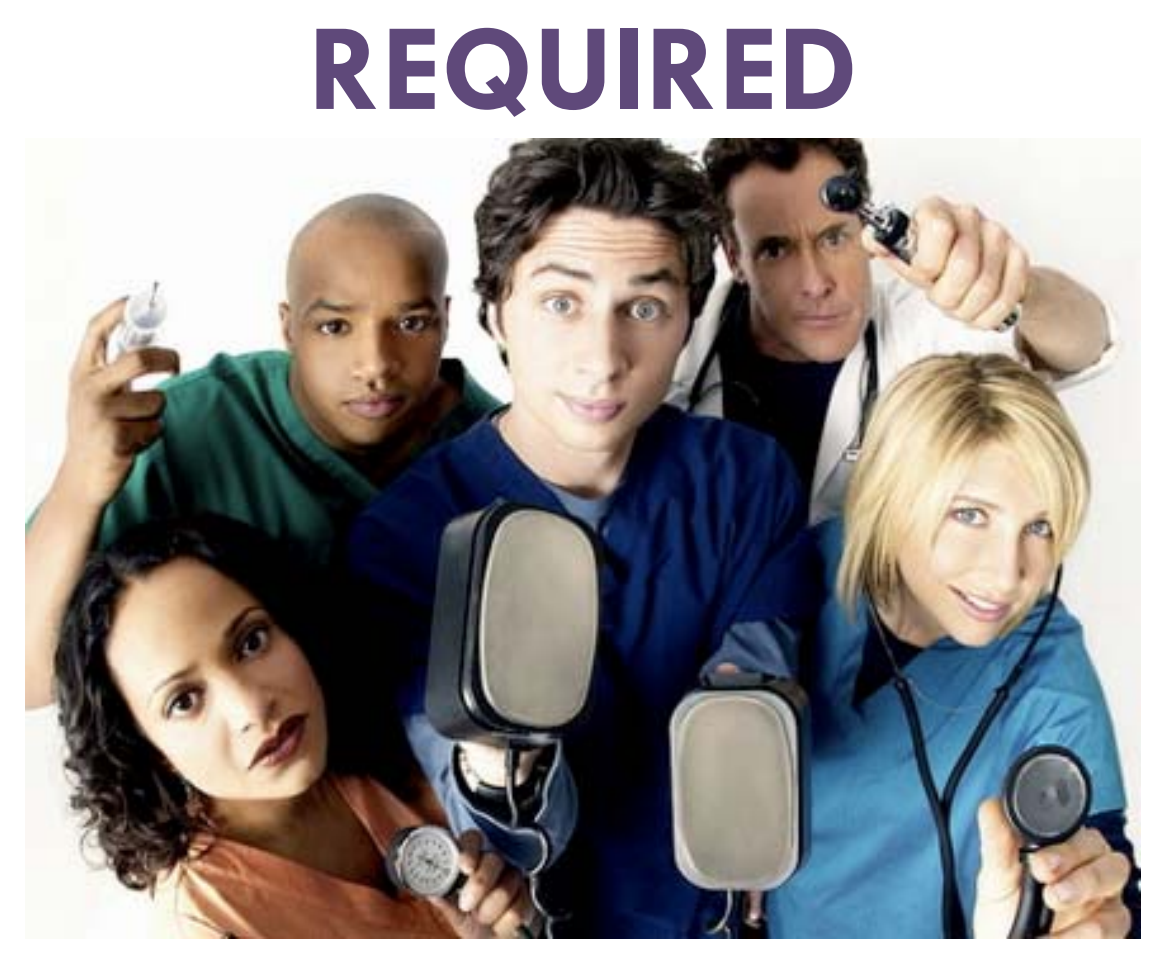

Are you a Registered Nurse who has worked in ICU for more than a year? I am looking for volunteers to take part in a study, which explores how nurses look after patients who have been in ICU for 28 days or longer.

If you would like further information or to take part in this important study please contact me:

\section{Anne Butt: 043855999 Ext 80432 (ICU) anne.butt@ccdhb.or.nz}




\section{Appendix 2 Participant Information Sheet}

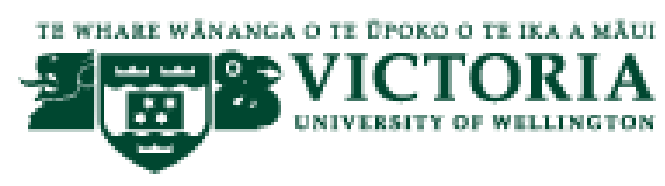

\section{a Study of chronically critically ill patients in ICU \\ Participant Information Sheet for}

Principal Investigator: Anne Butt: Staff Nurse, ICU Level 3 Wellington Regional Hospital, Riddiford Street, Newtown, Wellington

I am a Master of Nursing (Clinical) student at Victoria University of Wellington. I am undertaking a research project leading to a thesis: exploring and describing the nursing management of the Chronically Critically III (CCl) in ICU. $\mathrm{CCl}$ people are ICU patients whose length of stay exceeds 28 days, who have prolonged ventilator weaning due to respiratory failure; multi-organ dysfunction and general debilitation.

Youareinvited to participate in this important study if you are a registered nurse with at least 1 years ICU experience. You will be asked to attend a semi-structured interview lasting 60 mins. The interview will explore your understanding and experience of looking after $\mathrm{CCl}$ patients, familiarity with evidence-based recommendations, focus of care and how you think caring for $\mathrm{CCl}$ can be improved. Each interview will be audiotaped and later transcribed for data collection. The interview can be stopped at any time.

Should you wish to withdraw from the study, you may do so at any time before the data is analysed. No material that can personally identify you will be used in any reports on this study.

I may need to conduct a brief follow-up telephone interview with you, in the event that clarification of an answer is required.

This study has received ethical approval from the Multi-region Ethics Committee, which reviews national and multi regional studies, ethics reference number (INSERT). All data collected will be kept confidential and securely stored in a locked filing cabinet in Wellington ICU's Administration office. All identifying features will be removed and a coding system used so that you cannot be identified. Access to the audiotapes and transcriptions will be restricted to: myself (Investigator), Supervisor Nurse Lecturer (Sara Quirke),and Transcriber. The thesis will be submitted for marking to the Graduate School of Nursing, Midwifery \& Health at Victoria University Wellington and deposited in the University Library. It is intended that one or more articles will be submitted for publication in scholarly journals and presented at ANZIC's conference 2010. The transcriptions will be destroyed once the data analysis chapter has been written.

You may wish to receive a copy of the study results. You should be advised that a significant delay might occur between datacollection andpublication of the results. Alternatively you can request for me to discuss the outcomes of the study with you.

Please feel free to contact me or my supervisor if you have any questions about this study: anne.butt@ccdhb.org.nz. My supervisor: Ms Sara Quirke, the Graduate School of Nursing, Midwifery \& Health, Victoria University P.O. Box 600, Wellington. Phone 044636151 
Appendix 3 Research Synopsis

TE WHARE WANANCA O TY DPOKO O TY IKA A MXUI

:

\section{Nursing care of the chronically critically ill: an exploratory descriptive study}

The proposed study will explore and describe ICU nurses experiences of looking after chronically critically ill patients $(\mathrm{CCl})$. $\mathrm{CCl}$ people are $\mathrm{ICU}$ patients whose length of stay exceeds 28 days, who have prolonged ventilator weaning due to respiratory failure; mulit-organ dysfunction and general debilitation. This patient group is anticipated to increase in number, as surgical and medical interventions become more advanced and patients survive their acute illness. Reviewed literature has shown that nurses caring for $\mathrm{CCl}$ patients, face the following challenges: patient frustration due to slow progress, communication impairment, mental problems and frustrated families; poor continuity and coordination of care; poor knowledge about specific patient needs and the perception of this patient population as a burden. This research will explore New Zealand ICU nurses understanding and experience of looking after $\mathrm{CCl}$ patients, which will add to the body of knowledge surrounding this patient group. By describing these experiences training opportunities will be identified. Resources that have been accessed by the nurses will be described and restrictions to their practice articulated. Ideas of recommendations for improvements to their practice can be made. An interview design will be used to compare two ICU's in NZ (one North Island, one South Island). Three participants from each of the two ICU's will be interviewed individually, so that similarities and differences can be examined. ICU databases detailing patient admissions will be reviewed. Through understanding nurses' experiences when looking after $\mathrm{CCl}$ patients it is intended to inform clinical guidelines. Also the nursing care of these patients can be informed to improve both patient outcomes andjob satisfaction.

Principal Investigtor
Anne Butt RN, BNurs Hons

Staff Nurse, Intensive Care Unit

Level 3

Wellington Regional Hospital

Riddiford Street

Newtown

Wellington

Tel 3855999 ext ICU. Cell: 0212310495

anne.butt@ccdhb.org.nz 


\section{Appendix 4 Ministry of Health Advisory Letter}

Health
and
Disability
Ethics
Committees

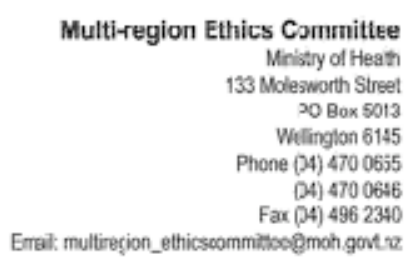

24 November 2009

Anne Butt

125 Cecil Road

Wadestown

Wellington 6012

\section{Dear Anne}

\section{MEC/09/3S/EXP}

Nursing care of the chronically critically ill: an exploratcry descriptive study

Thank you for your letter dated 4 November 2009 requesting some advice fer inclucion criteria for the above study. This information has been reviewed Jy the Chairperson of the Multi-Region Efnics Conmittee under delegated authority.

Whether the participant's results ane included or not is at the discretion of the researcher. However, if the data is used, the Multi-Region Ethics Comnittee resommends a full disclostre in the thesis about the change in incluaion critcria.

If the data is used in the research, this can be treated as a 'change in inclusion criteria' protccol amendment and can bo submitted for formal arproval by the Committee.

If you hav any futher queries piease do rot hesitate to contact me.

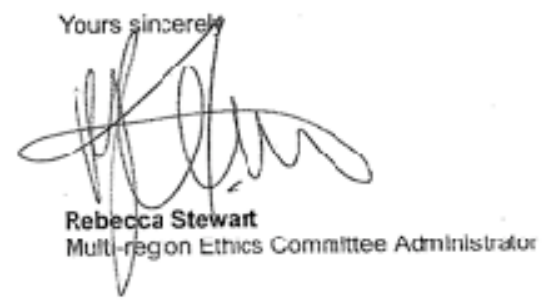




\section{Appendix 5 Participant Consent Form}

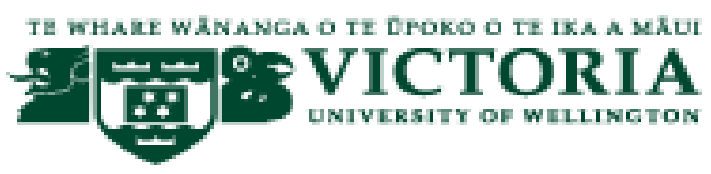

\section{Consent Form for Participation in Research}

\section{Name of study: Exploring and describing ICU nurses experiences of looking after chronically critically ill patients.}

I have read and I understand the information sheet dated $1^{\text {st }}$ May 2009, for volunteers taking part in this study. I have had time to consider whether to take part in the study, to ask questions and have them answered to my satisfaction.

I understand that taking part in this study is voluntary (my choice), and that I may withdraw from the study at any time, and this will in no way affect my employment.

I understand that my participation in this study is confidential and that no material that could identify me will be used in any reports on this study. I understand that any information I provide will be kept confidential to the researcher, supervisor and the person who transcribes the audio-tape of our interview. I understand that the data I provide will be presented in: a report of the study (MN(Clinical) 90 point thesis, an article for publication in an international journal, a presentation at ANZICs conference (2010).

I have had the opportunity to use whānau support or a friend to help me ask questions and understand the study.

I consent to my interview being audiotaped.

I know who to contact if I have any questions about the study in general.

I wish to receive a copy of the results. Participants should be advised that a significant delay may occur between datacollection andpublication of the results. Alternatively I would like the researcher to discuss the outcomes of the study with me.

I hereby consent to take part in this study.

Date:

Signature:

Full names of researchers:

Contact phone number for researchers:

Project explained by:

Project role:

\begin{tabular}{|l|}
\hline \\
\hline Anne Butt \\
\hline 044995311 \\
\hline Anne Butt \\
\hline Principal Investigator \\
\hline \\
\hline
\end{tabular}

Signature:

Date:

Contact: Anne Butt, ICU Level 3, Wellington Regional Hospital, Riddiford Street, Newtown, Wellington. Tel (04) 3855999 ext 80432

anne.butt@ccdhb.org.nz 


\section{Appendix 6 Interview Questions}

- Have you heard of the term 'chronically critically ill' and if so what does it mean to you?

- Is there a long-stay patient policy in the ICU where you work? If so, have you used it?

- What are the most common challenges you face when looking after a CCI patient?

- If you could change one aspect of CCI care what would it be?

- When you've experienced a good day looking after a CCI patient, what made it good?

- What aspects of looking after a CCI patient do you consider are the most important?

- What patient outcomes do you feel are most important?

- Does your nursing of CCI differ from shorter-term ICU patients?

- What areas of nursing CCI do you perceive are not done well and why?

- When allocated to look after a CCI patient, how do you feel?

- Are multi-disciplinary team members involved in CCI care?

- Do you think the ICU environment is a suitable place to care for CCI patients?

- Are there any other aspects of caring for CCI patients that you think are important?

- How long have you worked in ICU?

- What level PDRP are you?

- How many long-stay patients have you looked after in the last 12 months? 


\section{Appendix 7 Multi-region Ethics Approval Letter}

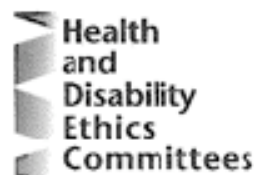

11 June 2009

Anne Butt

125 Cecil Road

Wadestown

Welington 6012

Dear Anne

Nursing care of the chronically critically ili: an exploratory descriptive study Lead Investigator: Anne Butt

\section{MEC/09/39/EXP}

The above study has been given ethical approval by the Muli-region Ethics Commitiee.

Approved Documents

- Letter of invitation to the Clinical Director and Nurse Manage: of ICU, Version 1

- Letter of invitation to the participant CU nurse, Version 1

- Participant Consent Form: DI ID Stakeholder Intorviowe, Version 1

- Participant Information Sheet for a Study of chronically critically ill paients in ICU, Version 1

- Confidentiaity Agreament for Transcriber of a Reasearch Study, Version 1

- Data collection Furna: Dalabase, Version 1

- Research Froposal

- Advertisement

\section{Accreditation}

The Committee involved in the approval of this study is accredited by the Health Research Council and is constituted and opcrates in ocoordance with the Operational Stanria'd for Ethics Committees. April 2006.

Firal Report

The study is approved until December 2009. A firal report is required at the end of the study and a form to assist with this is available at http://www.ethicscommittees.health.govt.nz. If the study will not be complerad as afviend, please forward a progress report and an application for extension of ethical aporoval one month before the above date.

\section{Amandments}

It is also a condition of approval that the Commitlee is advised of any adverse events, if the study dces not commence, of the sudy is altered in any way, includirg all documertation eg advertisements, le:ters to frospective participants.

Please quote the above ethics committee reference number in all correspondence.

It should be noted that Ethics Committee approval does not imply any resource cummitment or administrative facilitation by any healthcare provider within whose facility the research is to be carried out. Where applicable, authority for this must be obtained separately from the appropriate manager within the organisation. 